IMPACT OF SOCIAL COMPETENCE AS A PROTECTIVE FACTOR FOR VIOLENCE RESILIENCY

\author{
A Dissertation \\ Presented to \\ the Faculty of the Graduate School \\ University of Missouri-Columbia
}

In Partial Fulfillment

Of the Requirements for the Degree

Doctor of Education

by
LEIGH ANN BLUNT

Dr. George J. Petersen, Dissertation Supervisor

DECEMBER 2005 
(C) Copyright by Leigh Ann Blunt 2005 All Rights Reserved 
The undersigned, appointed by the Dean of the Graduate School, have examined the dissertation entitled

\section{IMPACT OF SOCIAL COMPETENCE AS A PROTECTIVE FACTOR FOR VIOLENT AND AGGRESSIVE BEHAVIOR}

Presented by Leigh Ann Blunt

A candidate for the degree of Doctor of Education

And hereby certify that in their opinion it is worthy of acceptance.

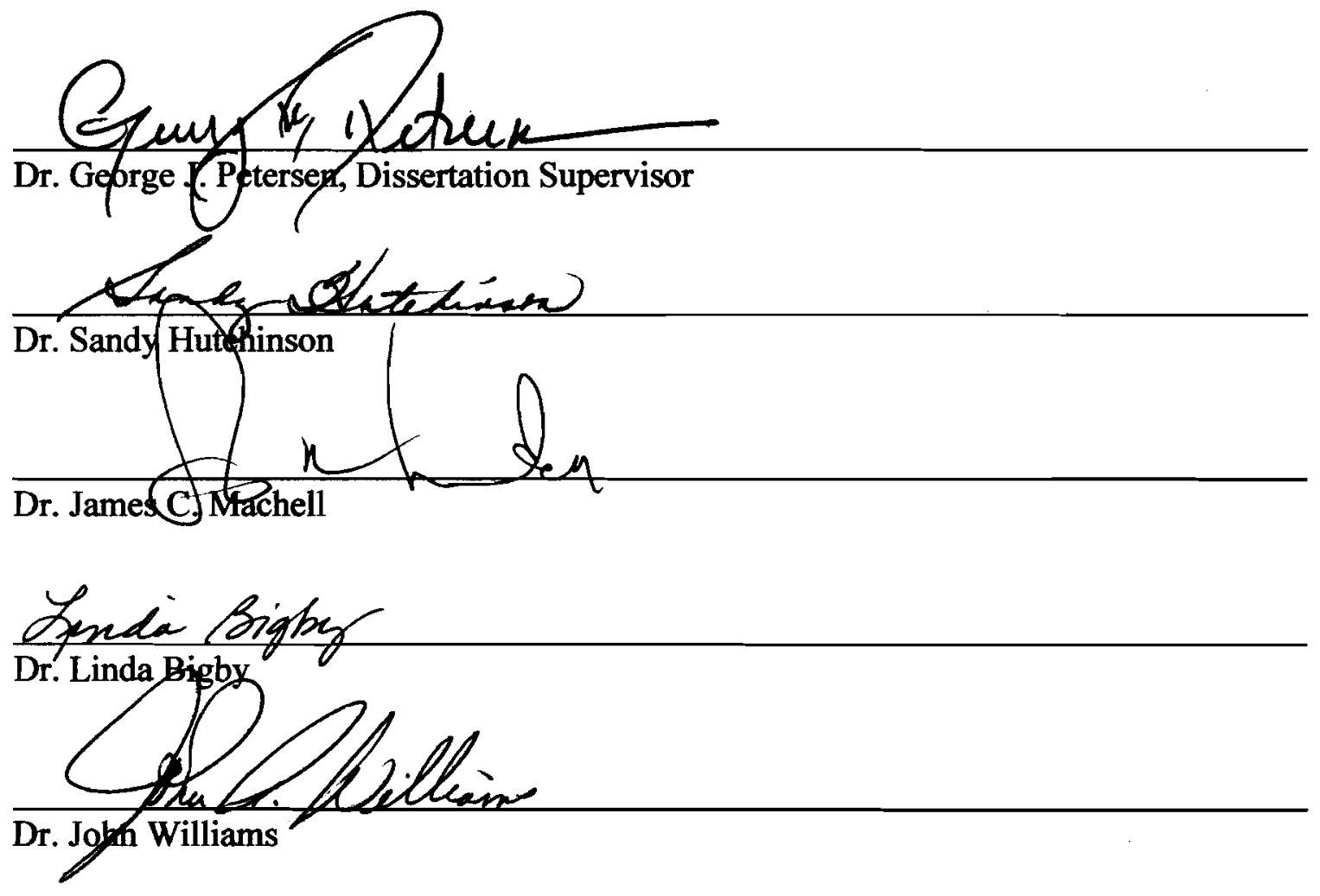




\section{ACKNOWLEDGEMENTS}

I would like to extend my sincerest gratitude to Dr. George Petersen, my dissertation supervisor. Your guidance, patience and support during this process have been most appreciated. Thanks for your faith and confidence.

I would also like to acknowledge the help and support provided by the members of my dissertation committee: Dr. Sandy Hutchinson, Dr. Jim Machell, Dr. Linda Bigby and Dr. John Williams. I am thankful for your time and assistance. You each provided me with unique insights and perspectives and I have learned a great deal from you.

Thank you to my colleagues and friends in the Department of Safety Sciences for your support. I will always appreciate Larry Womble's friendship and kindness. Thank you Larry, for always seeming to know when I needed to get away from the office for awhile. Thanks to Dennis Laster for your encouragement and proof-reading, and to John Zey for your upbeat attitude.

A special note of thanks and appreciation to my mother for always believing in me. You have supported me in every endeavor and I am most thankful to have you in my life. I will also be forever grateful to Omi for inspiring me to be a better person. I carry you with me everywhere I go.

Finally, I could not have successfully gotten through this process without the love and support of my husband Troy, and my twin daughters Kelly and Karyn. You kept the laughter in my life and always reminded me that family is what matters most. Anything is possible when family is by your side. I love you all. 


\title{
IMPACT OF SOCIAL COMPETENCE AS A PROTECTIVE FACTOR FOR VIOLENCE RESILIENCY
}

\author{
Leigh Ann Blunt
}

Dr. George J. Petersen, Dissertation Supervisor

\begin{abstract}
Youth violence has been targeted as a public health issue and has gained a considerable amount of attention in recent years. Homicide and suicide remain the leading causes of death for individuals between the ages of 10 and 24. Current research has identified risk factors (e.g., history of victimization, poverty, alcohol or drug abuse, and academic failure) that contribute to and promote violent and aggressive behavior in youth. However, there is considerably less information about protective factors that promote resilience and limit the potential influence of risk factors that contribute to the development of violent behavior.

The focus of this investigation was to determine the influence of the protective factor social competence on whether or not adolescent males engaged in violent or aggressive behavior at school. Further, the study sought to determine to what degree the elements of social competence serve as protective factors for violence resiliency among adolescent males exposed to known risk factors that contribute to violent and aggressive behaviors, which may be referred to as anti-social behavior in this report. Using both quantitative and qualitative methods this study utilized a case design to identify adolescent males who shared similar risk factors such as poverty, the use of alcohol and drugs, hyperactivity, risk taking, and a history of victimization in order to explore the relationship between risk factors and the elements of social competence and violence
\end{abstract}


resiliency. Data were collected through surveys, open-ended interviews with the participants, and focused interviews with selected school personnel. Interviews were recorded, transcribed, and analyzed with the processes of open and axial coding. The findings from this investigation indicate that several elements of social competence were positively associated with violence resiliency, including a sense of humor; development of positive relationships with parents, school personnel and friends; and empathy. Additionally, school connectedness, a sense of future, and helping behaviors emerged as potential protective factors for violence resiliency. Of importance is that young males who have accumulated significant risk factors related to the development of violent and aggressive tendencies can rebound and demonstrate violence resiliency. 


\section{TABLE OF CONTENTS}

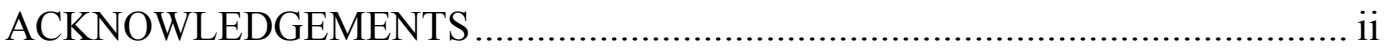

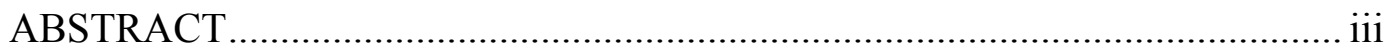

LIST OF TABLES ................................................................................ vii

CHAPTER

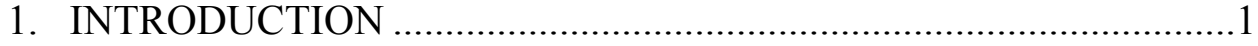

Statement of the Problem...................................................................... 3

Purpose of the Study ......................................................................5

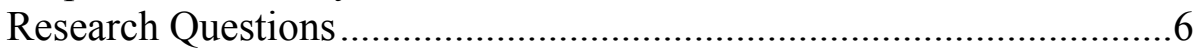

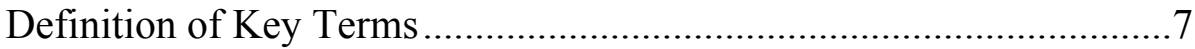

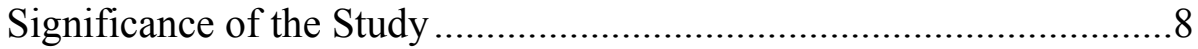

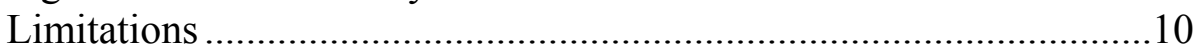

Summary ........................................................................... 11

2. REVIEW OF THE LITERATURE .............................................. 12

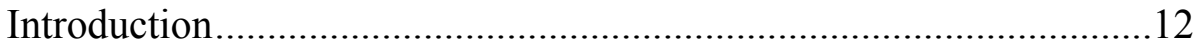

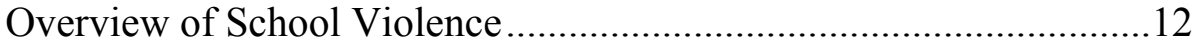

Targeted School Violence.............................................................16

Federal Legislation................................................................ 18

Violence Prevention in Schools ...................................................21

Risk and Protective Factors for Violent Behavior ..............................32

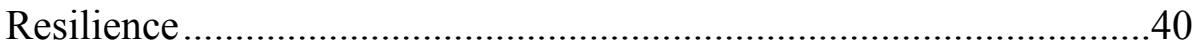

Summary ............................................................................. 47

3. RESEARCH DESIGN AND METHODOLOGY ..........................49

Theoretical Framework ....................................................................49

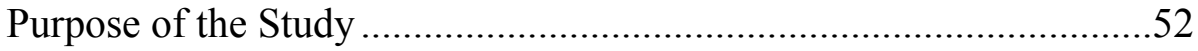

Research Questions ......................................................................53

Rationale for Qualitative Case Study Design ..................................53

Participants..............................................................................56

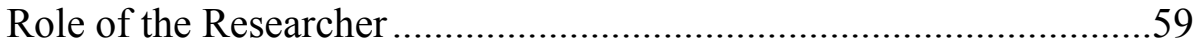

Data Collection .............................................................................60

Data Analysis ........................................................................6 63

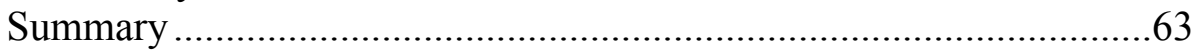

4. PRESENTATION AND ANALYSIS OF THE DATA ....................65

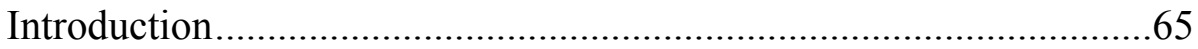

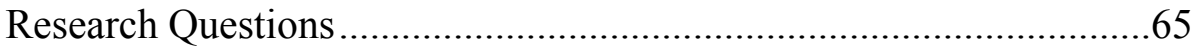

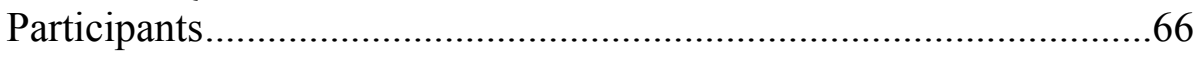

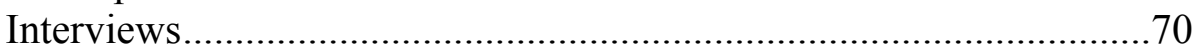

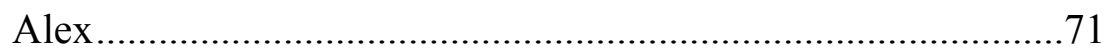

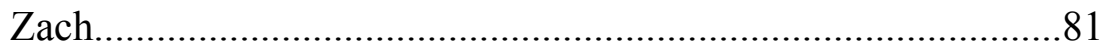

Elements of Social Competence .............................................94

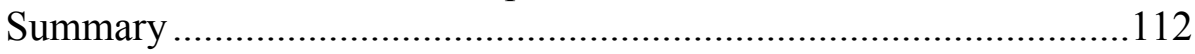

5. SUMMARY AND RECOMMENDATIONS.................................113

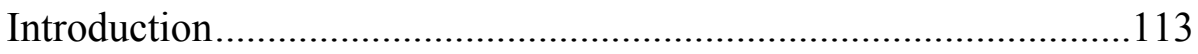

Summary of Findings........................................................... 114 


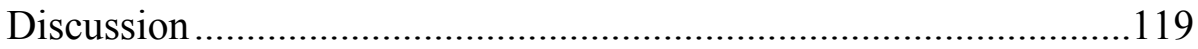

Limitations of the Study................................................................140

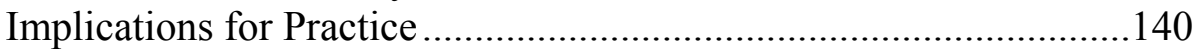

Recommendations for Future Research.............................................141

Summary Statements ..................................................................

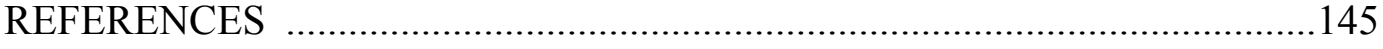

APPENDICES

A. Student Survey Questionnaire...........................................................159

B. District Consent Form....................................................................168

C. Parental Consent Form....................................................................171

D. Student Consent Form.....................................................................174

E. Teacher Consent Form....................................................................177

F. Student Interview Protocol ...........................................................179

G. Teacher Interview Protocol...........................................................181

H. Interpersonal Reactivity Index Questionnaire …………....................183

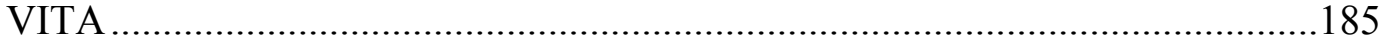




\section{LIST OF TABLES}

Table 1. Grades Reported by Students on Initial Survey ................................66

Table 2. Alcohol Use Reported on Initial Survey ..........................................68

Table 3. Drug Use Reported on Initial Survey............................................69

Table 4. Interpersonal Reactivity Index Scores .........................................103

Table 5. Grades Reported by Male Students on 2003 Youth Risk Behavior Surveillance System by Geographic Region and Race...............107

Table 6. Fights in the Previous 12 Months Reported by Male Students in the Midwest on the 2003 Youth Risk Behavior Surveillance System by Race 109

Table 7. Alcohol Use Reported by Male Students in the Midwest on 2003 Youth Risk Behavior Surveillance System by Race 110

Table 8. Drug Use Reported by Male Students in the Midwest on the 2003 Youth Risk Behavior Surveillance System by Race 


\section{CHAPTER ONE}

\section{INTRODUCTION}

Youth today are exposed to violence through a variety of media including television shows, movies, books and the Internet. Indeed, even the nightly news includes stories about stabbings, shootings, child abuse, robberies, be-headings and other fatal accidents. News coverage of the September 11, 2001 terrorist attacks on the U.S. trade towers and the ensuing war brought the harsh realities of fatal bombings and horrific gun fights into our living rooms. The Internet provides students with unlimited access to a variety of illicit information, including modernized versions of the Anarchist Cookbook which can be found with a simple key word search of Google.com or Yahoo.com. One web site offers a free download of the book that contains information on such things as making plastic explosives from bleach and constructing $\mathrm{CO}_{2}$ bombs, and has chapters titled "Do you hate school?" and "How to kill someone" (Anarchist Cookbook, 2004). For only fifteen dollars and the cost of shipping and handling, anyone can order the new 2004 CD-ROM version (Anarchist Cookbook). Perhaps even more disturbing are web pages dedicated to school shooters such as Kipland Kinkel (Kip Kinkel Organization, 2000). The Kip Kinkel Organization Web page offers information about the Oregon shooter, a guest book, and a fan club electronic mailing list for Kip Kinkel's supporters. The Web page also declares that "the real victims are the shooters, not those who were killed or survived" (Kip Kinkel Organization).

Beyond exposures to violence through the media, today's youth are often victims or witnesses of violence in their communities, schools and homes (U.S. Department of Health and Human Services, 2001). Additionally, adolescents are also perpetrating 
numerous violent and criminal acts. According to the Unites States Department of Health and Human Services [US DHHS] (2001), "Public health studies show that youth violence is an ongoing, startlingly pervasive problem" (p. 17). In the decade between 1983 and 1993, there were significant increases in the number of homicides and other violent crimes perpetrated by youth (US DHHS, 2001).

The federal government interceded in an effort to help schools create safe learning environments with the passage of the Safe Schools Act of 1994. In 1995, dire predictions of the evolution of a new youth "super-predator" caught the attention of many policy makers (Gluck,1997; Schiraldi, 2001). The predictions warned that America's future held "tens of thousands of severely morally impoverished juvenile super-predators" (DiIulio, 1995, para. 29). These young super-predators were described by Dilulio as selfingratiating individuals "capable of committing the most heinous acts of physical violence for the most trivial reasons" (para. 29). Additionally, this new breed of young terrorists were depicted as having no perception of right and wrong and living to fulfill their natural instincts to "murder, rape, rob, assault, burglarize, deal deadly drugs, and get high" (DiIulio, 1995, para. 29). Fortunately, the predictions proved to be false as "the number of homicides committed by youth in America dropped by 68 percent between 1993 and 1999" (Schiraldi, 2001, para. 3).

While youth violence is considered a serious public health issue (U.S. DHHS, 2001), categorically labeling an entire generation of youth as criminalistic superpredators can be viewed as naïve and irresponsible. The existence of risk factors and less than desirable life circumstances does not automatically lead to a life of crime and 
violence. On the contrary, research indicates that a large percentage of individuals labeled at-risk "become healthy, competent young adults" (Benard, 1993, p. 44).

\section{Statement of the Problem}

Schools are expected to effectively handle and promote the social, emotional and cognitive well being of America's youth. However, schools were unprepared for the onslaught of high profile incidents of targeted school violence that swept across the country in the 1990s. Suddenly, the unimaginable became possible and the results were thrust upon the American public in their living rooms. Students, parents and teachers feared that their school could be the next bloody headline in the national press. Despite the fact that the risk of a student being the victim of violence at school has not significantly changed in the last 20 years, "both students and their parents report being increasingly apprehensive about their schools" (U.S. Department of Health and Human Services, 2001, p. 32). Additionally, the U.S. Department of Health and Human Services (2001) reported that:

Today's school bullies are still more likely to be carrying guns than those of the early 1980 s, and the proportion of students reporting that they felt too unsafe to go to school has not changed since the peak of the violence epidemic in the mid-1990s. These findings add to the concern that the violence epidemic is not yet over. (p. 32)

In response, schools have implemented a variety of security measures coupled with stringent school policies and the use of violence prevention programs. However, many have approached the problems in a piecemeal fashion (Petersen, Thompson, Gawerecki \& Cauldwell, 2003). Unfortunately there are no simple answers for the complex issues of 
youth violence. Comprehensive plans that involve schools and communities are essential to successfully intervening in the cycle of violence (Christle, Jolivette \& Nelson, 2000).

Schools are not likely to have much control over the lives and activities of students outside the school building, although events outside the school frequently spill over into the school setting (Gagnon \& Leone, 2001). Each individual is likely to respond differently to life's stressors and will exhibit emotions and frustrations in a variety of ways that may change over time (Davis, 1999). Schools must learn to look beyond the symptomatic behaviors displayed by youth to see the total child.

Research has started to examine the success stories of our nation's youth to determine how they are protected from risk exposures (Davis, 1999). The "ability to bounce back successfully despite exposure to severe risks" (Benard, 1993) defines the concept of resilience. Studies have been conducted to determine the characteristics of resilient individuals, which include social competence, empathy, positive communication and relationship skills, and a sense of humor (Benard, 1993; Christiansen, Christiansen, \& Howard, 1997; Davis, 1999; Gordon Rouse, Longo \& Trickett, 1999). Further, the broad scope of resilience can be broken down into specific domains (Davis, 1999). Research has been conducted on educational resilience and on overall resilience in life (Davis, 1999; Gordon Rouse, Longo \& Trickett, 1999). However, the literature seems to be absent of information about violence resiliency as a specific domain of resilience.

America's youth display resilience on a variety of levels. It has become the responsibility of the schools to help foster such positive outcomes for students. According to Benard (1993), "Given the incredible stresses the family system is now experiencing, school has become a vital refuge for a growing number of children” (p. 45). 
A caring school environment can significantly impact the overall resilience of students exposed to multiple risk factors (Benard).

\section{Purpose of the Study}

Violence significantly contributes to the creation of a socially toxic environment (Vorrasi \& Garbarino, 2000). Yet, due to the complex nature of violence and variances between genders, it is essential to consider the variety of causal factors that converge and motivate students to become violent. Current research has identified a multitude of risk factors such as the use of alcohol and drugs, hyperactivity, risk taking, a history of victimization, poverty, and academic failure that contribute to an individual's predisposition toward the development of violent tendencies (Blum, Ireland, \& Blum, 2003; Christle, Jolivette, \& Nelson, 2000; Hawkins et al., 2000; Vorrasi \& Garbarino, 2000).

Gender differences are notable in that males are more likely to engage in violent behaviors than females (Daane, 2003; US DHHS, 2001; Valois, MacDonald, Bretous, Fischer \& Drane, 2002), males consistently report higher level of weapons carrying (YRBSS, 2003), and males are more likely to be physically victimized and threatened with a weapon (Hanish, 2000). Therefore, at the heart of the issue is the need to understand the root causes of violence so appropriate, and possibly gender specific, intervention and prevention strategies can be used by schools and other key stakeholders. Through the examination of the elements found in social competence and other potential protective factors, this investigation sought to discover what allows some students to rebound from toxic situations and experiences and avoid involvement in violence and aggressive behaviors while others do not. 
The focus of this study was to determine the influence of social competence on engagement in violent and aggressive behavior among adolescent males. Further, this study sought to determine to what degree the elements of social competence serve as protective factors for violence resiliency among adolescent males exposed to risk factors identified as contributing to the development of violent and aggressive behaviors. The study used a case design to identify exposure to risk factors and explore potential relationships between the elements of social competence and violence resiliency.

\section{Research Questions}

The overarching question guiding this investigation was why do some at-risk adolescent males refrain from committing violence and participating in violent acts while others do not? In order to address this larger question, this study was designed to examine the following research questions:

1. Do the elements of social competence (empathy, a sense of humor, communication skills, relationship skills, and social assertiveness) serve as protective factors for violence resiliency among at-risk adolescent males?

2. Is individual social competence influential on engagement in violent and aggressive behavior among at-risk adolescent males?

3. Are there other protective factors for violence resiliency that emerge as important in preventing violent behavior? 


\section{Definition of Key Terms}

Aggression and Aggressive Behavior. Behavior, physical or verbal, that is intended to harm another person (U.S. Department of Health and Human Services, 2000).

At-Risk adolescents are those who are exposed to identified risk factors that contribute to engagement in violent and aggressive behavior.

Empathy is the ability to share another individual's emotional state or context (Bush, Mullis, \& Mullis, 2000).

Protective Factors are "personal characteristics or environmental conditions that interact with risk factors to reduce their influence on violent behavior" (U.S. Department of Health and Human Services, 2000).

Resilience is "the ability to bounce back successfully despite exposure to severe risks" (Benard, 1993).

Risk Factors are personal characteristics or environmental conditions that increase the likelihood that a person will engage in violent behavior (U.S. Department of Health and Human Services, 2001).

Social Competence is "the ability to function appropriately in interpersonal interactions" (John, 2001). Social competence is marked by individual qualities such as empathy, communication skills, a sense of humor and flexibility (Benard, 1993).

Targeted Violence is "any incident of violence where a known or knowable attacker selects a particular target prior to their violent attack" (Vossekuil, Fein, Reddy, Borum \& Modzeleski, 2002). In terms of targeted school violence, the attack occurs at school and the target may be a particular person, a group of people, or "may even be the school itself” (Vossekuil, Fein, Reddy, Borum \& Modzeleski, 2002). 
Violence Resiliency is a term that was not found in this review of the extant literature. For this investigation, Violence Resiliency is defined as the successful avoidance of violent and aggressive behaviors at school despite the presence of multiple risk factors known to increase the likelihood of such behaviors occurring.

Significance of the Study

According to the U.S. Department of Health and Human Services (2001), focusing on the identification of protective factors is a new and emerging area of violence research. While current research has documented many risk factors that contribute to an individual's predisposition for developing violent and aggressive behaviors, little is known about protective factors for violence. In an effort to identify protective factors "most studies have looked for an effect on antisocial behavior in general, not on violence specifically; and those that have found buffering effects on violence have not been adequately replicated" (U.S. Department of Health and Human Services, 2001, p. 73).

This study sought to address this gap in the research literature related to protective factors and possible mitigating effects on violent behavior and the promotion of resilient outcomes. Specifically, this investigation focused on determining the impact of social competence as a protective factor for violence resiliency. Social competence has been cited as a characteristic of resilient individuals (Benard, 1993; Davis, 1999). Research has shown a positive correlation between social competence and areas including academic achievement and peer acceptance (West, 1996). Conversely, a lack of social competence has been shown to correspond with an increase in dropping out of school, mental health disorders, and juvenile delinquency (West, 1996). This investigation sought to understand how individual social competence interacts with risk factors for violent behavior to 
promote outcomes where youth are able to successfully handle conflict in productive ways.

Additionally, this study focused on the presence of multiple risk factors whereas much of the research on risk factors "identifies and measures their predictive value separately, without taking into account the influences of other risk factors" (U.S. Department of Health and Human Services, 2001, p. 59). The theory of accumulated risk proposed that as the number of risk exposures increases, the likelihood of resilient outcomes will decrease (U.S. Department of Health and Human Services, 2001; Vorrasi $\&$ Garbarino, 2000). Accordingly, the theory of accumulated risk is based on the assumption that people can cope with and adjust to levels of risk that do not exceed "a developmentally determined individual threshold" (Vorrasi \& Garbarino, 2000, p. 62). When accumulated risk exceeds the individual's capacity for coping and positive adjustment, protective or opportunity factors are required to prevent harm (Vorrasi \& Garbarino, 2000).

Due to the differences in how males and females display and respond to violent behaviors, this study examined individual differences specifically among adolescent males and the complex interactions of protective and risk factors that lead to violence resiliency. The focus on social competence is also important because "research on the consequences of children's social competence has been far from voluminous, if not quite weak" (Chen, Liu, Rubin, Cen, \& Li, 2002, p. 129). Undoubtedly, the research will generate additional questions and provide direction for future research efforts.

The research also offers practical implications for schools and communities by exploring ways to proactively address youth violence. Schools may not be able to 
mitigate certain risk factors faced by students such as poverty or exposure to violence at home, but they can reinforce protective factors to reduce the influence of those risks on violent behavior while at school. By focusing policies on positive outcomes rather than punitive measures, schools can create a caring environment for their students (Benard, 1993; Christle, Jolivette \& Nelson, 2000). According to Christle, Jolivette and Nelson, "A common thread runs through effective prevention models: instead of waiting for undesired behaviors to occur and then reacting with harsh punishment, educators should proactively teach the academic and social skills necessary for success in school and life" (p. 2).

\section{Limitations}

This study utilized an exploratory case design to compare levels of social competence between subjects exposed to similar levels of risk related to engagement in violent behavior. While case studies offer analytical generalization where "the investigator is striving to generalize a particular set of results to some broader theory" (Yin, 2003, p. 37), case studies cannot produce statistical generalization to a larger population (Yin). However, multiple-case designs are considered preferable to singlecase designs in terms of analytic benefits (Yin). Although the literature indicates some fundamental differences between males and females in the areas of violent behaviors and social interactions (Blum, Ireland \& Blum, 2003; Daane, 2003; Hanish, 2000; US DHHS, 2001; Valois, MacDonald, Bretous, Fischer \& Drane, 2002), this study examined only male students. 


\section{Summary}

Youth violence at school is a serious and complex issue that has gained a considerable amount of public attention. At the heart of the issue is the need to understand the root causes of violence so appropriate intervention and prevention strategies can be employed by schools and other key stakeholders. While current research has identified risk factors that predispose individuals toward the development of violent tendencies, less information is available about potential protective factors.

The focus of this investigation was to determine the influence of social competence on engagement in violent and aggressive behavior among adolescent males. Further, the study sought to identify to what degree the elements of social competence serve as protective factors for violence resiliency among at-risk adolescents. Through qualitative analysis, this study also sought to discover what other protective factors for violence resiliency may emerge. 


\section{CHAPTER TWO \\ REVIEW OF THE LITERATURE \\ Introduction}

In DeKalb, Missouri, twelve-year-old Nathan Faris, tired of being bullied and teased at school, took a .45 caliber automatic to his school of two hundred students and fired several rounds in his first-period class, killing another student and then committing suicide (Dedman, 2000). In West Paducah, Kentucky, 14-year-old Michael Carneal entered Health High School and randomly gunned down eight students, killing three of them (The History Channel, 1996). In Jonesboro, Arkansas, Mitchell Johnson, 13, and Andrew Golden, 11, pulled the fire alarm and snipered students from the trees as they evacuated the building and were trapped outside due to the self-locking fire doors (American Justice, 1999). Four students and a teacher were killed in the ambush. In Littleton, Colorado, students Eric Harris, 17, and Dylan Klebold, 18, launched an attack on Columbine High School killing twelve students and a teacher and wounding 23 students before committing suicide (The History Channel, 1996). These tragic incidents and many others are emblazoned on the collective memory of families and schools in the United States.

\section{Overview of School Violence}

High profile incidents like those described above are exploited by the media, creating a vivid image of schools struggling under a siege of attacks from unstable students, leaving educators with the question of whether or not our schools are truly safe. 


\section{Schools as Safe Havens}

In the report Youth Violence: A Report of the Surgeon General, the Department of Health and Human Services (2001) indicated that "The decade between 1983 and 1993 was marked by an unprecedented surge of violence, often lethal violence, among young people in the United States" (p. 1). However, since the peak of the violent epidemic in 1993, statistics based on arrest records, victimization data, and emergency room records show that youth violence has steadily declined (U.S. Department of Health and Human Services [U.S. DHHS], 2001). In the years between 1993 and 1999, "the number of homicides committed by youth in America dropped by 68 percent" (Schiraldi, 2001, para. 3) bringing youth crime to its lowest levels in 25 years (Schiraldi).

With statistics indicating that school crime has declined overall, school superintendents and principals reiterate the notion that schools are one of the safest places for our children (Walker, 1999). Fears of targeted school violence are allayed with the fact that it represents only a small proportion of violent behaviors occurring in schools today (Vossekuil, Fein, Reddy, Borum \& Modzeleski, 2002). Indeed, for the years from 1993 to 1997, the odds of a student in grades 9-12 being the victim of homicide or committing suicide at school were about one in one million (Vossekuil, Fein, Reddy, Borum \& Modzeleski, 2002). Additionally, school related homicides account for "less than 1 percent of all homicides among students" (U.S. DHHS, 2001, p. 31).

\section{Schools: Pretty Safe Isn't Safe Enough}

Despite statistics based on arrest records, victimization data and emergency room records that show declining trends in youth violence, "A fourth key indicator of violence - confidential reports by youths themselves - reveals that the proportion of young people 
who acknowledge having committed serious, potentially lethal acts of physical violence has remained level since the peak of the epidemic" (U.S. DHHS, 2001, p. 1). The U.S. Department of Health and Human Services (2001) warned that "The leveling off of these rates after 1993 is troubling, for it indicates that the rise and fall in arrest rates are set against a backdrop of ongoing violent behavior" (p. 24-5).

In 2001, homicide was the second leading cause of death for individuals age $15-$ 24 (Centers for Disease Control, 2001). In addition to being victims of homicide, Thornton, Craft, Dahlberg, Lynch and Baer (2002) reported that in 1997 "1700 youths under age 18 were implicated in 1400 murders" (p. 213). While less than one percent of homicides are school-associated, the frequency of school-associated homicides involving multiple victims has increased (U.S. DHHS, 2001). Although the probability of such an event occurring is small, the severity of such acts warrants the attention and concern of students, parents, educators and policy makers (Vossekuil, Fein, Reddy, Borum \& Modzeleski, 2002).

From September 1992 to November of 2003, the National School Safety Center [NSSC] (2003) has tracked 347 school associated violent deaths across the United States. The NSSC (2003) reports that 270 of the victims were male, 263 victims were shot, 90 incidents arose out of interpersonal disputes, 58 of the incidents were suicides, and 233 of the fatalities occurred at high schools. The data were collected through news and media reports and are not part of a mandatory reporting system, which lends to the potential for the total number of incidents to be under-represented.

No school is exempt from the possibility of school violence. In the 1996-97 school year, "10\% of all public schools reported at least one serious violent crime to a 
law enforcement representative" (DeVoe et al., 2002, p. 18). Serious violent crime was defined as including murder, rape, sexual battery, suicide, robbery, and physical attacks or fights with a weapon. Clearly, $10 \%$ is a fairly small percentage. However, Walker (1999) argued that "There are 125,000 schools in this country today; if 10\% of them are unsafe, that translates into 12,500 schools." Additionally, each school represents a large number of students, staff, and parents (Walker, 1999). The magnitude of the problem is far from insignificant as indicated by the more than 2.2 million nonfatal crimes, including 185,600 serious violent crimes, perpetrated against students ages $12-18$ while at or on the way to school in 1999 (DeVoe et al., 2002).

Schools face a variety of violence-related behaviors that require serious attention. In $2001,8.9 \%$ of students in grades $9-12$ reported being threatened or injured with a weapon on school property during the previous year (DeVoe et al., 2002, p. 62). That same year, $14.3 \%$ of $6^{\text {th }}$ graders and $13 \%$ of $7^{\text {th }}$ graders reported being bullied at school in the previous six months (DeVoe et al., 2002). Additionally, 6.4\% of students in grades 912 reported carrying a weapon on school property at least one day out of the previous 30 days, and $17.4 \%$ reported carrying a weapon anywhere at least one day out of the previous 30 days (DeVoe et al.).

Teachers and other school personnel are significantly impacted by acts of school violence. A recent study conducted by Petersen, Pietrzak and Speaker (1998) indicated that school personnel were not only concerned about physical threats and attacks from students, but also from students' parents. The study also indicated that $16 \%$ of the respondents had been "verbally threatened or intimidated six or more times" in the previous two years (p. 6). According to DeVoe et al., "Over the 5-year period from 1996 
through 2000 , teachers were the victims of approximately $1,603,000$ nonfatal crimes at school, including 1,004,000 thefts and 599,000 violent crimes (rape or sexual assault, robbery, aggravated assault, and simple assault)" (p. 24).

Self-directed violence is also a troubling issue for today's youth. In the past 30 years the incidence of adolescent suicide increased 300\% (Speaker \& Petersen, 2000). In 2001, suicide was the third leading cause of death for individuals age 10-24 (Centers for Disease Control, 2001). Additionally, research indicated that students with a history of a friend who has committed suicide are at increased risk for violence involvement (Blum, Ireland, \& Blum, 2003).

\section{Targeted School Violence}

School shootings and hostage situations are a school's worst nightmare. The media has flashed images of bloodied students being whisked away by ambulances, students running from buildings with their hands held high, and motionless bodies face

down on the sidewalks. While these incidents are rare, the unimaginable horror from the collective assaults in the 1990s has changed the perceptions of the American public and left them asking if their children are truly safe at school.

The U.S. Secret Service and the U.S. Department of Education began a study titled the Safe School Initiative in response to the deadly attack at Columbine High School in 1999 (Vossekuil, Fein, Reddy, Borum \& Modzeleski, 2002). The study examined 37 incidents of targeted school violence from 1974 through May 2000. Targeted school violence was defined as incidents where a current or former student attacked an individual with lethal means and deliberately selected the school as the 
location for the attack. The study focused on the possibility of identifying relevant warning information prior to an attack in an effort to facilitate prevention.

The Safe School Initiative analyzed pertinent records related to all 37 incidents and interviewed ten of the 41 identified attackers. The study identified ten key findings and delineated the implications of those findings. Findings from this investigation suggested that targeted school violence is rarely sudden or impulsive and typically was the end result of some systematic planning on behalf of the perpetrators. Additionally, other individuals, typically students, were often not only aware of the plan prior to the attack but may have aided in its formulation by encouraging the perpetrators. Most of the attackers did not directly threaten their targets and some made no threats at all. The study also found that many, but not all, of the attackers felt bullied at school and that most had displayed difficulty coping with a significant personal loss and had contemplated suicide. Access to weapons was also cited as a commonality among most attackers. Interestingly, only $27 \%$ of the situations were stopped through the intervention of law enforcement (Vossekuil, Fein, Reddy, Borum \& Modzeleski, 2002). Almost half of the incidents were resolved in less than 15 minutes and most attacks were ended by school personnel (27\%), other students (5\%), or by the attacker either voluntarily stopping on his own (22\%) or committing suicide (13\%) (Vossekuil, Fein, Reddy, Borum \& Modzeleski, 2002).

Perhaps the most important findings of the Safe Schools Initiative were that there are typically some behavioral signals indicating a cause for concern, but that there is "no accurate or useful profile of students who engaged in targeted school violence" (Vossekuil, Fein, Reddy, Borum \& Modzeleski, 2002, p. 33). This finding is also supported by the report The School Shooter: A Threat Assessment Perspective (O'Toole, 
n.d.) published by the Federal Bureau of Investigation which clearly stated that there is no way to reliably determine the identities of potential school shooters through the use of profile checklists. The report also clarified the concept that there is a distinct difference between a student making a threat and one who actually poses a threat (O'Toole, n.d.). The Secret Service and the FBI have provided valuable information to the dialogue on school violence.

\section{Federal Legislation}

As states struggled with the complex issues confronting them, federal policy makers also began to address the issues with the passage of legislation such as the Safe Schools Act of 1994, and the No Child Left Behind Act (NCLB) of 2001.

\section{Safe Schools Act}

The Safe Schools Act of 1994 is Title VII of the Goals 2000: Educate America Act. This act was created in order to assist schools in achieving an environment free of drugs and violence by the year 2000. The Safe Schools Act makes competitive grants available to local educational agencies (LEAs) for the purpose of creating drug and violence free schools. Eligible LEAs are those that serve areas with high rates of (1) homicides perpetrated by individuals between ages 5 and 18; (2) referrals to juvenile court; (3) youth under court supervision; (4) expulsions and suspensions from school, (5) disciplinary referrals of youth to alternative schools; and (6) victimization of youth (Goals 2000: Educate America Act, 1994). To retain funding under the Safe Schools Act for a second year, LEAs must submit an appropriate comprehensive school safety plan that addresses methods for reducing and preventing school violence and disciplinary problems (Goals 2000: Educate America Act, 1994). Funds received can be used for a 
variety of activities, including identification and assessment of school violence and disciplinary problems, school safety reviews, development and implementation of violence prevention curricula, and counseling programs for students exposed to violence as either witnesses or victims (Goals 2000: Educate America Act, 1994).

\section{No Child Left Behind}

The No Child Left Behind Act (NCLB) of 2001 was signed into law by George W. Bush on January 8, 2002 (U.S. Department of Education Website). NCLB contains two important pieces of legislation related to school violence: (a) the Gun-Free Schools Act and (b) the Unsafe Schools Choice Option. The Gun-Free Schools Act, originally passed in 1994 by President Clinton, is under Title IV of the NCLB and requires all states receiving funds under the Elementary and Secondary Education Act (ESEA) to develop state laws requiring a minimum one year expulsion for any student caught bringing a gun to school (Yell \& Rozalski, 2000). All 50 states were in compliance with the Gun-Free Schools act by 1995 (Yell \& Rozalski). The 1994 passage of the Gun-Free Schools Act spawned a proliferation of zero-tolerance policies in schools targeted not only at firearms, but also at a variety of infractions including the possession of other types of weapons, possession and use of drugs or alcohol, sexual harassment, and other inappropriate or threatening behaviors (Bowman, 2002; Cloud, Monroe, \& Murphy, 1999; Yell \& Rozalski, 2000).

With the passage of the NCLB the Gun-Free Schools Act was amended to also require a minimum one-year expulsion for any student in possession of a gun at school regardless of whether or not the student actually brought the gun to school (NCLB, 2001). The act does provide school districts with the latitude and authority to modify the 
length of the expulsion on a case-by-case basis so long as the modification is placed in writing (NCLB, 2001).

Title IX of the NCLB contains the Unsafe Schools Choice Option that allows students to transfer out a school if it is determined to be persistently dangerous (NCLB, 2001). Under the NCLB, states were required to set specific objective criteria defining the parameters for classifying schools as persistently dangerous (U.S. Department of Education Website; Howard, 2002). The 2003-04 school year marked the first year that students could choose to transfer out of a school classified as persistently dangerous (Howard, 2002). However, only 54 schools in the entire United States were classified as persistently dangerous, and amazingly, Philadelphia schools accounted for 28 of them (Robelen, September 2003). The number of schools was eventually reduced to just 38 after further scrutiny and reassessment by states (Robelen, October 2003). Critics question the lack of schools identified as persistently dangerous and argue that states may have intentionally set standards so stringently that most schools would never meet the criteria (Robelen, September 2003). There is also the possibility of under-reporting incidents and adopting changes in disciplinary actions to avoid meeting stated criteria (Howard, 2002).

The Unsafe Schools Choice Option also allows students to transfer out of a school if they were the victim of a violent crime while at school or on school grounds (No Child Left Behind, 2001). The transfer is optional and allows students to relocate to a school within the district deemed safe. The Unsafe Schools Choice Option only applies to students and therefore does not allow school personnel the opportunity to transfer out of a 
school declared persistently dangerous and does not allow for transfers in the event of violent victimization while at work (Howard, 2002).

\section{Violence Prevention in Schools}

Schools across the country employ a variety of techniques in an effort to curb school violence. Strategies include programs aimed at violence prevention through physical security measures that include access control, metal detectors and student searches; school policies such as zero tolerance and student profiling; and violence prevention curriculum.

Physical Security Measures

The use of physical security measures is an effective target hardening tactic. From a security standpoint, a hard target is one that is difficult to access, increases a perpetrator's chances of being identified or caught, and does not offer easy escape. A soft target is easily accessible and offers perpetrators little risk of capture or identification. Access control is an inexpensive measure that is proven to reduce security risks (Trump, 2000). Other inexpensive and effective crime prevention techniques include greeting individuals as they enter the building, consistent hallway monitoring, adequate lighting, natural fencing, and small scale landscaping that does not facilitate concealment of weapons or people. While these low-tech strategies are effective target hardening practices, they offer little allure as newsworthy attempts at maintaining safety (Trump, 2000). In the wake of tragedies such as Columbine, many schools adopted more high profile strategies such as metal detectors and massive sweeps of lockers and backpacks to ensure the community that student safety was taken seriously (Trump, 2000). 
Unfortunately, the effects of such policies can become harmful and may even serve to generate a climate of fear and mistrust (Peterson \& Skiba, 2000).

Metal detectors. Metal detectors can be used at school entrances that all students must pass through or can be utilized as a hand-held device to spot-check students at school or during extracurricular activities and events (Foster, 2000). A drawback of entry point walk-through metal detectors is that they may create lengthy delays as students are forced to wait in line to pass through the detectors (Medina, 2002). Empirically, "there is little evidence that these measures create safer education environments" (Gagnon \& Leone, 2001, p. 116). Compounding the problem is that metal detectors may actually serve to create a false sense of security (Trump, 2000; Walsh, 2001). Gagnon and Leone cited findings of the 1995 National Crime Victimization Survey and stated that: Findings suggest that when students know the rules and consequences for misbehavior and are aware that the rules in a school are applied fairly under the system of law, less victimization and disorder is present in the school. Where disorder exists, students reported engaging in more acts of self-protection. In contrast, the more efforts taken to run a secure building through physical means (metal detectors) and personnel interventions (school resource officers, staff watching hallways), the more victimization and disorder (fights, thefts) were reported present, and the less safe students reported feeling. (p. 116-17)

Additionally, the very presence of metal detectors serves as a visual indicator supporting the perception that the school is unsafe and can actually perpetuate student fears (U.S. Department of Education, 2002). 
While metal detectors may dissuade some students from bringing weapons into the schools, the impact on deterring targeted acts of violence appears minimal (Dedman, 2000). The U.S. Secret Service and the U.S. Department of Education conducted a study of 37 incidents of targeted school violence from 1974 through June of 2000 (Vossekuil, Fein, Reddy, Borum \& Modzeleski , 2002). In one targeted attack in 1996, Luke Woodham brutally stabbed his mother to death before proceeding to school with a rifle that he used to kill his ex-girlfriend and one other student (Dedman, 2000). Seven other students were also wounded in the attack (Dedman). When questioned about whether or not metal detectors would have stopped him, he replied “ I wouldn't have cared. What's it going to do? I ran in there holding the gun out. I mean, people saw it. It wasn't like I was hiding it" (Dedman, p. 10). In many of the recent high-profile incidents, including Littleton, Pearl and Jonesboro, the perpetrators began their shooting sprees outside the school building. Additionally, many attackers often make no attempt to conceal their weapons prior to an attack (Dedman).

Searches. Schools often utilize searches of students, lockers and automobiles in an effort to maintain schools free of weapons and drugs. Searches can be conducted manually or with the assistance of hand held metal detectors or drug dogs. Administrators are challenged with finding the appropriate balance between creating a safe school environment and protecting student rights (Ehlenberger, 2001-02; McCarthy \& Webb, 2000; Stader, 2002).

The 1985 United States Supreme Court case New Jersey v. T.L.O. set a legal standard for student searches based on the reasonableness of the search (Ehlenberger, 2002; McCarthy \& Webb, 2000; Pelliccioni, 2003; Stader, 2002; Yell \& Rozalski, 2000). 
The case affirmed students' Fourth Amendment rights, but also granted schools the authority to conduct searches without a warrant (Ehlenberger, 2002; McCarthy \& Webb, 2000; Stader, 2002; Yell \& Rozalski, 2000). Accordingly, schools are bound only to meet the standard of reasonable suspicion rather that the more difficult standard of probable cause required of law enforcement (Ehlenberger, 2002; McCarthy \& Webb, 2000; Stader, 2002; Yell \& Rozalski, 2000). The Supreme Court established guidelines for enabling the determination of reasonableness which included that a search had to be justified at its inception and that the scope of the search must be reasonably related to the infraction that precipitated the search (Ehlenberger, 2002; McCarthy \& Webb, 2000; Stader, 2002; Yell \& Rozalski, 2000). Additionally, a search must be not be excessively intrusive based on the age and gender of the student and the nature of the infraction (McCarthy \& Webb, 2000; Stader, 2002). Accordingly, although strip searches of students have been upheld in some courts as reasonable based on specific circumstances, it is generally considered unwise for schools to utilize such intrusive searches except in the most extraordinary circumstances (McCarthy \& Webb, 2000; Stader 2002; Yell \& Rozalski, 2000).

In addition to targeted individual student searches, schools often employ random suspicionless searches (Ehlenberger, 2002; McCarthy \& Webb, 2000; Stader, 2002; Yell \& Rozalski, 2000). Random searches may incorporate the use of metal detectors, locker searches, drug dogs, and searches of automobiles on school property (Ehlenberger, 2002; Yell \& Rozalski, 2000). While metal detectors may identify the presence of weapons, drugs will not be identified through this security method, leading schools to resort to locker searches and the use of drug dogs for the confiscation of illegal or banned substances. 
Locker searches can be validated and successfully defended in litigation by developing comprehensive school policies that clearly indicate that lockers are the property of the school district and may be periodically inspected, thus diminishing the students' expectations of privacy (Ehlenberger, 2002; McCarthy \& Webb, 2000; Yell \& Rozalski, 2000). The use of drug dogs is more controversial and should also be clearly delineated in school policy (Ehlenberger, 2002; Stader, 2002). While the legality of using drug dogs to search student lockers and automobiles on school property is supported by the courts, it is a violation of students' Fourth Amendment rights to utilize dogs to sniff individual persons without the presence of reasonable suspicion (Ehlenberger, 2002; McCarthy \& Webb, 2000; Stader, 2002).

\section{School Policies}

Schools use a variety of policies to generate an appropriate climate conducive to learning. Policies set forth behavioral and academic expectations for students and outline disciplinary outcomes for failure to comply. Policies address such areas as academic eligibility for athletics, school dress codes, tardiness, excessive absenteeism, fights, inappropriate language, and alcohol and tobacco use. Traditional disciplinary actions include revocation of privileges, loss of eligibility for athletics and other extra-curricular activities, after school detention, in-school and out-of-school suspensions, and expulsion. Along with the more traditional policies, many schools have adopted stringent zero tolerance policies with pre-determined penalties, and have begun to use profiling techniques to preemptively identify would be offenders (Cloud, Monroe, \& Murphy, 1999; Holloway, 2002; Skiba \& Peterson, 1999). 
Zero tolerance. Zero tolerance policies have generated significant controversy in the last decade (Bowman, 2002; Curwin \& Mendler, 1999; Derbyshire, 2001; Holloway, 2002; Pelliccioni, 2003; Skiba \& Peterson, 1999). Zero tolerance policies establish severe penalties for specified violations despite the circumstances (Skiba \& Peterson, 1999; Yell \& Rozalski, 2000). The policies began to emerge in schools across the country after President Clinton and the United States Congress passed the Gun-Free Schools Act in 1994. This act required schools to expel students caught with a gun for one year (Bowman, 2002; Cloud, Monroe \& Murphy, 1999; Cohen, 1999; Skiba \& Peterson, 1999; Yell \& Rozalski, 2000). There are substantial concerns surrounding the involvement and interference of the federal government, including federal courts, with the administration and policies of school districts (Pelliccioni, 2003; Yell \& Rozalski, 2000). The Gun-Free Schools Act circumvented constitutional concerns by discontinuing funding from the Improving America's Schools Act for any state that did not establish laws requiring expulsion for gun violations (Yell \& Rozalski, 2000). By 1995, all 50 states were in compliance with the Gun-Free Schools Act (Yell \& Rozalski, 2000).

Many schools did not stop at zero tolerance for gun violations, and expanded the list of infractions punishable by expulsion to include such things as alcohol and drug violations, sexual harassment, possession of other weapons such as knives and explosives, and any behavior in general that is perceived as threatening (Bowman, 2002; Cloud, Monroe, \& Murphy, 1999; Yell \& Rozalski, 2000). Zero tolerance policies are frequently operationalized through the use of metal detectors and student searches. While it may seem that get tough policies are necessary in today's climate of fear related to school violence, the "increasingly broad interpretations of zero tolerance have resulted in 
a near epidemic of suspensions and expulsions for seemingly trivial events" (Skiba \& Peterson, 1999, Near Epidemic, para. 1). Examples of zero tolerance gone awry include a six year old suspended for possession of organic lemon drops (Derbyshire, 2001), seven fourth graders given detention for a week for using their fingers as weapons in a recess game of soldier-versus-aliens (TheDenverChannel.com, 2002), and a fifth grader in Missouri suspended for drawing a picture of an airplane hitting the twin towers (Bickel, 2001).

Pelliccioni (2003) pointed out that most zero tolerance policies lack scienter (guilty knowledge), which means that students can be expelled for an offense that they were unaware of committing. Pelliccioni cited the case of Seal v. Morgan where Dustin Seal was expelled after school officials located a knife in his car, despite the fact that an acquaintance of Seal's had placed the knife there without his knowledge. Curwin and Mendler (1999) argued that “Any intervention for changing children's behavior that is simple is simple-minded, and those that substitute formulas for decisions made by people who understand the circumstances are dangerous" (para. 3).

Despite the prevalence of zero tolerance policies, there is no evidence to suggest that such policies have an effect on reducing school violence (Skiba \& Peterson, 1999). On the contrary,

Widespread advocacy for such social politics as zero tolerance and "adult time for adult crime" actually may exacerbate youth aggression and violence and influence popular opinions that such policies are effective when, in fact, they are not. The lack of accountability and inattention to research and results has led policy makers 
to advocate practices that are fashionable. (Christle, Jolivette, \& Nelson, 2000, p. 2)

Student profiling. Identification of risk factors has contributed to the development of a variety of checklists designed to profile students who may be potentially dangerous to themselves or others. Profiling has been criticized for presenting the possibility of bias and for infringing on student's civil liberties by unfairly labeling them as potentially violent (Reddy, Borum, Berglund, Vossekuil, Fein \& Modzeleski, 2001). The risk of generating false positives is substantial with profile checklists (Reddy et al., 2001). It is essential to acknowledge that even with the presence of multiple risk factors, between 50 to 80 percent of students are able to achieve success in life (Benard, 1993). Just as disconcerting as unfairly labeling innocent students is the fact that profiling may not identify students who actually pose a risk of violence (Reddy et al., 2001; Vossekuil, Fein, Reddy, Borum \& Modzeleski, 2002).

Research in this area seems to indicate that profiling is largely ineffective and that there is no empirical evidence supporting the validity of profiling to identify prospective attackers (Reddy et al., 2001) Additionally, "Labeling students 'at-risk' can set in motion a vicious self-fulfilling prophecy. No matter how well-meaning, targeted programs that label children as 'at-risk' may be doing more harm than good" (Benard, 1993, p. 47). In the FBI report The School Shooter: A Threat Assessment Perspective (O'Toole, n.d.), it clearly stated that "even clues that appear to help interpret past events should not be taken as predictors of similar events in the future" (p. 3). Student behavior and youth violence issues are complex and varied. A multitude of causal factors must be taken into account with the understanding that "no one factor is decisive" and yet "no one factor is 
completely without effect"' (O’Toole, p. 4). Rather than focus on checklists to label students, often unfairly, "A more effective approach is to identify factors that contribute to resiliency in the presence of risk factors, and use these in creating strategies for prevention" (Christle, Jolivette, \& Nelson, 2000, p. 1).

\section{Violence Prevention Programs}

Schools across the country are employing the use of a variety of programs designed to prevent and curb violent behaviors. Despite the prevalence of such programs, there is little evidence measuring the effects of many of them (U.S. Department of Health and Human Services, 2001). As schools struggle with limited resources, it is unfortunate that "much of the money America spends on youth violence prevention is spent on ineffective - sometimes even harmful - programs and policies" (U.S. DHHS, 2001, p. 99). Regrettably, some programs may actually influence students to become violent (Johnson \& Johnson, 1995). At its worst, some believe that many violence prevention programs may represent little more than political maneuvering by school districts to demonstrate that they have taken some form of protective actions to reduce violence (Johnson \& Johnson, 1995).

School-based violence prevention programs can be approached from an individual or small group perspective where participation is determined by an assessed or perceived need, or programs can be implemented universally school-wide (Breunlin, Cimmarusti, Bryant-Edwards \& Hetherington, 2002; Farrell, Meyer, Kung \& Sullivan, 2001; Johnson \& Johnson, 1995). It has been argued that programs aimed at school-wide audiences have not been proven to reduce violent behaviors among students who are at-risk (Breunlin et al., 2002). It would then follow that programs are needed that focus on targeted groups of 
students who are determined to be at-risk (Breunlin et al., 2002). However, Johnson and Johnson (1995) argued that in terms of the more universal conflict resolution programs, "The more students who are trained how to negotiate and mediate, however, the greater the number of conflicts that will be managed constructively in the school" (p. 66). It is important to acknowledge that violence among and between students occurs for multiple reasons and manifests itself differently (Breunlin et al.). Clearly, there are no easy solutions and it is unlikely that any one program can effect across-the-board results for all students or all types of violence likely to be encountered in the school setting.

Several promising strategies have been identified by the U.S. Department of Health and Human Services (2001) as potentially effective for mitigating or reducing violence including skills training, moral reasoning and problem solving, social perspective taking, and parental training. Strategies identified as ineffective include peer mediation, non-promotion to succeeding grades, gun buyback programs, and boot camps (U.S. DHHS, 2001). Additionally, the long standing Drug Abuse Resistance Education (DARE) program has recently received criticism for being ineffective as a deterrent for drug use (Study, 1999; U.S. DHHS, 2001).

According to Johnson and Johnson (1995) successful programs must go beyond violence prevention and incorporate fundamental conflict resolution skills. Conflict is a natural part of daily life and does not always result in negative outcomes (Breunlin et al., 2002; Johnson \& Johnson, 1995). The key to success lies in teaching students how to productively manage conflict to result in positive outcomes where they are able to negotiate win-win situations (Brendtro \& Long, 1995; Johnson \& Johnson, 1995; LeBoeuf \& Delaney-Shabazz, 1997). Conflict resolution can be approached in a variety 
of ways including peer mediation, mentoring programs for students and/or parents, and utilizing academic controversy to promote critical thinking and reasoning skills (Brendtro \& Long, 1995; Johnson \& Johnson, 1995; LeBoeuf \& Delaney-Shabazz, 1997).

There is disagreement in the literature regarding the effectiveness of peer mediation programs (Breunlin et al., 2002; Gagnon \& Leone, 2001; LeBoeuf \& DelanyShabazz, 1997; Peterson \& Skiba, 2000; U.S. DHHS, 2001). While some proclaim that peer mediation is a promising practice for effectively improving school climate and for reducing violent behaviors (LeBoeuf \& Delany-Shabazz, 1997; Peterson \& Skiba, 2000) others have indicated that peer mediation is an ineffective violence prevention tool (Breunlin et al., 2002; U.S. Department of Health and Human Services, 2001). The effectiveness of peer mediation programs is greatly influenced by the commitment of key stakeholders and by the degree to which mediators are adequately trained (Peterson \& Skiba, 2000).

Violence is a complex phenomenon that requires complex solutions. Schools cannot eliminate risk factors for violence such as poverty or the availability of guns or drugs in neighborhoods and homes (Johnson \& Johnson, 1995). Selecting violence prevention programs requires that school administrators be aware of research that identifies potential advantages and drawbacks related to individual program effectiveness. Farrell, Meyer, Kung and Sullivan (2001) summed it up by stating that:

No matter how well intentioned, the widespread implementation of programs of unknown effectiveness is unlikely to have a significant impact on this serious problem. On the contrary, it may lull policy makers and members of the community into falsely believing they are addressing 
this problem when the resources committed to such efforts could be better used to develop more effective programs. (p. 207)

Violence prevention programs must be part of a comprehensive approach that addresses "the complexity of social, familial, and developmental issues facing youth" (Petersen, Thompson, Gawerecki, \& Cauldwell, 2003, p. 28).

\section{Risk and Protective Factors for Violent Behavior}

Youth violence is complicated and is impacted by the interactions of multiple factors that create risk exposures or offer protective measures to mitigate risk. Before effective prevention techniques can be developed and implemented, it is essential to understand the multitude of causal factors that reinforce violent tendencies or promote violence resiliency.

\section{Risk Factors}

A large number of risk factors that contribute to an individual's predisposition toward developing violent behaviors have been identified in the extant literature (Blum, Ireland, \& Blum, 2003; Christle, Jolivette, \& Nelson, 2000; Hawkins et al., 2000; Moseley, 1999). Risk factors can be individual, family, school, peer-related, and/or community and neighborhood factors (Blum, Ireland, \& Blum, 2003; Christle, Jolivette, \& Nelson, 2000; U.S. DHHS, 2001; Hawkins et al., 2000).

Individual Risk Factors

Aggressiveness among males is an individual factor that has proven to be a consistent predictor of later violence (Hawkins et al., 2000). The use of alcohol and drugs is also associated with youth violence (Blum, Ireland \& Blum, 2003). Additionally, hyperactivity, concentration problems, risk taking, and a history of victimization are also 
correlated to later violence (Blum, Ireland, \& Blum, 2003; Christle, Jolivette, \& Nelson, 2000; Hawkins et al., 2000).

Gender Differences. On a more fundamental individual level, being male has been identified as a risk factor (Blum, Ireland, \& Blum, 2003; U.S. DHHS, 2001; Valois, MacDonald, Bretous, Fischer \& Drane, 2002). Research indicates that males are more likely to engage in violent behaviors than females (Daane, 2003; U.S. DHHS, 2001; Valois et al., 2002). Explanations for this phenomenon include the possibility that "boys are socialized into roles that encourage higher levels of physical aggression" (Valois et al., 2002), and that there may be "some biological or biological-environmental interaction as the causal mechanism" (U.S. DHHS, 2001).

Results of the 2003 Youth Risk Behavior Surveillance System [YRBSS] found that approximately $40 \%$ of males versus only $25 \%$ of females reported having been in a physical fight at least once in the previous 12 months. Males consistently reported higher levels of weapons carrying with $26.9 \%$ of males and $6.7 \%$ of females indicating they had carried a weapon (gun, knife, club) at least once during the previous 30 days and $8.9 \%$ of males and $3.1 \%$ of females reporting carrying a weapon to school in the previous month. Additionally, $10.2 \%$ of males and only $1.6 \%$ of females reported carrying a gun during the previous 30 days. Results also indicated that almost twice as many males than females reported being threatened or injured with a weapon at school during the previous year.

Females tend to engage in more subtle forms of aggression "such as alienation, ostracism, and character defamation. Females also often display relational aggression via exclusion of peers, gossip, and collusion directed at relational bonds between 'friends"” 
(Valois et al., 2002, p. 455). An analysis by Blum, Ireland and Blum (2003) indicated that family connectedness was associated with a reduced likelihood for engagement in aggressive behaviors for girls but was not a significant factor for boys. Conversely, skipping school was found to correlate with increased levels of overall violence for boys but not for girls (Blum, Ireland \& Blum; 2003). Blum, Ireland and Blum (2003) iterated that differences between genders

may suggest a differential effect of school on males and females, for not only is skipping school associated with violence involvement uniquely for males, so too is school connectedness uniquely protective for males. This is consistent with the work of Eccles, which has shown school to more positively affect male than female self-esteem. (p. 239)

Additionally, Gagnon and Leone's (2001) review of the research related to school-based interventions found that the Resolving Conflict Creatively Program, "an example of a social-cognitive intervention in which students are taught conflict resolution through modeling, role playing, interviewing, and small group work" (p. 105), seemed to provide "fewer positive effects for boys, younger children, and children in high-risk classrooms and neighborhoods" (p. 105).

Victimization. According to Blum, Ireland and Blum (2003), victimization is consistently related to youth violence. In their study of gender differences in juvenile violence, "victimization was the strongest finding associated with juvenile violence, for both males and females" (p. 238). The study reported that a history of victimization resulted in an increased odds ratio (OR) for individual involvement in violence for both males $(\mathrm{OR}=35.67)$ and females $(\mathrm{OR}=31.61)(\mathrm{p} .237)$. 
Victimization is more common among younger children, but older children appear to be victimized more selectively by their peers, resulting in consistent and repeated victimization over time (Hanish, 2000). "The degree to which particular children are targeted for victimization by peers depends, in large part, on their personal characteristics and behaviors, the dynamics of the peer group, and the structure and climate of the school environment" (Hanish, 2000, Why Do Children Get Victimized, para. 1).

Victimization can take both physical and psychological forms. According to Hanish (2000) boys are more likely to be physically victimized and threatened with a weapon, while girls are more likely to be victimized sexually or through more subtle processes such as gossip and exclusion from social activities. Peer bullying has begun to be recognized as a serious social problem that manifests itself with tragic outcomes including homicide and suicide (Bowman, 2001; Hazler, 2000). According to Hazler (2000),

Violence does not begin with gang warfare, rape, murder, and suicide.

That is when society becomes afraid of violence. Instead it begins as put downs, insults, threats, harassment, and bullying, where inappropriate lessons of how to deal with others are learned and where frustration, resentment, and anger build. (Violence Continuum, para 6)

In $2001,14.3 \%$ of sixth graders, $8.6 \%$ of ninth graders, and $2.4 \%$ of twelfth graders reported being bullied at school during the previous six months (DeVoe et al., 2002). Youth are often victimized and bullied because they "exhibit socially incompetent behaviors that their peers interpret as aversive or deviant" (Hanish, 2000, Behavioral 
Characteristics, para. 2). Additionally, research indicates that association with delinquent friends increases the opportunities for victimization (Schreck, Miller, \& Gibson, 2003). It has also been shown that students who carry a weapon to school are more likely to report victimization than those students who do not (Addington, Ruddy, Miller \& DeVoe, 2002; Schreck, Miller, \& Gibson, 2003). Interestingly, a national study found that targethardening strategies employed by school districts did not have an impact on reducing student victimization at school and schools that utilized locker searches actually tended to report higher levels of victimization (Schreck, Miller, \& Gibson, 2003).

\section{Family Risk Factors}

Certain family factors are associated with an increased risk of engaging in violent behavior. Poverty is an insidious risk factor that simultaneously exposes individuals to a variety of related risks for violence (Vorrasi \& Garbarino, 2000). According to Wilson (2000), "Being abused or neglected as a child increases the likelihood of arrest as a juvenile by 53 percent and of arrest for a violent crime as an adult by 38 percent" (p. 7). Additionally, children who are abused or neglected commit crimes younger and nearly twice as often as children who were not abused (Wilson, 2000). Domestic violence also significantly impacts youth. Petersen (2005) pointed out that,

Making more insidious the physical trauma and residual psychological effects of domestic violence, are the antisocial behaviors modeled by adults in the home. Children in these situations may perceive violence as an acceptable and appropriate method of handling social conflict. (Domestic Violence, para. 1) 
Additionally, a recent study indicated that individuals who were victimized in adolescence are twice as likely to suffer adult violent victimization (Menard, 2002). An association has also been found between leaving home at an early age and high levels of violence in both males and females (Hawkins et al., 2000). A recent study identified the presence of guns in the home and the availability of guns from peers as a risk factor for violence involvement (Blum, Ireland, \& Blum, 2003). Goldstein (1996) stated that the mere presence of a gun may actually stimulate aggression and that "as the researchers put it, sometimes 'the trigger pulls the finger"' (p. 16).

\section{Peer and School Risk Factors}

Peer and school related factors may also create risks for students. "Involvement with deviant peers is seen as the most proximal risk for delinquent involvement" (Henry, Tolan, \& Gorman-Smith, 2001, p. 172). Gang membership is also associated with an increased risk for engagement in violence (U.S. DHHS, 2001; Valois, MacDonald, Bretous, Fischer \& Drane, 2002). According to the U.S. Department of Health and Human Services (2001), “Gang membership increases the risk of violence above and beyond the risk posed by having delinquent peers" (p. 70).

Academic failure has also been shown to contribute to student delinquency (Blum, Ireland, \& Blum, 2003; Hawkins et al., 2000; Valois, MacDonald, Bretous, Fischer \& Drane, 2002). Low bonding to school is considered a risk factor for violent behavior (Valois, MacDonald, Bretous, Fischer \& Drane, 2002). Hawkins et al. (2000) reported that student bonding to school can actually serve as a protective factor against crime. In a study of juvenile violence that focused on gender differences (Blum, Ireland, \& Blum, 2003) school connectedness was found to be a protective factor for adolescent 
boys, but not for girls. It has also been found that adolescents with a history of a friend having committed suicide is a significant risk factor for both males and females (Blum, Ireland, \& Blum).

Accumulation of Risk Factors

Research suggests that the effects of multiple risk factors are cumulative in nature and that as exposure to additional risk factors for violence increases, the likelihood of engagement in violent behaviors also increases (U.S. DHHS, 2001; Walker \& Sprague, 1999). Petersen (2005) stated that "research has shown that individuals who experience too many stressors at one time are at increased risk for becoming violent" (Amassing Risk, para. 2). The theory of accumulated risk is based on the assumption that children can cope with and adjust to levels of risk that do not exceed "a developmentally determined individual threshold" (Vorrasi \& Garbarino, 2000, p. 62). When accumulated risk exceeds the individual's capacity for coping and positive adjustment, protective or opportunity factors are required to prevent harm (Vorrasi \& Garbarino, 2000).

\section{Protective Factors}

While current research has documented many risk factors that contribute to an individual's predisposition for developing violent and aggressive behaviors, little is known about protective factors for violence (U.S. DHHS, 2001). According to the U.S. Department of Health and Human Services (2001), most studies have not focused on identifying protective factors specifically for violence. The National Center for Injury Prevention and Control [NCIPC] (2002) has placed a priority on identifying "modifiable factors that protect youths from becoming victims or perpetrators of violence” (p. 78). Additionally, the NCIPC emphasized that research focused on "modifiable protective 
factors has important implications for prevention that is not being addressed elsewhere" (p. 79).

There is disagreement about the operational definition of protective factors (U.S. DHHS, 2001). While some research views protection and risk as opposites on a single continuum, this linear conceptualization loses the distinction between the two concepts and they appear to become two extremes of the same phenomenon (Davis, 1999; U.S. DHHS, 2001). Others view risk and protection as fundamentally different and unique (Davis, 1999). The U.S. DHHS (2001) defines protective factors as "characteristics or conditions that interact with risk factors to reduce their influence on violent behavior" ( $p$. $62)$.

Research has identified protective factors in a variety of contexts including individual, family, community, school, and peer (Davis, 1999; U.S. DHHS, 2001). It is important to note that most studies have not focused specifically on protective factors that mitigate or minimize violent behavior (U.S. DHHS, 2001). However, generalized protective factors include the presence of a caring adult, school connectedness, a caring school environment, intelligence, pro-social orientation, stable family life, higher socioeconomic status, friendship with non-delinquent peers, and involvement with school supported social groups (Christle, Jolevette \& Nelson, 2000; Davis, 1999; U.S. DHHS, 2001). The U.S. Department of Health and Human Services (2001) identified two protective factors that have demonstrated a buffering risk on violence specifically. The first, an individual characteristic, is "an intolerant attitude toward deviance" (p. 74). The underlying concept reasons that individuals who strongly disapprove of violence are unlikely to engage in violence or to place themselves in situations likely to result in 
violent outcomes. The second factor identified as buffering against violence is a commitment to school. In this context, school provides an arena for student success and recognition that may not be available in other aspects of their lives. However, a study by Blum, Ireland and Blum (2003) found that school connectedness was a protective factor for boys but not for girls. The study found that for girls, family connectedness was a more important protective factor.

It has also been suggested that protective factors, like risk factors, have the capacity to accumulate (Davis, 1999; Vorrasi \& Garbarino, 2000) and that risk factors can be counteracted by protective factors "even when patterns of risk are thought to be impervious to intervention" (Vorrasi \& Garbarino, 2000, p. 63). With the potential to mitigate or minimize the effects of risk factors, protective factors are an important tool for violence prevention (U.S. DHHS, 2001). At the heart of the issue is the concept that risk exposure does not necessitate certain failure. According to Christle, Jolivette \& Nelson (2000):

Many youth who are exposed to risk factors do not display aggressive and violent behaviors. Certain protective factors appear to account for this phenomenon. Often, these factors are described in terms of resiliency-the ability to recover strength and spirit under adversity on both internal (self) and external (family, school, community) factors for a positve out-come. (p. 1)

\section{Resilience}

The field of resilience research began with Dr. Norman Garmezy and his work with schizophrenic parents and their children (Davis, 1999). While Garmezy did find that 
a child's risk of developing schizophrenia increased if parents suffered from the illness, a surprisingly high percentage of the children in his study did not develop the illness (Davis). This was a significant turning point as researchers began to look beyond the risks and sought out the circumstances and conditions that enable individuals to successfully rebound from bad situations. Later research also found that at-risk individuals frequently achieved success in their lives despite the presence of significant adversity (Benard, 1993; Davis, 1999; Werner \& Smith, 2001).

There are many inconsistencies in the research related to the definition of resilience (Gordon Rouse, Longo \& Trickett, 1999; Mandleco \& Peery, 2000). Early research utilized terminology such as invulnerable and invincible to describe individuals who overcame adversity (Davis, 1999). The work of Dr. Michael Rutter argued that such terminology was flawed because it suggested that these individuals were incapable of being harmed (Davis). Resilience should not imply super-human qualities, but rather reflect the positive spiritual, emotional and intellectual attributes of the human condition that allows individuals the capacity to bend without breaking. Henderson and Milstein (2003) stated that resilience "is a process more than a list of traits" (p. 11) and that resilience varies among individuals and over time. Rutter (2000) defined resilience as "relative resistance to the adverse effects of risk experiences" (para. 1).

Rutter (2000) argued that resilience should not be viewed as a characteristic inherent to some individuals because "resistance to one form of stress may not be paralleled by an equal degree of resistance to other, rather different, forms of stress or adversity" (Resilience as Resistance to Stress or Recovery from Sequelae, para. 1). Rutter (2000) indicated that the social context of a situation has significant impact on individual 
outcomes. Further, Rutter (2000) argued that there is a need to "distinguish between risk indicators and risk mechanisms" (Identification of Specific Environmentally Mediated Risks, para. 1). As an example, he cited that family separation has historically been viewed as a risk factor, but that the actual risk lies not in the separation, but in the context of the separation. In such cases, risk lies with the possibility of "disturbed relationships and poor parenting that have been brought about by loss or separation" (Identification of Specific Environmentally Mediated Risks, para. 1).

The existence of varied definitions of resilience has resulted in inconsistent methods for measuring resilience. Mandleco and Peery (2000) iterated that: researchers seldom define or differentiate resilience as a construct separate from factors or variables influencing resilience. Part of this problem may be related to difficulties inherent in how resilience is measured compared to factors actually affecting or contributing to resilience. For example, personal characteristics such as empathy, coping ability, social competence, peer relations, self-worth, mental health, cognitive competence, and locus of control have been used not only as evidence but also as definitions of resilience. (para. 6)

While general definitions of resilience may be adequate for global discussions, research must carefully consider and operationalize the definition of resilience so that global discussions can lead to practical applications.

Resilient outcomes are not static and vary by risk (Davis, 1999; Henderson \& Milstein, 2003; Rutter, 2000). Accordingly, assessing overall general resilience is difficult if not impossible without determining context. A fifteen-year-old girl may be 
exposed to identified risk factors for academic failure, early engagement in sexual activity, and substance abuse. If she succumbs to only one of these, how would a researcher determine overall resilience? Does academic success and avoidance of substance abuse outweigh engagement in sexual activity? Resilient outcomes should be measured within the context of a specific risk at an identifiable time in life in a particular setting. The broad scope of resilience can be broken down into specific domains (Davis). Research has been conducted on educational resilience and on overall resilience in life (Davis; Gordon Rouse, Longo \& Trickett, 1999). Measurement of education resilience includes items such as grades and standardized test scores (Davis). The literature seems to be absent of information about violence resiliency as a specific domain of resilience.

\section{Characteristics of Resilient People}

Research on resilience has yielded a compilation of characteristics attributable to resilient individuals (Benard, 1993; Christiansen, Christiansen \& Howard, 1997; Davis, 1999; Gordon Rouse, Longo \& Trickett, 1999). Benard indicated that "Resilient children usually have four attributes; social competence, problem-solving skills, autonomy, and a sense of purpose and future" (p. 44). Davis' (1999) review of resilience research indicated that individuals deemed resilient often display physical, social and relational, cognitive, emotional, moral, and spiritual competencies.

McWhirter \& McWhirter (1994) identified the "Five Cs of Competency", characteristics of adolescents they believed "discriminate youngsters moving through life with high potential for success from those who are not doing well" (para. 1). The Five Cs include critical school competencies such as academic skills, concept of self and selfesteem, positive communication skills, coping skills, and control. According to 
McWhirter and McWhirter (1994), "High-risk individuals are deficient in one or more of these skills, which results in youngsters moving into self-destructive risk behaviors that include school dropout, substance abuse, pregnancy, delinquency, and suicide” (para. 1).

Additionally, research indicates that resilient individuals are intelligent (Davis, 1999), good-natured and display a sense of humor (Benard, 1993; Christiansen, Christiansen \& Howard, 1997), capable of adapting and coping with life's challenges (Christiansen, Christiansen \& Howard, 1997; D’Imperio, Dubow, \& Ippolito, 2000; McWhirter \& McWhirter, 1994), and demonstrate problem solving skills (Benard, 1993; Christiansen, Christiansen \& Howard, 1997). While these attributes may contribute to overall resilience in life, each of the characteristics may be more or less relevant within the context of a specific risk and during different developmental phases of life. Davis discussed Luthar's finding that overt indications of competence may not be accompanied by the more covert aspects of good mental health. Of importance is that resilience does not come without personal struggles and serious contemplation of difficult decisions. Without risk, resilience does not exist (Davis).

\section{Social Competence}

John (2001) defined social competence as the ability to function appropriately in interpersonal interactions" (p. 182). Benard (1993) identified social competence as one of the attributes displayed by resilient children. She further stated that "Social competence includes qualities such as responsiveness - especially the ability to elicit positive responses from others - flexibility, empathy, caring, communication skills, and a sense of humor" (p. 44). Barber and Erikson (2001) defined social competence as "a broad term that encompasses numerous forms of social behaviors thought to be indicative of 
adaptive, healthy, and productive social functioning” (p. 327). They described socially competent adolescents as

those who, among other things, are involved in their social worlds, have a sense of social responsibility, act prosocially, are achievement oriented, are friendly, are facilitative of others, are self-determined, and have learned to balance their personal goals with the goals of others. (p. 327)

Research has indicated that children with positive and secure parental relationships tend to display higher degrees of social competence and that "adolescents have interpersonal connections in a variety of social contexts, all of which also may be instrumental in shaping levels and types of social competence" (Barber \& Erickson, 2001, p. 328).

Empathy. Empathy is an important component of social competence and is defined as "sharing another's emotional state or context" (Bush, Mullis, \& Mullis, 2000, p. 467). According to Goldstein (1996), "It appears to be the case that the greater the empathy we feel for another person, the more we perceive his or her world and humanness, the less able we are to hurt him or her" (p. 32). Additionally, Litvak-Miller and McDougall (1997) stated that "The gradual transformation from empathetic distress to sympathetic concern is seen as having important consequences for the relationship between empathy and behavior" (p. 2).

Empathy offers important implications for promoting violence resiliency. Empathetic skills can and should be taught. According to Kehret (2001), it is important for children to 
learn to imagine themselves in someone else's skin. They need to see how painful it is to lose personal belongings to a thief or to be bullied, and they also need to learn how satisfying it is to help someone who needs assistance. They need to experience empathy (para. 4)

Hazler (2000) also argued that "Young people need exposure to the hurt that degrading human dignity causes and the benefits of gaining empathic understanding of others" (Dehumanization, para. 2).

Research indicates there is an inverse relationship between empathy and inappropriate behaviors (Bush, Mullis, \& Mullis, 2000; Sneed, 2002). Empathy can help combat dehumanizing tactics that make it easier for people to victimize others (Goldstein, 1996; Hazler, 2000). Dehumanization has serious implications for victims and those around them. According to Hazler, individuals dehumanize others so that they do not need to treat them as living, breathing, feeling persons just like themselves. For the victim, names that dehumanize confirm their already low self-concept and validate their negative self-evaluation. They are treated and referred to as less than human, and the degree to which they accept that description reduces the value they put on their own human life or the lives of others. This is a point at which the potential of hurting themselves or others is greatly expanded. (Dehumanization, para. 1) Teaching empathetic skills can help reduce dehumanization tactics as people learn to understand what it means to be a victim (Hazler, 2000).

Relationship skills. The ability to develop positive relationships is another component of social competence (Benard, 1993; Christiansen, Christiansen \& Howard, 
1997; Davis, 1999; Meisels, Atkins-Burnett, \& Nicholson, 1996). According to Benard (1993), "From early childhood on, resilient children tend to establish positive relationships with both adults and peers that help bond them to their family, school, and community" (p. 44). Research points to the notion that aggression is correlated with peer rejection (Meisels, Atkins-Burnett, \& Nicholson, 1996), which emphasizes the importance of positive peer relationships (Davis, 1999). The overarching issue is not popularity, but the ability to choose friendships that will stand the test of time (Davis). Resilient individuals tend to be good-natured and are able to gain "positive attention from others. They are easy to be around and usually have a close bond with a caregiver or significant adult" (Christiansen, Christiansen \& Howard, 1997, Resilient Children, para. $1)$.

Sense of humor. Another characteristic of socially competent individuals is the presence of a sense of humor (Benard, 1993; Christiansen, Christiansen \& Howard, 1997; Davis, 1999). A sense of humor is an important aspect of effectively coping with life stressors (Christiansen, Christiansen \& Howard, 1997; Davis, 1999). According to Davis, "Good-natured humor allows people to laugh with each other and not take themselves so seriously" (p. 34).

\section{Summary}

School shootings and other tragedies have generated a climate of fear in America's public schools. As a result, many schools have implemented a variety of measures to ensure student safety, including increased physical security, stringent school policies and the adoption of violence prevention programs. While supported by good 
intentions, many of these measures are ineffective and some are actually detrimental to the students and to the overall climate of the school.

Students are exposed to a multitude of risk and protective factors for violent behavior. Accumulated risks and protective factors impact student behaviors in different ways and to varying degrees. While much is known about risk factors for violence, little is known about protective factors that may contribute to violence resiliency. Protective factors are individual characteristics and environmental conditions that may reduce the overall influence of risk factors that contribute to violent behaviors. Protective factors are often "described in terms of resiliency" (Christle, Jolivette \& Nelson, 2000, p. 1). Specific characteristics associated with resilient individuals include social competence, which is marked by empathy, a sense of humor, communication skills, and positive relationship skills.

Chapter 3 of this study outlines the theoretical framework that guided this investigation and discusses social competence as a protective factor for violence resiliency. Chapter 3 also provides the rationale supporting the use of a qualitative case study design. Data collection and analysis techniques are also described, as is the role of researcher in this investigation. 


\section{CHAPTER THREE \\ RESEARCH DESIGN AND METHODOLOGY}

Theoretical Framework

The field of resilience research began with Dr. Norman Garmezy and his work with schizophrenic parents and their children (Davis, 1999). While Garmezy found that a child's risk of developing schizophrenia increased if parents suffered from the illness, a surprisingly high percentage of the children in his study did not develop the illness (Davis). This was a significant turning point as researchers began to look beyond the risks and sought out the circumstances and conditions that enabled individuals to successfully rebound from bad situations. Later research that focused on individual resilience found that at-risk individuals frequently achieved success in their lives (Benard, 1993; Davis; Werner \& Smith, 2001).

There are many inconsistencies in the research related to the definition of resilience (Davis, 1999; Mandleco \& Peery, 2000). Early research utilized terminology such as invulnerable and invincible to describe individuals who overcame adversity (Davis). The work of Dr. Michael Rutter argued that such terminology was flawed because it suggested that these individuals were incapable of being harmed (Davis). A 1987 publication by Rutter (as cited in Davis) argued that resilience may change over a period of time and may change in response to varying circumstances. Accordingly, resilient outcomes should be measured based on a specific risk at a particular time in life.

The broad scope of resilience can be broken down into specific domains (Davis, 1999). Much research has been conducted on the domain of educational resilience and includes measures such as grade point average and standardized test scores (Davis). This 
research focused on violence resiliency, defined as the successful avoidance of violent and aggressive behaviors at school despite the presence of multiple risk factors known to increase the likelihood of such behaviors occurring. Violence resiliency represents new terminology that was absent in this review of extant literature. This research investigation focused specifically on adolescent males and contended that violence resiliency is a behavioral outcome of individuals who are able to acknowledge and handle conflict in positive and productive ways without internalizing their aggression. In a review of research on resilience, Davis cited work by Luthar (1991) that "found that highly stressed but overtly socially competent adolescents reported increased levels of depression, anxiety, and self-criticism, much more so than competent children from low-stress backgrounds" (Davis, p. 8). Additional research in this area contends that positive behavioral outcomes should be accompanied by psychological well-being (Davis). In determining violence resiliency, this study focused on the interaction of risk and protective factors to determine the influence of individual social competence.

\section{Risk Factors}

Current research has identified a variety of risk factors that contribute to an individual's predisposition toward developing violent behaviors (Goldstein, 1996; Hawkins et al., 2000; Hazler, 2000; Menard, 2002; Moseley, 1999; U.S. Department of Health and Human Services, 2001; Vorrasi \& Garbarino, 2000; Wilson, 2000). Identified risk factors include poverty, risk taking, childhood abuse and neglect, victimization, academic failure, access to weapons, gang association, witnessing violence, and the availability of drugs and alcohol. Research also suggests that the effects of multiple risk factors are cumulative in nature and that "the more risk factors a child is exposed to, the 
greater the likelihood that he or she will become violent" (U.S. Department of Health and Human Service, p. 59). The theory of accumulated risk is based on the assumption that children can cope with and adjust to "low levels of risk until the accumulation exceeds a developmentally determined individual threshold" (Vorrasi \& Garbarino, p. 62). When accumulated risk exceeds an individual's capacity for coping and positive adjustment, opportunity (protective) factors are required to mitigate risk factors and reduce the likelihood of anti-social behaviors (Vorrasi \& Garbarino).

\section{Protective Factors}

Protective factors are "characteristics or conditions that interact with risk factors to reduce their influence on violent behavior" (U.S. Department of Health and Human Services, 2001, p. 62). Dunst and Trivette (as cited in Vorrasi \& Garbarino, 2000) suggest that protective factors also have the capacity to accumulate and that "risk factors may be neutralized or at least partially offset by the introduction of opportunity factors into other realms of the child's life, even when patterns of risk are thought to be impervious to intervention" (p. 63). Unfortunately, little information is currently available about protective factors for violence (U.S. DHHS, 2001).

However, protective factors are often "described in terms of resiliency" (Christle, Jolivette \& Nelson, 2000, p. 1). Research on resilience has yielded a compilation of common characteristics attributable to resilient individuals (Benard, 1993; Christiansen, Christianse, \& Howard, 1997; Davis, 1999; Gordon Rouse, Longo \& Trickett, 1999; Luthar, 1991). Social competence, which includes qualities such as empathy, good communication skills, a sense of humor, and establishment of positive interpersonal relationships, (Benard, 1993) has been identified as one characteristic of resilient 
individuals (Benard; Davis; Luthar). However, Mandleco and Peery (2000) pointed out that characteristics such as social competence "have been used not only as evidence but also as definitions of resilience" (para. 6). It should be established that for this investigation social competence neither defines nor provides evidence of resilience. Rather, this research investigation theorized that social competence serves as a potential protective factor for violence resiliency during adolescence for males.

\section{Purpose of the Study}

Violence significantly contributes to the creation of a socially toxic environment (Vorrasi \& Garbarino, 2000). Yet, due to the complex nature of violence, it is essential to consider the multitude of causal factors that converge and motivate students to become violent. Current research has identified a multitude of risk factors such as the use of alcohol and dugs, hyperactivity, risk taking, a history of victimization, poverty, and academic failure that contribute to an individual's predisposition toward the development of violent tendencies (Blum, Ireland, \& Blum, 2003; Christle, Jolivette, \& Nelson, 2000; Hawkins, 2000; Vorrasi \& Garbarino). Therefore, at the heart of the issue is the need to understand the various causes of violence in order to implement appropriate intervention and prevention strategies by schools and other key stakeholders. This investigation sought to discover what allows some students to rebound from toxic situations and experiences and avoid involvement in violence and aggressive behaviors while others do not?

This study examined the influence of social competence on engagement in violent and aggressive behavior among adolescent males. Further, the study sought to determine to what degree the elements of social competence (empathy, a sense of humor, 
communication skills, relationship skills, and social assertiveness) serve as protective factors for violence resiliency among adolescent males exposed to risk factors that have been identified as contributing to the development of violent and aggressive behaviors. The study used a multiple case design to identify exposure to risk factors and explore potential relationships between the elements of social competence and violence resiliency.

\section{Research Questions}

The overarching question guiding this investigation was why do some at-risk adolescent males refrain from committing violence and participating in violent acts while others do not? In order to address this larger question, this study asked:

1. Do the elements of social competence (empathy, a sense of humor, communication skills, relationship skills, and social assertiveness) serve as protective factors for violence resiliency among at-risk adolescent males?

2. Is individual social competence influential on engagement in violent and aggressive behavior among at-risk adolescent males?

3. Are there other protective factors for violence resiliency that emerge as important in preventing violent behavior?

\section{Rationale for Qualitative Case Study Design}

In determining which research strategy to employ, Yin (2003) stated that researchers must consider the following three conditions: "(a) the type of research question posed, (b) the extent of control an investigator has over actual behavioral events, and (c) the degree of focus on contemporary as opposed to historical events" (p. 5). Based on these conditions, "case studies are the preferred strategy when 'how' or 'why' 
questions are being posed, when the investigator has little control over events, and when the focus is on a contemporary phenomenon within some real-life context" (Yin, p. 1). Accordingly, a case study is appropriate for this investigation because it focused on the question of why some at-risk adolescent males refrain from committing violence and participating in violent or aggressive behaviors while others do not. Additionally, the researcher has no control over the extent or nature of the violent or aggressive behavior displayed by the participants. Finally, the issue of youth violence continues to be a contemporary phenomenon that has serious implications in school settings (Hanish, 2000; Hazler, 2000; NCIPC, 2002; Trump, 2000; U.S. DHHS, 2001).

This investigation represents a multiple case design with two cases deliberately chosen from opposite extremes (Yin, 2003). According to Yin, a multiple case design is often preferable to single case design because it offers the ability of "strengthening the external validity of your findings compared to those from a single case alone" (p. 54). When conducting a case study, every case should have a specific purpose and "Each case must be carefully selected so that it either (a) predicts similar results (a literal replication) or (b) predicts contrasting results but for predictable reasons (a theoretical replication)" (Yin, p. 47). This replication logic is inherent in case studies and replaces the notion of sample size and generalization to a larger population. Yin answered the question of generalization with the following:

The short answer is that case studies, like experiments, are generalizable to theoretical propositions and not to populations or universes. In this sense, the case study, like the experiment, does not represent a "sample," and in doing a case study, your goal will be to expand and generalize 
theories (analytic generalization) and not to enumerate frequencies (statistical generalization). (p. 10)

Qualitative research is often employed in case studies, utilizes a small and purposeful sample, seeks to develop understanding and creates an environment where the researcher is directly involved with the subjects (Bogdan \& Biklen, 1998). The qualitative approach utilized in this investigation is a natural complement to the case study research strategy. Qualitative research offers the opportunity to more fully understand the influences of setting on human behavior (Bogdan \& Biklen). Qualitative researchers are concerned with individual perspectives and with "how different people make sense of their lives" (Bogdan \& Biklen, p. 7). As with case studies, issues of generalizability are different than those utilized in quantitative research. Qualitative researchers "concern themselves not with the question of whether their findings are generalizable, but rather with the question of to which other settings and subjects they are generalizable" (Bogdan \& Biklen, p. 33). This type of analysis fits well with the analytic generalization offered by case studies.

Of importance in this investigation is not a statistical analysis of student engagement in violent or aggressive behaviors, but a deeper understanding of why they did or did not engage in violent or aggressive behaviors given the context of their risk exposures. Bogdan and Biklen (1998) indicated that:

The qualitative researchers' goal is to better understand human behavior and experience. They seek to grasp the processes by which people construct meaning and to describe what those meanings are. They use empirical observation because it is with concrete incidents of human 
behavior that investigators can think more clearly and deeply about the

human condition. (p. 38)

By utilizing a qualitative case study approach, this research sought to more fully

understand the interaction of factors that influences violence resiliency or that contributes to involvement in violent and aggressive behaviors.

\section{Participants}

The setting for the study is a mid-western suburban high school. The school district was selected based on its positive reputation and its proximity to the researcher. Participants included male students currently enrolled in grades nine through twelve.

\section{District}

The participating school district is a mid-western suburban school district with more than one high school. District consent was obtained from the Superintendent and additional assistance was provided by the district Director of Secondary Education. Overall district enrollment exceeded 11,500 in 2004, with approximately $51 \%$ of students eligible for the free and reduced lunch program. The student population is composed of primarily white students with fewer than $8 \%$ black students and fewer than 3\% Hispanic students. Compared to overall averages of student demographics within the state, the district's percentage of black students is less than half, but the number of Hispanic students is consistent.

\section{School}

One high school, selected by the district Director of Secondary Education, was included in the study. The school serves students in grades nine through twelve and has an average enrollment of approximately 950 students. The school is composed of $90 \%$ 
white students, approximately 4\% black students, and just under $4 \%$ Hispanic students. Attendance rates are $93 \%$ and the school graduation rate in 2004 was close to $90 \%$. Almost $44 \%$ of the students are eligible for the free and reduced lunch program.

\section{Students}

Participation in this study was limited to male students in grades nine through twelve. The extant literature supports that males are more likely to engage in violent behaviors than females (Daane, 2003; U.S. DHHS 2001; Valois, MacDonald, Bretous, Fischer \& Drane, 2002). Males are more likely to carry weapons on and off school property and are more likely to engage in physical fights on school property (YRBSS, 2003). Females are more likely display more subtle forms of aggression "such as alienation, ostracism, and character defamation" (Valois, MacDonald, Bretous, Fischer \& Drane, p. 455). Victimization has been consistently related to youth violence for males and females (Blum, Ireland \& Blum, 2003). However, Hanish (2000) indicated that victimization is experienced differently by gender and identified the following distinctions:

Boys are more likely than girls to be physically victimized; they are more often punched, kicked, and threatened with a weapon. Girls, in contrast, are more likely to be relationally and sexually victimized; they are more often gossiped about, intentionally excluded from social activities, and sexually harassed. (Demographic Characteristics, para. 2)

Additionally, protective factors vary by gender with family connectedness serving as an important factor for girls, while school connectedness was more significantly protective for boys (Blum, Ireland \& Blum, 2003). In addition to varying risk and protective factors, 
and different manifestations of antisocial behaviors, Hanish (2000) reported that "social interaction styles differ by gender” (Demographic Characteristics, para. 2).

The total male student population at the time of the study was 414 . Potential participants were randomly generated by computer based on the number of office referrals during the academic year. Office referrals would indicate that a student had broken some school rules, but would not indicate any propensity for violent or aggressive behaviors. Of the 414 male students, 261 (63\%) had no office referrals during the academic year and $80(19 \%)$ had three or more office referrals during the year. The study was conducted during the last eight weeks of the academic year. Parental consent forms were initially mailed to 50 students with no office referrals and 50 students with three or more office referrals. Second mailings were sent to all students whose parents had not replied, and an additional 50 parental consent forms were mailed to students with no office referrals.

Participation in the research was completely voluntary. Written parental consent and written child assent were obtained. Consent and assent forms were approved by the IRB prior to use and maintained compliance with 45 CFR 46.116. Even with parental consent, the student could elect not to participate. Participation in the research could have been withdrawn at any time by either the parent or the student without consequence. Each time there was interaction between the researcher and the participants, the student was reminded that participation was voluntary and that he could choose not to respond to particular questions or could choose to withdraw from participation completely without any negative consequences. A small token of appreciation was offered to students for 
completing the initial survey, and a \$50 gift card to Wal-Mart was offered to students who participated in the interviews.

Issues of confidentiality were specifically addressed in the consent and assent forms. Data collected from the students were not shared with parents, the school, or any other individual or organization familiar with the students. Individual names were not utilized in the research report and will remain anonymous in any other subsequent publications or presentations.

\section{Role of the Researcher}

The researcher is a key component in qualitative research. Qualitative researchers seek to better understand the human experience within the context of individual perspectives (Bogdan \& Biklen, 1998). To more fully understand the perspectives of individuals, researchers must interact with participants to interpret visual and verbal clues. The question of researcher bias is significant in qualitative studies. However, researcher bias can also be found in experiments, historical research and survey questionnaires (Bogdan \& Biklen; Yin, 2003). While researcher bias cannot be completely eliminated, by acknowledging personal biases a researcher can more effectively minimize its effects (Bogdan \& Biklen). In the end, "The data must bear the weight of any interpretation, so the researcher must constantly confront his or her own opinions and prejudices with the data" (Bogdan \& Biklen, p. 34). It is also important to recognize that 'the researcher's primary goal is to add knowledge, not to pass judgment on a setting” (Bogdan \& Biklen, p. 34).

Through the use of multiple sources of information, such as documentation, archival records, interviews, and direct observations, researchers can significantly 
strengthen the findings of the study (Yin, 2003). The use of multiple sources of information is referred to as data triangulation (Yin).

\section{Data Collection}

Data were collected from a variety of sources including initial surveys completed by the student participants, interviews conducted with students and teachers, and the Interpersonal Reactivity Index. General observations of the school environment were also utilized.

\section{Initial Survey}

Surveys measuring exposure to risk factors and engagement in violent and aggressive behaviors were administered to students in an individual and confidential setting. The surveys were utilized to confirm exposure to risk factors and whether or not the participant had engaged in violent or aggressive behaviors at school and utilized questions from the Youth Risk Behavior Surveillance System developed by the Centers for Disease Control. To qualify for inclusion in the interviews, the student had to have exposure to three or more risk factors (including, but not limited to risks such as poverty, victimization, academic failure, access to weapons, gang association, use of alcohol and drugs, and risk taking). In her review of research on resilience, Davis (1999) outlined the findings of a study conducted by Rutter et al. (1975) which focused on the development of psychiatric disorder among children. The study determined that the presence of one risk factor did not impact the likelihood of developing psychiatric disorder while the presence of two factors "produced a 4-fold increase in the likelihood of psychiatric disorder, and 4 factors increased the risk 10-fold" (Davis, p. 17). Similarly, Davis reported on a study by Sameroff et al (1987) that explored the impact of risk factors on 
children's intelligence scores. The study determined that intelligence scores began to drop significantly in the presence of three risk factors. Based on these examples and the theory of accumulated risk, this investigation focused on the presence of multiple risk factors, with the understanding that not all risk factors are equally weighted (Vorrasi \& Garbarino, 2000).

\section{Interviews}

Yin (2003) stated "One of the most important sources of case study information is the interview" (p. 89). In qualitative case studies, interviews are often considered to be guided conversations (Bogdan \& Biklen, 1998; Yin). Interviews often utilize open-ended questions that allow the participant to share their thoughts and ideas (Bogdan \& Biklen; Yin). The researcher has an obligation to pose unbiased questions in a manner that is not intimidating to the subjects (Yin).

This investigation utilized several open-ended interviews with selected participants (Appendix B). Focused interviews were also conducted with teachers familiar with the student participants. With participant consent, interviews were tape recorded and later transcribed for analysis.

\section{Interpersonal Reactivity Index}

Davis (1983) developed the Interpersonal Reactivity Index (IRI) to measure four separate dimensions of empathy that include Empathic Concern, Perspective Taking, Personal Distress, and the Fantasy Scale. The IRI is a 28 -item self-report questionnaire that includes 7 questions for each of the four subscales of empathy. Each item consists of a five point Likert scale response ranging from 0 (does not describe me well) to 4 
(describes me very well). Overall scores for each of the subscales ranges from 0 to 28 .

Higher scores are indicative of higher personal levels of that component of empathy.

Perspective Taking and the Fantasy Scale represent cognitive aspects of empathy while Empathic Concern and Personal Distress are emotional (Davis, 1983). Davis described the four scales as follows:

The Perspective-Taking (PT) scale assesses the tendency to spontaneously adopt the psychological point of view of others; the Fantasy (FS) scale taps respondents' tendencies to transpose themselves imaginatively into the feelings and actions of fictitious characters in books, movies, and plays. The other two subscales measure typical emotional reactions of the respondents: The Empathic Concern (EC) scale assesses "other-oriented" feelings of sympathy and concern for unfortunate others, and the Personal Distress (PD) scale measures "self-oriented" feelings of personal anxiety and unease in tense interpersonal settings. (p. 113-14)

The IRI has demonstrated test-retest reliability and construct validity (Davis, 1983; Lindsey, Carlozzi \& Eells, 2001; Sperber, 2003).

\section{Observations}

Observations can add valuable data to qualitative case study research (Yin, 2003). It is important to remain unobtrusive and to acknowledge that the mere presence of an outsider has the potential to influence the behaviors of individuals within the setting being observed (Bogdan \& Biklen, 1998). This study utilized observation of the general school environment at various times throughout the school day, but was unable to observe the participants in the classroom setting due to confidentiality issues. 


\section{Data Analysis}

Data obtained from the initial surveys were analyzed to confirm student risk exposures and engagement in antisocial behaviors. Quantitative scores for the selected study participants were analyzed in conjunction with qualitative information obtained in the participant interviews and the Interpersonal Reactivity Index scores.

Bogdan and Biklen (1998) defined data analysis at "the process of systematically searching and arranging the interview transcripts, fieldnotes, and other materials that you accumulate to increase your own understanding of them and to enable you to present what you have discovered to others" (p. 157). To improve the quality of data analysis, researchers should evaluate all of the evidence, address rival theories and interpretations, focus on the primary issue of the case study, and utilize his/her own expertise (Yin, 2003). Data analysis may begin to take place in the field during data collection although it is advisable to take a short break once the data have been collected, typed and transcribed (Bogdan \& Biklen).

With the consent of participants, interviews were tape recorded and transcribed. The transcripts were coded in search for any regularities, patterns and topics (Bogdan \& Biklen, 1998). The process of open coding (Strauss \& Corbin, 1998) consists of breaking down, examining, conceptualizing, and beginning to categorize the data. The next phase of the coding process, axial coding, consists of reassembling to (re)conceptualize the data and the phenomena these data represent (Strauss \& Corbin).

Summary

The purpose of this study was to determine why some adolescent males are able to rebound from toxic situations and experiences and successfully avoid engagement in 
violent and aggressive acts and behaviors while others do not. This investigation proposed that social competence is a potential protective factor for violence resiliency.

Data were collected through open-ended interviews with the participants and focused interviews with selected school personnel. Interviews were recorded, transcribed, and analyzed with the processes of open and axial coding. Data were also collected through the use of initial surveys, the Interpersonal Reactivity Index, and then through general observations within the school. 


\section{CHAPTER FOUR \\ PRESENTATION AND ANALYSIS OF THE DATA}

Introduction

The focus of this study was to determine the influence of social competence on engagement in violent and aggressive behavior among adolescent males. Further, this study sought to determine to what degree the elements of social competence serve as protective factors for violence resiliency among adolescent males exposed to risk factors identified as contributing to the development of violent and aggressive behaviors. The study used a case design to identify exposure to risk factors and explore potential relationships between the elements of social competence and violence resiliency.

\section{Research Questions}

The overarching question guiding this investigation asked, why do some at-risk adolescent males refrain from committing violence and participating in violent acts while others do not? In order to address this larger question, this study was designed to examine the following research questions:

1. Do the elements of social competence (empathy, a sense of humor, communication skills, relationship skills, and social assertiveness) serve as protective factors for violence resiliency among at-risk adolescent males?

2. Is individual social competence influential on engagement in violent and aggressive behavior among at-risk adolescent males?

3. Are there other protective factors for violence resiliency that emerge as important in preventing violent behavior? 


\section{Participants}

A total of 18 parental consent forms were received. Of these, 16 parents provided consent for their son to participate. Fifteen of the students were successfully contacted at school and participated in the initial survey.

\section{Demographics}

The participants included 14 white students and one Hispanic student. Eleven students had no office referrals during the school year, and 4 students were referred to the office three or more times during the school year. Students from all grades were included with 5 freshmen, 4 sophomores, 4 juniors and 2 seniors. Six of the students were eligible for the free and reduced lunch program and 3 of the students were not sure of their

eligibility. Four of the students reported skipping school during the year. Academically, almost half of the students described their grades as mostly A's and only 1 student reported his grades as below C's. Table 1 includes the breakdown of grades reported by all students.

\section{Table 1}

\section{Grades Reported by Students on Initial Survey}

Grades Number

$\begin{array}{lc}\text { Mostly A's } & 7 * \\ \text { Mostly B's } & 4 * \\ \text { Mostly C's } & 4 \\ \text { Mostly D's } & 1\end{array}$

Note. *One student circled both Mostly A's and Mostly B's. 


\section{Alcohol Use}

Participants responded to five questions related to alcohol consumption. Six students indicated they had never used alcohol other than a few sips (see Table 2). At the time of their first drink, 4 students indicated they were 15 or 16 years old, 2 students were 13 or 14,1 student was 11 or 12 , and 2 students were 9 or under. In the previous 30 days, 5 students indicated they had at least one drink of alcohol on one or two days, and 2 indicated they had at least one drink of alcohol on three to five separate days. In the previous 30 days, 2 students indicated they had five or more consecutive drinks of alcohol on one day and 1 student had five or more consecutive drinks on two separate days. Lifetime alcohol use was estimated at 40 to 99 days by 1 student and over 100 days by another.

One student responded inconsistently by indicating he had consumed alcohol on one or two of the previous 30 days, yet also responding that he had consumed five or more consecutive drinks on three to five separate days during the previous 30 days. He is also the only student to report drinking alcohol on school property, indicating this behavior on three to five separate days during the previous 30 days, and he reported his lifetime alcohol use to be three to nine days.

\section{Drug Use}

Questions related to drug use revealed that five students had used marijuana in their lifetime (see Table 3). Two students used it once or twice and 3 students indicated they had tried it 10 to 19 times. The student who provided inconsistent reports of alcohol use indicated that his lifetime marijuana use was 10 to 19 times, that he had used 
marijuana 10 to 19 times in the previous 30 days and that he had used marijuana at school 10 to 19 times during the previous 30 days. He is the only student to report use of a drug aside from marijuana, indicating he had used heroin on 3 to 9 days in his lifetime. Other students reported no marijuana use in the previous 30 days at school or anywhere else. Four students reported being offered, sold, or given an illegal drug on school property during the past year.

Table 2

Alcohol Use Reported on Initial Survey

Alcohol Use

Number

Never had a drink other than a few sips

6

Age at first drink

15 or 16

4

13 or 14

2

11 or 12

under 9

2

Alcohol Use in Previous 30 days

One drink on 1 or 2 days

5

Once drink on 3 to 5 days

2

Five or more consecutive drinks on 1 day

2

Five or more consecutive drinks on 2 days

1 
Table 3

Drug Use Reported on Initial Survey

Drug Use

Number

Lifetime Marijuana Use

Never tried it

10

Once or twice

2

$10-19$ times

3

Marijuana Use in Previous 30 days

None

14

$10-19$ times

1

At School

1

Lifetime Heroin Use

None

14

3-9 times

1

\section{Victimization}

Two students reported being threatened or injured with a weapon such as a gun, knife, or club on school property in the previous year. Three students reported that someone had stolen or deliberately damaged their property such as their car, clothing, or books on school property in the previous year. Two reported this occurred on two or three occasions, and 1 indicated it occurred on four or five occasions. One student reported being purposely hit, slapped or physically hurt by his girlfriend in the previous year. Five 
students reported being teased or picked on at school a few times in the previous year, and 1 student indicated he was teased or picked on at least two to three times a month in the previous year.

\section{Violence and Aggressive Behaviors}

Seven students reported being in a physical fight in the previous year. Of these, 4 students were in one fight, 2 students were in two or three fights, and 1 student was in four or five fights. Two students reported being in a fight at school in the previous year. Seven students reported teasing or picking on one or two other students during the previous year. The student who reported being teased or picked on at school at least two or three times a month during the previous year indicated that during that time he had teased or picked on three or four other students.

\section{Interviews}

After analyzing the quantitative data obtained from the initial survey, 5 students were selected to participate in the interview process. The 5 students all had multiple risk factors and 3 of them reported having been in at least one fight and engaging in bullying behaviors. Three or four open-ended interviews were conducted with each of the 5 selected students. Additionally, focused interviews were conducted with 6 teachers who were familiar with one or more of the students. Based on information obtained in the interviews, the two 2 students with the highest levels of accumulated risk were selected for final inclusion in the study. One student displayed violent and aggressive tendencies both at and away from school, while the other had not. The pseudonyms of Alex and Zach were assigned to the students. All names utilized in this study have been changed to protect the confidentiality of the individual participants, the school and the district. 


\section{Alex and Zach}

Alex participated in four separate interviews and Zach participated in three. Alex was a junior and Zach was a freshman and both had three or more office referrals during the academic year. The quantitative data obtained from the initial survey did not provide a complete or accurate picture about either student and was, at times, misleading. The student interviews uncovered significant risk factors not touched on by the survey and explained circumstances surrounding instances of fighting. Of the six teachers interviewed, four (two for Alex and two for Zach) also provided valuable corroborating information and in some instances revealed a few deceptions.

\section{Individual Risk Factors and Incidence of Violent or Aggressive Behaviors}

Common risk factors that may lead to the development of violent or aggressive behaviors were addressed in Chapter 2 and include individual and family issues such as victimization, drug and alcohol use, poverty, the availability of guns at home, and a history of abuse or neglect. Other risks include academic failure, low bonding to school, involvement with deviant peers, and a history of a friend who has committed suicide. Alex and Zach have both been subjected to numerous risk factors, yet have displayed extremely different behaviors and attitudes in terms of violence and aggression.

\section{Alex}

Information provided by Alex on the initial survey indicated that he was Hispanic, eligible for the free and reduced lunch program, that he skipped school 2 or 3 times this year, and that his grades are mostly C's. Additionally, in the previous year he had been threatened or injured with a weapon at school once, had property stolen or damaged at school two or three times, had been in two or three fights, and had a history of a friend 
who committed suicide. He indicated his lifetime alcohol and marijuana use were both 10 to19 days, but that he had not used either in the last 30 days. The interviews revealed additional risk factors that include an unstable home life and a history of abuse as a child. Alex answered questions spontaneously in a manner that appeared sincere. Information obtained in the interviews with teachers was consistent with information he provided during his interviews.

Socioeconomic status. Alex lives on a farm with his mom, step-dad and one of his sisters. He explained that "We built a little house - it's small right now. But me and my sister stay in the camper and we just add on to the house every once in awhile when we get enough money and stuff". He stated that "we have enough money to buy groceries but not to go out and do stuff". When asked to compare his money situation with most of the kids at school he indicated

"We make ends meet I guess. I really don't know how much some of the kids some of the kids are pretty screwed. They come here and stuff. I don't know anything about average, but we have probably a different scale of different money. There's all different kinds of kids that come here with money problems". Overall, he indicated that "I don't feel like I'm the worst off. I don't feel like I'm the best either". He also believes that with a good education he can get a job to support himself and be comfortable, but he does not judge success by money. He had $\$ 20$ stolen from his locker during the school year, and he did not report it to anyone stating, "I don't care about money too much though. If they wanted it that bad then I guess they can have it”.

Skipping school. Interviews with Alex revealed that skipping school was more problematic than the two or three times he indicated in the survey. When questioned 
about skipping school, Alex replied "Yeah, that's my big problem right now, skipping school". He stated that he always gets caught and gets in trouble both at home and at school. One teacher confirmed that "he's been in ISS a good part of this year". When she questioned him about why he skips, he told her he didn't know and appeared to not want to talk about it. During the interviews he indicated several times that he didn't know why he did it, and that he didn't always skip the whole day and frequently did not even leave the school building. He stated that he would often skip only certain classes and went on to say “Sometimes I don't even skip very long - I just like skip like 30 minutes and then I go back". He reported that he usually spent his time in the school gym playing basketball and hanging out. In the final interview he stated that he would skip part of the day once or twice a week. When asked if he skipped because he did not like particular classes or teachers, he responded "I don't know what it is. It's like it's a drug I guess. It got addictive somehow and then I just don't want to go there. I just don't want to go there and I didn't go".

Despite his propensity to skip some or all of the day, he stated numerous times that he wanted to do better in this regard. When asked about the biggest challenge he faced at school he replied "I'd probably say coming here. I've been in a bad habit of skipping and stuff. So, I want to come to school and try and get me a good education". Part of the challenge associated with getting to school stems from the fact that his family moved out of district, which accounts for a 20-30 mile commute. One teacher indicated that because of the distance "for him to come here is amazing". In a later interview he indicated that he considered the free education to be the most important thing he was 
getting at school and that "You got people like me that are skipping school and missing a good opportunity, and I kind of feel dumb for doing it. So, I hope to get better".

Academics. Alex described his grades as mostly C's on the initial survey. When asked about grades during the interviews he responded "right now I get D's, F's, and I get all over. It's all over. A's, B's, D's, F's". He indicated that 'I've been trying to get grades up again, doing homework and stuff. That's what really hurts me, is not doing my homework". His assessment was supported by information provided in the teacher interviews. One teacher described Alex as "one of those kids that's been on the cusp of failing, several times" and also stated that his poor grades were "another one of those cases in which he just wasn't doing all the work". The teacher went on to say Alex was good about asking questions when he needed help. She stated He'll come in to me sometimes and ask me about his English class if she's not here or he'll ask me about certain things in class. So he's good about asking, like I said he's really nice when he asks and does his best to understand.

Another teacher said

He's been in ISS a good part of this year. It's a shame. I know that he cares, he's smart. And you can't tell it so much from the work he does, cause he misses so much class that he doesn't make it all up.

She continued "when you just sit and talk to him, he's intelligent and he's articulate". Based on teacher comments, his academic struggles do not seem to reflect his abilities but rather appear to be associated with a certain amount of laziness and his propensity for skipping all or part of the school day. 
Alex appears to understand the importance of improving his grades and indicated several times that he would like to attend college. When asked to describe his top goals for the next ten years he said "I want to get to college and do good there. I want to get me a nice stable, livable home. And I just want to get a good career started for me".

Victimization. On the survey Alex indicated that in the previous year he had been threatened or injured with a weapon at school once and had property stolen or damaged at school two or three times. During the interviews, with regard to being teased or picked on, Alex stated "No, I don't - not really, I haven't been picked on". Neither of the teachers interviewed had ever witnessed him being teased or bullied; however, one teacher reported

I have heard that there are kids that do make fun of him, but I've never witnessed it in my class. Maybe it's me, I don't know. But I've heard other teachers say that they see him get made fun of a lot. And I don't know why. It's like I don't know why. He's just such a good kid. He's a nice kid and I don't know where that comes from.

With regard to other bad situations in his life, Alex described the loss of his grandfather (who he considered to be a father figure) by indicating that "it kind of sucked when he died" and similarly described the childhood abuse he suffered as "Yeah, it kind of sucked". By all estimations, Alex's "kind of sucked" would be considered extremely traumatic by many. It is possible that, for Alex, being teased or picked on requires fairly high levels of aggression from someone before he considers it a problem worth mentioning. 
When asked if he had ever had anything stolen from him at school he responded "Just 20 bucks out of my locker". He said he never knew who took it and that he did not report the incident to the principal's office. When asked why he didn't report it he simply stated "I didn't care". He later indicated that while he likes money, "I ain't no freak about it". His general attitude was that if whoever stole his money wanted it that bad, then they could have it. He also stated several times throughout the interviews that he tended to avoid conflict whenever possible.

Suicide. Although the survey indicated that he had known a friend who committed suicide, he indicated in the interview that had never known anyone who committed suicide. When asked if he ever considered suicide, he replied

No. I don't think - I mean I think about it, but I don't think about doing it. I just wonder about like if I did do it, then what would like the outcome be and it's like never worth it. Everybody has tough luck. You just have to suck it up and go on with it.

Marijuana and alcohol use. On the survey, Alex indicated his lifetime alcohol and marijuana use were both 10 to19 days, but that he had not used either in the last 30 days. His individual alcohol use was not addressed in the interviews, but when asked if he'd ever tried drugs, Alex responded "Yeah. I haven’t tried like a variety of drugs. I mean like one, marijuana. That's the biggest one. And pills, which is not very good for you that'll screw you up. And that's all'. He indicated that he first tried marijuana when he was 10 years old and that he got it from a cousin who was about his same age. He stated that he used it for about a year and quit because "I didn't like it too well". When asked how the marijuana made him feel when he was using it, he replied 
It made me feel like, like I couldn't really, I didn't have control of my body. And that's what I really didn't like cause I couldn't control my body too well. So, I didn't like that too well. So I quit doing that.

He also indicated that a few kids bring alcohol and drugs into the school but that it was more prevalent outside of school.

Abuse as a child. During the first interview, the first question was designed to provide an opportunity to learn a little bit about the home life of the students. When asked to "tell me a little about home", Alex responded

I've had, well I've had a rough childhood. My childhood wasn't the best. I had an abusive father when I was little and stuff like that. And so I didn't even know - I used to live with my grandma to start out with. I lived with her for about three or four years. Her and my grandpa - he ended up dying. They were like mom and dad to me. They took care of me. My mom was working all the time, so she really didn't have much time.

He went on to say that he later spent much of his life living with his uncle, although he now lives with his mom, step-dad and one of his sisters.

When questioned about the abuse and whether it was physical or verbal, he indicated "Oh - it was all around". He went on to say "All around, yeah. He just, he was abused when he was a child and he didn't know how to do the discipline thing so he'd do what his father did to him pretty much". He continued

It's just little things that tick him off. The littlest things would make him go off. He roughed me up good, he's put me in the hospital 3 or 4 different times. He broke my ribs a few times. Because we were doing, we were working on the farm 
- that's what we did. And if I wouldn't do something right or something like that then he'd always make me do push-ups or something. Cause he was in the military so I got the rough part of the deal. And if I wouldn't do them right, the way he wanted to, he'd just kick me. Yeah, it kind of sucked.

He later stated that small things would make his father angry. As an example he said "If I wouldn't shovel right or something like that, he, he used to get mad".

When asked if his dad was that way just with him or if he was that way with his mother or other people as well, he responded I don't know. I know he showed a lot of aggression with me. I don't know why, but he did. He, I don't know if he was that mean to my sister, the one I live with now. But, he was pretty mean.

When asked if he had the opportunity to talk with someone about his experiences, Alex indicated that "Yeah, I went to a counselor for awhile, but I just quit going to that". He stated that he simply did not like going to the counselor but did not say if it had helped him or not.

Incidence of violence or aggressive behaviors. On the initial survey, Alex indicated he had been in two or three fights in the last 12 months. When questioned, he responded that he'd been in a fight at school while he was in ISS and that he'd been in a fight over family issues. He did not seem to want to discuss the family issues, but in terms of the fight in ISS he elaborated that

Well, it's just, there's this kid - his name is Matt - and I play football and stuff like that, so the coach is one of the ISS teachers, and this kid just like took his remote. And he was kind of acting childish about it. So I went over there and said 
"give the remote back to him" and he said "no", so then we got into it about that. And that's really all it was about. Nothing big.

He explained that it "wasn't a fight fight" but that it was "Just a little wrestle around thing". When asked what the coach said, he commented "He was provoking it a little bit because the kid is kind of a little mouthy and he can't do anything about it, so. He's not all for that, when a kid's mouthy". Neither of the teachers interviewed had ever seen him display any ill temperament or aggressive behaviors and had never had to send him out of class to the office. When asked how he interacted with the principals or other authority figures, one teacher stated "I've never heard anyone describe him as a behavioral problem, so I think as far as administration goes, he's a good kid too".

When questioned about kids that get picked on at school he responded that he sees it sometimes in gym and at lunch. He said "People like to choose somebody and just mess around with them I guess, but it's still considered picking on them". When asked if he picked on anybody else, he asserted "No. I'm not all in to that. That's kind of screwed up".

During the interviews, Alex was given several scenarios and asked how he would respond in each case. When presented with a situation where someone intentionally pushed or shoved him, he expressed “I don't know. It would depend how the day was going I guess. Like if it's an alright day, I wouldn't fight or anything. But we'd play around a little if it was a bad day". If someone pushed or shoved one of his friends he stated that it "Depends what the friend did I guess. Like if he like started something, you know that's his problem. I'd help him out if it was something he didn't do or something". 
When asked when it is alright to walk away from a fight and when it is alright to fight back, he replied

My opinion. I honestly don't like fighting at all. I mean I probably wouldn't fight in most of those scenarios, but if it got to the point I got really mad or something I would. Rest of the time I wouldn't. I'm not all for violence. I'm a peace loving kind of guy, so I really wouldn't fight. I think it's alright to walk away from a fight whenever, you know. If you don't want to do it, just walk away.

When questioned about the possibility of talking your way out of a fight, he said "You'd really have to be a pretty good sort of talker". He stated that he'd never talked his way out of a fight because "if I know there's going to be conflict or something like that I don't talk about it. Cause I ain't got that kind of skills when I'm mad".

Alex indicated that he believes some people probably deserve to get beaten up and that 'I'm all for the eye and eye thing, whatever. So, yeah I think if they do something to you then you should be able to do it back". However, given the context of the war in Iraq and being sent to the front lines, he thought it would be difficult for him to fire on other people. He commented "I'm kind of conscious about killing things you know. Even if I run over something dead it kind of spooks me a little bit. But, I don't know". Asked his opinion on the death penalty he replied I'm going to probably contradict myself here from what I was saying, but I don't know if I could take a life or something like that. And I don't think other people should really have that decision. Even if it is some, I think they should be able to sit in jail. But it's kind of a two way sword there because you know if something happens to you, like you know child molester or something like that, then you're 
going to wish they were dead and stuff like that so you're going to be all for it. So I - I don't know. I guess I'm kind of a middle man - I'm for it and I'm not for it. Overall, Alex displayed the characteristics of a tolerant individual who avoids conflict when possible. He appears to be a non-violent youth who behaves appropriately at school.

\section{Zach}

Information provided by Zach on the initial survey indicated he was unsure if he was eligible for the free and reduced lunch program, had skipped school once this year, and that his grades were mostly C's. During the previous year he had be threatened or injured with a weapon at school two or three times, had been in four or five physical fights, and was unsure if he'd ever had a friend who had committed suicide. He reported that his lifetime alcohol use exceeded 100 days and that in the previous 30 days he had consumed alcohol on three to five separate days and that on one of these occasions had five or more drinks in a row. He indicated his lifetime marijuana use was 10 to 19 days, but that he had not used it in the previous 30 days. The interviews revealed additional risk factors including a lack of school connectedness and a personal tragedy involving a family member's involvement in a murder-suicide. Information obtained in the interviews with teachers was not always consistent with information he provided during his interviews.

Socioeconomic status. Zach indicated in the initial survey that he was unsure of his eligibility for the free and reduced lunch program. He currently lives over his mother's beauty shop with his mom and step-dad, but stated that his mom just bought a house and they would be moving soon. He stated that his mom just finished her college 
degree while working full time and that she was going to go to law school next. He has a half sister who currently lives with her father. He has a personal cell phone that his father pays for and has a computer in his room, which is not connected to the Internet.

When asked what makes a person successful, he indicated "Somebody that makes a lot of money". Asked to clarify how much money, he responded "like an athlete kind of money. Or my mom. Cause she just got out of college, so she'll become a lawyer, so, hopefully she'll make quite a bit of money". He went on to state that he believed he would someday make a lot of money

Because my mom and dad both make quite a bit - my dad makes about, depends on how much he works, but he can make around up to $\$ 100,000$ a year. And my mom, whenever she becomes a lawyer, she'll probably make that much too. So, hopefully I can make that much.

He believes that he will be financially successful because his dad makes good money and his mom had the potential to make a lot of money in the future. He does not reflect on his willingness to work or his level of education as factors in achieving financial success.

Skipping school. Zach indicated on the initial survey that he had skipped school once this school year and in the interviews he stated "This year I've only skipped I think like twice". When asked if he got caught he stated "Not the first time I didn't, but the second time I did, so I'm not doing that no more". He also reported that he had skipped the entire day and had also just skipped certain classes. When asked what classes he would most likely skip he stated "Math is $2^{\text {nd }}$ hour. I mean, but math is my favorite subject it's just the teacher I, I can't stand him he's so boring. And then metals cause that teacher just hates me. And then science". Interviews with his teachers did not support his 
contention that he had only skipped once or twice during the year. Both teachers who were interviewed indicated he had skipped their class. One teacher said "see here's the weird thing about him, is he was here every day. Until last month, and then just dropped off the face of the earth". Zach had literally not been attending that class for at least four weeks.

Academics. Zach indicated in the interviews that he skipped $8^{\text {th }}$ grade and was advanced directly from $7^{\text {th }}$ to $9^{\text {th }}$ grade. When questioned how he was able to skip $8^{\text {th }}$ grade, he stated "Well, my mom talked to the school guy and whatever, and I got moved up". When asked what he thought about that, he replied "I thought it was pretty cool" and agreed it would be good to finish school a year early. Lead to believe that he had been academically promoted, the researcher asked if he made good grades, and he responded "Not really. I mean they're alright. Yeah, first quarter I did really good, then like a bunch of stuff happened to me, so my grades kind of dropped". In later interviews he indicated that he thought he was failing three required courses and would have to attend summer school. He indicated that he frequently did not do his work, not because he was not capable, but because he simply was not interested.

Both teachers interviewed indicated that he was failing their classes, one with a $31 \%$ and the other with $18 \%$. They both confirmed that he did not do the work, stated that he did not ask questions or seek any help, and one teacher commented "He walks into my room like this - with nothing. Never a pencil. Never a pen. No books". Additionally, one teacher corroborated his statement that he had been promoted from $7^{\text {th }}$ to $9^{\text {th }}$ grade, but clarified that he had been socially placed after taking $7^{\text {th }}$ grade twice. She further 
indicated that "there were requirements he was supposed to meet to do that. He didn't meet them and they didn't make him go back".

When asked to describe a significant challenge he had faced in his life, Zach responded

Probably [middle school]. Whenever I first went there I never did any of my work and all the teachers hated me. And then I tried to do my work at the end of the year and it was like, they wouldn't even take it really. But then I got moved up. Because I was in $7^{\text {th }}$ grade last year and I got moved up to [high school]. When asked if he had to face any particular challenges at the high school, he stated "No, not really. It's been pretty easy actually". He indicated that he did not think he was learning anything academically in school that would benefit him later in life and said "I mean they teach me a lot of stuff, but I usually don't listen to them cause I think I know everything, but I don't really. But, like I've made a lot of friends coming to school'” When questioned about whether or not he intended to focus more on his work so he could graduate he indicated that he "probably" would and that "I'm not going to drop out no matter what. Even if I have to be here for 5 or 6 years, I'm still not dropping out". His experiences have shown him that even if he fails to meet academic requirements he can be promoted to the next grade level. It is possible that he may equate attendance rather than performance with graduation.

Victimization. Zach indicated on the initial survey and in interviews that he had not been teased or picked on at school. One teacher indicated that he had never seen Zach get picked on and that "I've never seen teasing that isn't an even exchange". Another teacher stated that she had never seen him get victimized at school, but recounted that "he 
had a different haircut one day and they (students) kind of picked on him about that, but he changed it right back". She also said that throughout the year several comments were made by some students about how "hot" Zach's mom was, which may not be the type of attention a teenage boy wants. Additionally, she stated that "There have been little comments made about, you know - Zach didn't even take the $8^{\text {th }}$ grade" and that

I think he's just seen as different in that way that, you know that he doesn't have to do the work, doesn't have to go to $8^{\text {th }}$ grade. Just from little comments the other kids have made is what makes me think that, you know, they just really don't have any use for him.

She further indicated

he's kind of one of those that can dish it out but he can't take it. He thinks that he can pick on people and make fun of people, but then when it turns around on him he gets very defensive.

While Zach does not appear to get physically bullied at school, he does seem to be subject to more subtle forms of teasing.

Marijuana and alcohol use. On the initial survey, Zach reported that his lifetime alcohol use exceeded 100 days. He further indicated that in the previous 30 days he had consumed alcohol on three to five separate days and that on one of these occasions had five or more drinks in a row. He indicated his lifetime marijuana use was 10 to 19 days, but that he had not used it in the previous 30 days. When asked whether he used drugs or alcohol during the interviews, he responded "Not at school. But I have, in the past. I don't do it no more because I - my dad and mom is drug testing me, so I quit". He stated that he had mainly used marijuana and that "I've never really done a lot of it, just with my 
friends". In describing one of his closest friends he stated "he smokes a little bit of stuff and we'll drink sometimes".

It appears that his drug use was a substantial problem for his parents to resort to drug testing. Zach indicated that his mom listens to him but that "my dad sometimes is kind of like, because he was the one that drug tested me and found out all this, so he kind of don't trust me that much no more".

Suicide. Zach indicated on the initial survey that he was unsure if he had known a friend who committed suicide. When asked if he had ever known anyone who committed suicide he responded

Uh, no. But I don't, like people say my (family member) did, but I don't think he did. They say he shot himself and like three other people, but I don't really think he did. But I mean, I don't really like to talk about that.

Due to his obvious discomfort, no further questions were asked about the incident. One teacher indicated that one of Zach's family members had died during the school year, but was either unaware of or did not offer information about the circumstances of the death. She recalled that Zach's mother was concerned he might be suicidal since he was close to the family member that died, but the teacher did not notice any difference in his daily behaviors and no one ever contacted her about it again. A search of news stories confirmed that, according to police findings, the family member was the perpetrator of a murder-suicide plot that resulted in the deaths of four people.

During the final interview, Zach revealed

A lot of my friends that go to (names school), a lot of the girls - they like, they slit their wrists. And I always tell them that's dumb and I always make fun of 
them for it. But I can't really do anything about it. So, I just tell them, you guys are dumb for doing that. Why would you do that?

When asked what he thought the girls were thinking at the time, he responded While I'm saying all this? I have not a clue. But they're probably, when they do it, they probably think "oh, I have a terrible life" and just think their life is so bad. I used to think like that, but I never done something dumb like that. Zach projects a tough image and appears unsympathetic towards his friends that have attempted suicide. He appears conflicted about his family member's suicide, but makes no mention of the three murder victims despite the fact that two of them were young teenage girls who attended school in the same district.

School connectedness. During all of the interviews, Zach was very clear that he did not like school and that it was more of a social event than an academic environment for him. When asked to describe a bad day at school he stated with all seriousness "every day". He then clarified "Like if I don't go to bed and I'm tired and almost fall asleep in every class". He then described a good day as

If I have a lot of sleep or something. I don't know, just like, cause sometimes I wake up and my mom will be all griping at me like - cause she does a lot in the morning and then. But like some days she'll wake up, she'll be like "oh, have a good day at school" and I'll be like "I will". Stuff like that. Makes a big difference.

A good day at school is connected more to his morning interactions with his mother than any particular event that may occur at school. Throughout all of the interviews he spoke about his mother frequently and with high regard. 
His lack of school connectedness was evident in each of the interview sessions. When asked if he would have to switch schools because of the new house his mom was buying he responded 'I don't think I'm going to. But if I do, I don't really care. It don't bother me". Zach later indicated that it would not bother him if he was told he would have to attend another school in the district "cause I can make friends if I needed to. And I have a lot of friends at different schools". When asked if he had a sense of belonging at school he stated

Somewhat. I mean, I know like a lot of older people and everybody's really pretty cool to me, so I think. I don't really like, I come to school and I'll do my work and stuff but I like coming to school just to see my friends pretty much, so.

His friends are the most important component of school and he is confident that he will have friends wherever he goes. He stated that "I only have like a couple of really really close friends, but they - I have just a bunch of friends. Like everybody at the school pretty much knows me".

He does believe that the school is safe and that teachers, principals and counselors all listen to students if they have complaints or if something is going on, but when asked if students generally get treated fairly he replied

Some of them. But I mean they don't really like the kids that don't do their work. I mean, they like em, it's just they don't - I don't know really how to say it. They just don't, like they won't get as much privileges. Like cause some students, like they'll get to go to the bathroom and stuff, and me - cause I usually don't do my work - they'll tell me "no" I can't go. But if it's a different student they'll say yes. 
Despite the fact that he thinks it is unfair, he takes responsibility by indicating "I mean it was my fault for not doing the work". He also stated that he once got caught cheating on a test and the teacher threw it away, and his response was "my fault for cheating". He later reiterated this when he indicated that he did not think he himself was treated fairly by his teachers

Because I don't really do my work. And they won't let me - like I'll ask them to go use the bathroom and stuff, they're like "no". But like if somebody that gets good grades and stuff asks them, they'll let them go.

Then he followed up the statement by saying "But I mean, I should do the work". He does not think he is treated fairly, but acknowledges that he has a large degree of accountability for his failure to complete the work.

When asked if the teachers care about the students at school, he replied "Some of them. But, well yeah most of em do. But a lot of my teachers, I don't think they like me. But if they do, I don't care". When asked why he thought they didn't like him he replied "Maybe because I don't do most of my work. But I've been trying to do most of it". According to one of the teachers at school "He told a substitute one day when I wasn't here that I hate him. Which I've never said that. I've said like 'I don't like it that you don't do your work". She continued

But he never gets angry at me for trying to get him to work. And usually if I put him out in the hall or to the principal's office, he knows why. He never says "what did I do?" like some people will say "well what did I do"? He never, he knows what he'd done or what he hasn't done. So I don't know how he does with 
everybody else. I can't think of any time he was ever even the slightest bit mad at me for trying to discipline.

Overall, Zach views school as a social setting and admits that he does not do the required work. He understands that his failure to complete his school work leads to treatment that he considers unfair. While he accepts responsibility, he stated that he does not want to do the work because it is boring.

Incidence of violence and aggressive behaviors. On the initial survey, Zach indicated he had been in four or five fights in the last 12 months but had not been in any fights at school. When questioned during the interviews he indicated "I never got into a fight at this school. But my old schools I did. I've got in a fight at the park, at people's houses, but I don't fight at school.” When questioned about why he doesn't fight at school he replied "My mother's told me not to fight at school" and continued by stating “Well, I'll get arrested. Cause they'll find out and just get kicked out of school. My mom then will be mad at me. So I don't fight at school". When asked what causes the fights at the park or someone's house he responded "Well, those fights is because somebody called me some names and then they grab me. And so I just went off on them”. However, in a later interview he was asked how he would respond if someone called him names and he said “Oh, I don't really care if people call me names. It don't bother me”.

When questioned about kids that get picked on at school he responded "There's a few. But I mean, it's not really that bad. They're just messing around with them". He stated that he had teased people at school, particularly one male student who professed to be homosexual. Zach explained 
Like this kid, I don't know if he's gay, but he tells people he's gay. And I just, I don't know. I mean, I don't have a problem, it's just I don't like want him - I just don't want to be near him. Like he'll come around me and stuff and he's talking to me, I'll just turn and walk away or I'll say something to him.

Zach indicated that he never got in trouble for teasing the boy “cause he don't, he don't want to tell nobody". He justified his actions by stating "I mean, he shouldn't be telling everybody he's gay and stuff. But I don't, I mean that's him so". When asked how he thought the kids at school that were picked on felt, he replied Well, whenever I talk to Chad like that, he just like plays like nothing's wrong with him. And so I might get away and all this stuff and call him names and stuff, but he really don't - I don't know if it hurts him or not, but he goes around telling everybody he's gay. And I mean, if I was gay, I wouldn't really want to tell a lot of people because I'd get made fun of maybe. He just says it cause he likes the attention. But I don't know for sure.

Interestingly, one teacher described a recent situation in class when Zach became angry with one of the girls in the classroom:

this girl was getting on his nerves and so he was yelling at her. And usually they get along very well. It's just a very day-to-day, you just never know what to expect when he's going to come in. But he'd start to say, he'd say things like "this is gay", “everything's gay". You know, then he'd start calling other students gay. I think he was just wanting to be, he wants attention I guess.

She later stated that some of the other teachers in school had expressed to her that they believed Zach may be gay, but she did not know if those assessments had any merit. 
During the interviews, Zach was given several scenarios and asked how he would respond in each case. When presented with a situation where someone intentionally pushed or shoved him, he said he would "Probably push em back. Or hit em". If someone pushed or shoved one of his friends he stated

I'd probably just jump in and say that they don't need to be fighting. I wouldn't like do anything to the person that did it. I'd just probably get in between them and tell them they don't need to fight. Unless it was somebody that I knew my friend could fight and beat up. Then I'd let them go at it. If it was somebody bigger than them, I wouldn't - I'd stop it. Cause I don't want to see my friend getting beat up.

When asked when it would be alright to walk away from a fight he replied I usually don't walk away from fights, but like if somebody cheap shot's you or something, walk away. Because like when my friend got into a fight and then the dude threw a brick at him. And then he stayed in and the dude pulled a knife on him. So then, I think if somebody like tries to throw a brick at me, I'm gonna walk away cause I really wouldn't want to die.

Zach indicated he has intentionally provoked others into fighting and commented "I just like, I mean I just like watching people fight. It's kind of funny, but if somebody starts to seriously get hurt I'll jump in and pull them off or something".

He stated that you could tell if he was angry "Just probably by what I'd say. I'd say it's pretty bad stuff. So, I'm usually not an angry person, but I can be". He indicated that if he was upset with an individual he would probably confront them, but not at 
school. When asked if it made a difference if the person he was angry with was a friend or not he replied

No, not really. Cause, about two weeks ago one of my best friends was saying all this stuff, like his cousin is a famous rapper and I was like "why you always gotta say lies". I mean I'm like your friend, you don't have to lie to me. He's like "whatever dude, I ain't lying" and all this stuff. And I just got mad at him and he was saying he was gonna beat me up and I just hit him, so. Doesn't really matter if it's my friend or not, just if they do something to make me mad.

Interestingly, while he does not want to see anyone else beat up one of his friends, it is acceptable for him to do it if they make him angry.

Zach indicated he had been arrested a few times, including once for fighting at his former school and explained "well, it wasn't really a fight, it was an assault, cause I hit the kid". In addition to his arrest record, he had also recently been accused of molesting four young girls. In response to a question about his failure to do his school work he responded

But like the first quarter, I had all C's and above. But then somebody, somebody that doesn't like my mom, accused me of raping four little girls. So like two months, that was going on for like two months, all this stuff. Started getting bad grades and after that was over my (family member) killed himself. So just everything, this year's been a weird year for me.

When asked how he was able get through such a difficult situation he replied I just ignored what they were saying. But I mean, I could've went to court and went to jail and everything for it. I could've got locked up for two years. But all 
the little girls that was there, they was telling that lady "you're stupid, He wouldn't do anything like that". Cause they're my sister's best friends and they just get on my nerves. I can't stand em.

He indicated that no charges were ever filed and that "It was just somebody running their mouth".

\section{Elements of Social Competence}

John (2001) defined social competence as the ability to function appropriately in interpersonal interactions" (p. 182). Elements of social competence were addressed in Chapter 2 and include communication skills, the ability to foster positive relationships with others, social assertiveness, a sense of humor, and empathy.

\section{Communication Skills}

Alex and Zach were both talkative and friendly during the interviews. Interactions with Alex and comments from teachers indicated that he was down to earth, shy, and quite intelligent. During the interview sessions, Zach appeared very relaxed and came across as outgoing and confident.

Alex. According to teacher interviews, Alex communicates very well with them.

One teacher indicated "when you just sit and talk to him, he's intelligent and he's articulate". He is willing to ask questions and he interacts appropriately with authority figures. One teacher stated that he often stays after school just to talk.

Zach. According to interviews with the teachers, Zach does not communicate well with them. One teacher indicated 
You know, a lot I don't know. I haven't gotten to know him. I've tried to talk to him - what are your future plans, what do you want to do with your life, what do you think you're going to accomplish. And he doesn't open up at all.

Another teacher did not have any knowledge of Zach outside the classroom setting. The teacher tried to convince Zach to join the wrestling team at the beginning of the school year, but Zach was not interested. Both teachers indicated that he never asked questions in class.

\section{Relationship Skills}

The ability to develop positive relationships is a component of social competence (Benard, 1993; Christiansen, Christiansen \& Howard, 1997; Davis, 1999; Meisels, Atkins-Burnett, \& Nicholson, 1996). Alex and Zach both shared information about family, friends, teachers and the relationships they considered the most important in their lives.

Alex. During the interviews, Alex described his childhood as rough because of an abusive father and moving around from place to place. He spent several years living with his grandparents who he described as "like mom and dad to me. They took care of me". He has fond memories of them and spoke frequently about his uncle, whom he lived with for a great deal of his life. Alex described his uncle as the most important person in his life because he is the individual who helped get Alex out of the abusive situation. Alex explained "like I said before, you know he took care of me. So I mean we have, we have something you know. He really cares about us".

Despite the abuse, Alex spoke of his father and said "I mean, I love him cause you know, he's my dad. But that's about as far as it goes". He also indicated that when he was 
little "my mom was working all the time, so she really didn't have much time" but did not seem to harbor any resentment towards her. He explained

Like I said, my grandma was my mom at the time. She kept me occupied. And my grandpa, he was pretty good to me. I was spoiled when I was little. He spoilt me kind of. Because I guess that he had grandkids that his daughter wouldn't let him see, so I was like his favorite grandson because I lived with him all the time. It kind of sucked when he died.

When asked if he had ever thought about running away, he responded that he had thought about it but never did. He explained

Just being in a loving environment I guess. Because I know that they like me, and I was under punishment though - cause that was mostly when I got punished. But it was my punishment and I deserved it. So that's what pretty much got me.

Despite the hardships Alex faced growing up, he had several family members he trusted and could count on for help and guidance.

Alex spoke about his friendships and stated "I mean, I associate with everybody. So I'm just friends, I mean I only hang out with like a few people on the weekends and stuff like that". Asked to describe his two closest friends he responded

They're pretty nice people. I mean we care for each other, we help each other out all the time. Like we just buy each other something to drink or something, or we all (inaudible), we play basketball, we pay for gas for each other. I mean we look out for each other.

He also described his former teammates on the football team as "like a family". When asked about his friends, one of the teachers indicated "I haven't seen him hang out with 
anyone recently. I see him talk to people, but not anybody I would think he was really close with". Another teacher stated "He gets along very well with other students. And they - he's got some good friends in the $9^{\text {th }}$ hour class. He gets along well with them. He's shy, real shy".

In terms of his relationships with his teachers, Alex indicated that his teachers are "Pretty nice to me. I talk to about all of them - all my teachers anyway. They're just cool". When asked if he thought his teachers cared about him he replied "I don't know if they do or not, but (laughs) they're pretty nice to me and stuff'. He spoke highly of one of his coaches and stated

Yeah, he's been good to me. I mean he's, he's been like a father figure to me too. Cause I mean I really haven't had no father in my life. But he's been there. He took me to, when I got hurt and stuff he took me there. He's always been there for me.

There is only one staff member that Alex said he did not like because "she's rude". He explained that

She talks about everybody behind their back. She was talking about Coach Anders, the ISS teacher. He's also like the football coach. Said that he's like a jack-off, or something like that, for not turning attendance in or something like that.

Aside from this individual, Alex thinks that the teachers and principals care about the students and are all generally nice. When asked how he thought his teachers would describe him, he replied "I don't know. That I need to come to class a little more, they'd probably argue about that. But, I really don't mouth the teachers or anything like that. I'm 
pretty, I'm pretty calm”. When asked if he thought most of his teachers would say they like him "Yeah, I don't see why not. Pretty much, yeah". Both teachers who were interviewed spoke highly of Alex in terms of his personality and behaviors. One teacher commented

He keeps to himself a lot. He's a very very nice kid. I mean there's, Alex is just, he's just such a nice kid. Again, when I talk to him he's just a sweet, very nice, very polite kid. One of those kids who, if he sees somebody not put up a chair, he'll go right over and make sure they're all up, just for me. But, he separates himself from the group.

Another teacher stated that he is "sweet and well behaved" and detailed that He always stays for several minutes after class. He helps me stack books and throw away papers and put up the chairs and organize the room. We chat while he's doing that and he does that almost every single night.

The teacher also said

He comes in sometimes after school - actually this year he hangs around quite a bit after school. And I always ask him if there's anything he needs and the only thing he seems to need is just to chat. He likes to talk. He came in a week ago today and stayed for an hour after school. Just because he wanted to talk about everything that day - religion, God, are you an atheist. I said where's all this coming from? And he didn't say where it's coming from, he just wanted to talk. Both teachers indicated that academically he was not doing very well, but when asked if they would provide him with a letter of recommendation one stated "character wise - 
great kid. Nice kid, polite kid. Academic wise, no". The other teacher responded "Yeah I would. Based on his character".

Overall, Alex seems to have developed a number of positive relationships with family, friends and teachers. His perceptions about how his teachers view him is accurate. In general, he thinks highly of the school, the principals and the teachers, and often describes people he cares about as "like family".

Zach. During the interviews Zach spoke frequently about his mother and stated that he would rather be grounded than have her say that she was disappointed in him. $\mathrm{He}$ is confident in his mom's ability to successfully get through law school and bragged about her 4.0 grade point average. He said his communication with his mom was pretty good and that she listens to him. When asked if he'd ever thought about running away he responded that he had thought about it before, but never did because "my mom and them would be mad at me and probably call the cops on me and I'd probably get arrested". He also indicated that he avoids fighting at school because his mom told him not to and he did not want to make her mad. According to one of his teachers, "from what I hear him say she's more of a friend than a mom". Zach identified his mom and dad as the most important people in his life. However, he indicated that he does not see he dad often and that his dad does not trust him as much as his mom does.

Zach also spoke of his friends during the interviews. He indicated that "I only have like a couple of really really close friends, but they - I have just a bunch of friends. Like everybody at the school pretty much knows me". Asked to describe his two closest friends, Zach responded 
Let me think of two. I have a lot of friends, so. (pause). Well one of them, he plays basketball a lot and he doesn't, well I don't really - cause I don't really hang out with him that much, but we're like good friends. But I don't think he drinks. He might drink, but I know he don't like do any drugs or anything. But one of my other close friends, he smokes a little bit of stuff and we'll drink sometimes, but. He ain't really into sports or anything.

He repeatedly commented that he mainly attends school to see his friends and that he has "a lot of friends at different schools".

According to one teacher, "I never see him with anybody, and he pretty much, everybody in the class - it's a small class - I wouldn't say that he has friends in this class. I can't really say why. They're just not". The teacher commented "I think he just wants to be liked and I don't think he knows how to do that". Another teacher indicated that "He can really get on kids' nerves. I mean, he tries to push buttons".

In terms of school personnel, Zach indicated that if something were bothering him he could talk to the school counselors. However, he believes that most of his teachers do not like him and specifically indicated that his metals teacher and all the teachers from his middle school hated him. According to one of his teachers, "He told a substitute one day when I wasn't here that I hate him". When asked how he thought his teachers would describe him, he said

Well, people say I'm really outgoing, cause I have a lot of friends. I can be smart, like in my school-work and stuff but I usually just want to play around. I joke around a lot. That's pretty much. Oh - I'll do anything for a friend. Unless it's gonna get me in trouble. 
His perceptions about how his teachers view him are inconsistent and inaccurate.

Interviews with teachers revealed that they did not dislike him, but they did view him as a poor student academically and they felt he tended to annoy other students. Neither of the teachers would be willing to provide him with a letter of recommendation.

\section{Social Assertiveness}

Social assertiveness is another component of social competence. Overall, Alex appeared fairly shy and quiet while Zach projected a more outgoing and boisterous personality.

Alex. When asked if he would consider himself shy or outgoing, Alex responded "A little of both. I like to help people if they're in need or something like that. I mean I'll help some guy on the street if he needs some money or something like that". He went on to say "Yeah. I like doing that. It's fun. To me it is anyway". He said that he tends to "associate with everybody" and that "It doesn't bother me to say 'hi' to nobody". Both teachers interviewed indicated that they considered him to be shy and one teacher stated that "He keeps to himself a lot". Despite his shyness, he was quite talkative during interview sessions.

Zach. During interviews, Zach described himself as outgoing and indicated that he had a lot of friends. One teacher said that he was social "at times as a fault" and commented

Yeah, there have actually been incidences. I can remember one or two little things early in the year in here. But that was squelched pretty quickly. And I also heard some comments from another teacher in the same hallway about inappropriate things being said to other students. 
Another teacher stated

he likes to flirt with the girls. He tries to come off as the tough guy a lot of times. You know, if anybody says anything to him sometimes - it just depends on the day. If somebody says something to him he will just get up and I heard him be known to say "I'm going to kick your ass". You know, almost fight in the classroom.

The teacher also commented

I know that he thinks he's very cute and charming maybe. He's like, "Oh, Mrs. Smith you look so nice today" and you know, just stuff like that. He knows it's not going to do any good, but he does it anyway.

It appears that he does assert himself socially, but that he does not tend to do it in appropriate ways.

Sense of Humor

Another characteristic of socially competent individuals is the presence of a sense of humor (Benard, 1993; Christiansen, Christiansen \& Howard, 1997; Davis, 1999). Alex and Zach both felt that they had a good sense of humor although teacher perceptions offered some unique insights.

Alex. Asked to describe his sense of humor, Alex replied "I think everything's funny I guess. I find the littlest things funny”. His sense of humor came through a couple of times during the interviews and he projected an image of an easy going and thoughtful individual. One teacher indicated "I think he has a great sense of humor. But I don't know that he, that he exhibits it with the other kids. But he does around teachers. He jokes, kind of casual and relaxed. Pretty socially skilled". 
Zach. Asked to describe his sense of humor, Zach replied "I'm pretty funny". His humor did not come out during the interviews and one teacher indicated that his sense of humor was typically at someone else's expense. Another teacher stated "You know, he never really says anything super funny that people laugh at. He just doesn't. I think you could just take him out and things would still be pretty much the same". Additionally, one teacher said "He thinks he can pick on people and make fun of people, but when it turns around on him he gets very defensive".

Empathy

Empathy is an important component of social competence and is defined as “sharing another's emotional state or context" (Bush, Mullis, \& Mullis, 2000, p. 467). Alex and Zach both completed the Interpersonal Reactivity Index (IRI), an instrument designed to measure four separate components of empathy including Empathic Concern, Personal Distress, Perspective Taking, and the Fantasy Scale. The results of the IRI are included in Table 4. Slight differences were found between Alex and Zach on Empathic Concern and Perspective Taking, while considerably larger differences were noted on Personal Distress and the Fantasy Scale.

Table 4

Interpersonal Reactivity Index Scores

\begin{tabular}{lcc} 
Subscale (range 0-28) & Alex & Zach \\
\hline Empathic Concern & 18 & 14 \\
Perspective Taking & 16 & 21 \\
Personal Distress & 10 & 2 \\
Fantasy Scale & 6 & 17 \\
& & \\
\hline
\end{tabular}


Alex. Results of the IRI for Alex revealed high levels of Empathic Concern and Perspective Taking, an average score on Personal Distress, and a low score on the Fantasy Scale. During interviews, Alex was presented with several scenarios and asked what his opinions were in each instance. Given a scene with a man sitting on the street corner with a "will work for food" sign, Alex responded "I kind of wonder how he got in that situation, you know like what put him there. Like was he addicted or something". He went on to say "Yeah, I probably just think about how he got in his situation, was it a good one or bad one, did he lose it because of bankruptcy or something. I'd probably think about those things". He did not judge the person and in an earlier interview even stated that he would be willing to give money to someone on the street who needed it, explaining "I like doing that. It's fun".

Provided a scenario of a serious automobile accident on the side of the highway with emergency services at the scene he replied

First of all, I wouldn't want to see one of my parent's cars or someone I know that look like their cars. Because I'm probably going to freak out there. And I'd probably think about that. Cause I always think like that for some reason. Like I always think its one of my family members or something first, before I get really close.

He also indicated in an earlier interview that he was considering a career in public services, possibly as a paramedic, because he wanted to help people. He explained "it's good to help somebody. Makes you feel good about yourself".

Zach. Results of the IRI for Zach revealed considerably high levels of Perspective Taking as well as high scores on Empathic Concern and the Fantasy Scale. Results also 
showed substantially low levels of Personal Distress. During interviews, Zach complained numerous times that his teachers did not like him and that he was treated unfairly. On an intellectual level, he acknowledged that if he were to put more effort into his school work he would be able to retain privileges, including bathroom passes. He understands his teachers' perspectives about the loss of privileges, but on an emotional level he continues to feel slighted and purports that his teachers hate him.

Interviews suggested that Zach does not easily relate to the feelings of some individuals. Regarding his teasing of a homosexual student, he indicated that 'I don't know if it hurts him or not" and said that the student should not tell people he's gay if he does not want to be teased. He also stated that he believed most students who get teased bring it on themselves and that 'they'll say stuff about themselves so then people make fun of it, and they'll get mad at 'em. But I mean, you shouldn't say that about yourself'. He also commented that he makes fun of some of his friends who have attempted suicide but does not have any idea how his words might affect them. He indicated that although he had some bad times in his life he would not consider doing "something dumb like that" and he cannot understand why anyone else would consider it either.

Zach was presented with several scenarios during the interviews and asked what his opinions were in each instance. Given a scene with a man sitting on the street corner with a "will work for food" sign, Zach said

Oh, I feel bad for 'em. My mom always, like whenever we see people like that, she'll always give 'em money and stuff. And I'm always like "why you give 'em money? All they're gonna do is go buy booze and stuff". And she's like "well, it's 
helping them I guess". So I'd probably give them money cause that's what my mom always has done.

He indicated that he thought it was a scam but that he would still give them some money and went on to say that his dad would never give money to one of these individuals but that "I don't really listen to my dad that much".

Provided a scenario of a serious automobile accident on the side of the highway with emergency services extracting injured people, Zach's response was

Probably somebody stupid driving. Just wasn't paying attention or something. Just being dumb. Cause I've been into a couple car accidents when my friends were being dumb, wasn't paying attention. Actually, I got into a car wreck about a month ago. My friend was working over at Dairy Queen, we ran right into the back of a van.

He focused on one potential cause of the accident but did not consider the injured people in the scenario.

\section{Initial Survey Results}

As a method of general comparison, results of the 2003 Youth Risk Behavior Surveillance System (YRBSS) were downloaded from the Centers for Disease Control's web page and analyzed with the SPSS statistical package version 12.0.1 for Windows. Results were compiled for grades, fights, alcohol use and drug use reported by male students.

Grades

Both Alex and Zach reported on the initial survey that their grades were mostly C's. Of the 7598 males who participated in the 2003 YRBSS, 66.1 percent of white 
Table 5

Grades Reported by Male Students on 2003 Youth Risk Behavior Surveillance System by Geographic Region and Race

\begin{tabular}{lccccccc} 
& \multicolumn{3}{c}{ United States } & & \multicolumn{3}{c}{ Midwest } \\
\cline { 3 - 4 } Grades & All & White & Hispanic & All & White & Hispanic \\
Mostly A's & 18.8 & 26.0 & 12.0 & & 23.2 & 31.5 & 09.3 \\
Mostly B's & 37.8 & 40.1 & 38.6 & & 32.6 & 35.7 & 18.5 \\
Mostly C's & 28.5 & 22.3 & 31.1 & & 27.7 & 22.4 & 42.6 \\
Mostly D's & 06.6 & 05.6 & 08.5 & & 07.7 & 05.7 & 14.8 \\
\hline & & & & & & & \\
\hline
\end{tabular}

students and 50.6 percent of Hispanic students reported grades of mostly A's and B's (see Table 5). Broken down by geographic region, the majority of white students in the Midwest (67.2\%) reported grades of mostly A's and B's. In sharp contrast, the majority of Hispanic students in the Midwest (57.4\%) reported grades of mostly C's and D's. Although the YRBSS is not designed to include a representative sample of students in each geographic region or by race, the observed differences are substantial. Also worthy of notation is that Hispanic students in the Midwest reported lower grades than the total sample of Hispanic students in the United States who participated in the YRBSS. Given that some students may inflate their answers, the discrepancy between white students and Hispanic students becomes even more significant. Alex's self-reported grades are consistent with those reported by the majority of Hispanic students in the Midwest while 
Zach's grades are lower than those reported by the majority of white students in the Midwest. It could be argued that being Hispanic in the Midwest is a risk factor for poor academic achievement.

\section{Fights}

On the initial survey Alex reported being in two or three fights in the previous year and Zach reported being in four or five fights. Neither Alex nor Zach reported being in a fight on school property in the previous year. Of the 1240 males in the Midwest who participated in the 2003 YRBSS, $27.6 \%$ of white students and $31.4 \%$ of Hispanic students reported being in one to three fights in the previous year (see Table 6). This places Alex with approximately one-third of the Hispanic respondents. Likewise, Zach would be placed with the $5.1 \%$ of white males that reported being in four to seven fights during the previous year. Both Alex and Zach would be among the large majority of students who reported being in no fights at school during the previous year. It is interesting to note that in the Midwest, Hispanic males were more likely than white males to engage in fights at school or anywhere.

Alcohol Use

On the initial survey Alex reported his lifetime alcohol use at 10 - 19 days while Zach reported his lifetime alcohol use in excess of 100 days. For the previous 30 days Alex indicated he had not used any alcohol and Zach indicated he had consumed alcohol on three to five separate days and had on one of those occasions consumed five or more consecutive drinks. For students in the Midwest who participated in the 2003 YRBSS, it appears that white students drink more frequently and more heavily than Hispanic students (see Table 7), which held true in this study. 
Table 6

Fights in the Previous 12 Months Reported by Male Students in the Midwest on the 2003

Youth Risk Behavior Surveillance System by Race

Fights

All White

Hispanic

Anywhere

$\begin{array}{rrrr}0 & 58.7 & 62.7 & 52.5 \\ 1-3 & 27.6 & 27.6 & 31.4 \\ 4-7 & 4.8 & 5.1 & 5.6\end{array}$

At School

\begin{tabular}{cccc}
0 & 81.2 & 85.9 & 77.8 \\
$1-3$ & 13.6 & 11.2 & 14.8 \\
$4-7$ & 0.9 & 0.5 & 1.2 \\
\hline$N=\quad 1240$ & 731 & 162 \\
\hline
\end{tabular}


Table 7

Alcohol Use Reported by Male Students in the Midwest on 2003 Youth Risk Behavior Surveillance System by Race

Alcohol Use

Lifetime Alcohol Use

No alcohol use

1 to 9 days

10 to 39 days

40 or more days
All

20.8

23.0

20.6

23.7

White

Hispanic

Alcohol Use in Previous 30 days

No alcohol use

51.7

50.8

51.2

One drink on 1 or 2 days

17.3

19.3

18.5

One drink on 3 to 5 days

8.9

10.1

6.2

One drink on 6 or more days

14.0

15.8

8.7

5 or more consecutive drinks

29.3

34.3

22.8

$N=$

1240

731

162

Drug Use

On the initial survey, both Alex and Zach indicated that their lifetime marijuana use was 10 to 19 times and that they had not used marijuana in the previous 30 days. Table 8 contains results of the 2003 YRBSS for males in the Midwest. The large majority 
of students in the Midwest reported no marijuana use in the previous 30 days. However, it was observed that Hispanic students were more likely than white students to have used marijuana in their lifetime as well as in the previous 30 days, which was not observed in this study. It is likely that since Zach's parents were currently drug testing him, his lifetime marijuana use may have been under-reported. This may also be a contributing factor to his lack of marijuana use in the previous 30 days.

Table 8

Drug Use Reported by Male Students in the Midwest on the 2003 Youth Risk Behavior Surveillance System by Race

Drug Use

Lifetime Marijuana Use

Never tried it

Once or twice

3-9 times

$10-19$ times

20 or more times

Marijuana Use in Previous 30 days

None

At School

(nt

At School

\section{All}

White

Hispanic

$\begin{array}{lll}54.4 & 59.4 & 49.4\end{array}$

07.2

07.1

07.4

$\begin{array}{lll}09.0 & 08.5 & 12.3\end{array}$

03.6

03.6

03.7

21.0

18.7

21.6

72.3

78.2

69.1

$\begin{array}{lll}07.3 & 04.4 & 09.9\end{array}$

$\mathrm{N}=$

1240

731

162 


\section{Summary}

The focus of this investigation was to determine the influence of social competence on engagement in violent and aggressive behavior among adolescent males. Further, the study sought to identify to what degree the elements of social competence serve as protective factors for violence resiliency among at-risk adolescents. Through qualitative analysis, this study also sought to discover what other protective factors for violence resiliency may emerge.

Data were collected through open-ended interviews with the participants and focused interviews with selected school personnel. Interviews were recorded, transcribed, and analyzed with the processes of open and axial coding. Data were also collected through the use of initial surveys and the Interpersonal Reactivity Index. Chapter 5 includes the summary of findings, discussion, implications for practice and recommendations for future research. 


\section{CHAPTER FIVE \\ SUMMARY AND RECOMMENDATIONS}

Introduction

Violence significantly contributes to the creation of a socially toxic environment (Vorrasi \& Garbarino, 2000). Yet, due to the complex nature of violence and variances between genders, it is essential to consider the variety of causal factors that converge and motivate students to become violent. Current research has identified a multitude of risk factors such as the use of alcohol and drugs, hyperactivity, risk taking, a history of victimization, poverty, and academic failure that contribute to an individual's predisposition toward the development of violent tendencies (Blum, Ireland, \& Blum, 2003; Christle, Jolivette, \& Nelson, 2000; Hawkins et al., 2000; Vorrasi \& Garbarino, 2000).

Gender differences are notable in that males are more likely to engage in violent behaviors than females (Daane, 2003; US DHHS, 2001; Valois, MacDonald, Bretous, Fischer \& Drane, 2002), males consistently report higher levels of weapons carrying (YRBSS, 2003), and males are more likely to be physically victimized and threatened with a weapon (Hanish, 2000). Therefore, at the heart of the issue is the need to understand the root causes of violence so appropriate, and possibly gender specific, intervention and prevention strategies can be used by schools and other key stakeholders. Through the examination of the elements found in social competence and other potential protective factors, this investigation sought to discover what allows some students to rebound from toxic situations and experiences and avoid involvement in violence and aggressive behaviors while others do not. 
The focus of this study was to determine the influence of social competence on engagement in violent and aggressive behavior among adolescent males. Further, this study sought to determine to what degree the elements of social competence serve as protective factors for violence resiliency among adolescent males exposed to risk factors identified as contributing to the development of violent and aggressive behaviors. This case study identified the extent of student exposure to risk factors and explored potential relationships between the elements of social competence and violence resiliency.

The overarching question guiding this investigation was why do some at-risk adolescent males refrain from committing violence and participating in violent acts while others do not? In order to address this larger question, this study was designed to examine the following research questions:

1. Do the elements of social competence (empathy, a sense of humor, communication skills, relationship skills, and social assertiveness) serve as protective factors for violence resiliency among at-risk adolescent males?

2. Is individual social competence influential on engagement in violent and aggressive behavior among at-risk adolescent males?

3. Are there other protective factors for violence resiliency that emerge as important in preventing violent behavior?

\section{Summary of Findings}

Quantitative data were obtained from an initial survey designed to measure exposure to risk factors and incidents of violent or aggressive behaviors. The results of the survey were utilized to identify 5 students for follow-up interviews. After the interviews were completed, 2 students were selected for final inclusion in the study. 
Teacher interviews were conducted and the Interpersonal Reactivity Index was administered to triangulate the data.

The initial survey was administered to 15 male high school students in a Midwestern school district. The participant included 14 white students and 1 Hispanic student. Eleven of the participants had no office referrals during the school year, and 4 students were referred to the office three or more times during the school year. Students from all grades were included with 5 freshmen, 4 sophomores, 4 juniors and 2 seniors. Six of the students were eligible for the free and reduced lunch program and 3 of the students were not sure of their eligibility. Four of the students reported skipping school during the year. Academically, 10 students described their grades as mostly A's or B's.

Six of the students indicated they had never had a drink of alcohol other than a few sips. In the previous 30 days, 5 students indicated they had at least one drink of alcohol on one or two days and 2 students indicated they had at least one drink of alcohol on three to five separate days. Five students reported using marijuana in their lifetime, but only 1 student had used it in the previous 30 days. One student reported heroin use on 3 to 9 days in his lifetime. Four students reported being offered, sold, or given an illegal drug on school property during the past year.

Two students reported being threatened or injured with a weapon such as a gun, knife, or club on school property in the previous year. Three students reported that someone had stolen or deliberately damaged their property such as their car, clothing, or books on school property in the previous year with 2 reporting this as occurring on two or three occasions, and 1 indicating occurrence on four or five occasions. One student reported being purposely hit, slapped or physically hurt by his girlfriend in the previous 
year. Five students reported being teased or picked on at school a few times in the previous year, and 1 student indicated he was teased or picked on at least two to three times a month in the previous year.

Seven students reported being in a physical fight in the previous year. Of these, 4 students were in one fight, 2 students were in two or three fights, and 1 student was in four or five fights. Two students reported being in a fight at school in the previous year. Seven students reported teasing or picking on one or two other students during the previous year. The student who reported being teased or picked on at school at least two or three times a month during the previous year indicated that during that time he had teased or picked on three or four other students.

After analyzing the quantitative data obtained from the initial survey, 5 students were selected to participate in the interview process. The 5 students all had multiple risk factors and 3 of them reported having been in at least one fight and engaging in bullying behaviors. Three or four open-ended interviews were conducted with each of the 5 selected students. Additionally, focused interviews were conducted with 6 teachers who were familiar with one or more of the students. Based on information obtained in the interviews, 2 students with numerous risk factors were selected for final inclusion in the study. Four of the 6 teachers provided information on the two students. One student displayed violent and aggressive tendencies both at and away from school, while the other had not. The pseudonyms of Alex and Zach were assigned to the students.

\section{Alex}

Information provided by Alex on the initial survey indicated that he was Hispanic, eligible for the free and reduced lunch program, that he skipped school 2 or 3 times this 
year, and that his grades are mostly C's. Additionally, in the previous year he had been threatened or injured with a weapon at school once, had property stolen or damaged at school two or three times, had been in two or three fights, and had a history of a friend who committed suicide. He indicated his lifetime alcohol and marijuana use were both 10 to19 days, but that he had not used either in the last 30 days.

Interviews with Alex confirmed he is economically disadvantaged, he struggles academically, and he has a propensity for skipping school. Although he reported on the survey that he had been in two or three fights, interviews with Alex and his teachers revealed that he does not display violent or aggressive behaviors at school and is in fact quite reserved. His use of marijuana started at age 10 and ended about a year later. Interviews also revealed substantial risk factors that include an unstable home life and a history of abuse as a child. Information obtained in the interviews with teachers was consistent with information he provided during his interviews.

Alex possesses many of the qualities of a socially competent person including good communication skills; positive relationships with family, teachers and friends; a good sense of humor; and empathy. He appears to be less adept at social assertiveness and is often quiet and reserved at school. Based on the Interpersonal Reactivity Index (IRI), Alex demonstrates high levels of Empathic Concern and Perspective Taking, an average score on Personal Distress, and a low score on the Fantasy Scale. Interviews confirmed that he appears to be empathetic towards others.

Overall, Alex has demonstrated an amazing resiliency form violent and aggressive behaviors despite the accumulation of significant risk factors such as poverty, 
abuse as a child, an unstable home life, drug and alcohol use, academic failure and skipping school.

\section{Zach}

Information provided by Zach on the initial survey indicated he was unsure if he was eligible for the free and reduced lunch program, had skipped school once this year, and that his grades were mostly C's. During the previous year he had be threatened or injured with a weapon at school two or three times, had been in four or five physical fights, and was unsure if he had ever had a friend who had committed suicide. He reported that his lifetime alcohol use exceeded 100 days and that in the previous 30 days he had consumed alcohol on three to five separate days and that on one of these occasions had five or more drinks in a row. He indicated his lifetime marijuana use was 10 to 19 days, but that he had not used it in the previous 30 days.

Interviews with Zach revealed that his dad makes good money and that his mom owns a business and is preparing to attend law school. He stated that he only skipped school a couple of times, which was not supported by information obtained in teacher interviews. One teacher had not seen him in class in over a month. He is struggling academically and failed three required courses this academic year. He indicated that he skipped eighth grade, but interviews with teachers revealed he was socially promoted to the ninth grade after taking seventh grade twice. His use of marijuana was substantial enough that his parents are drug testing him. He has been arrested several times, including an assault incident at his former school. He indicated that several of his friends had been arrested and that some of them use drugs and alcohol. Interviews revealed additional risk factors including a lack of school connectedness, an accusation of 
molesting several young girls, and a personal tragedy involving a family member's involvement in a murder-suicide.

Zach does not possess as many qualities of a socially competent person. He does not communicate well with teachers but says that he does have good communication with his mom. He does not appear to have fostered positive relationships with his teachers or with other students in his classes. He is socially assertive, but it tends to be in inappropriate ways. He believes he has a good sense of humor but teachers indicated it was usually at the expense of someone else. He does not appear to be able to laugh at himself and gets defensive when the tables are turned.

Based on the IRI, Zach has considerably high levels of Perspective Taking and has high scores on Empathic Concern and the Fantasy Scale. The IRI also revealed extremely low levels of Personal Distress with a score of 2 on a scale with a range of 0 to 28. In contrast, interviews did not suggest high levels of Perspective Taking or Empathic Concern.

Overall, Zach has an accumulation of significant risk factors including drug and alcohol use, academic failure, low bonding to school, involvement with deviant peers, a history of arrest, and a history of a family member who committed a murder-suicide. Zach has not been able to successfully rebound from his situation and has demonstrated violent and aggressive behaviors both at and away from school.

\section{Discussion}

This study focused on the influence of social competence on engagement in violent and aggressive behaviors among adolescent males. Using quantitative and qualitative methods the researcher identified exposure to risk factors, levels of social 
competence including four dimensions of empathy, and overall levels of violence resiliency. In addition to social competence, other themes emerged as potential protective factors for violence resiliency. This investigation represents a multiple case design with two cases deliberately chosen from opposite extremes (Yin, 2003). The two selected students represent a theoretical replication, which Yin defines as separate cases that predict "contrasting results but for predictable reasons" (p. 47). This replication logic is inherent in case studies and replaces the notion of sample size and generalization to a larger population.

\section{Social Competence}

John (2001) defined social competence as "the ability to function appropriately in interpersonal interactions" (p. 182). Benard (1993) identified social competence as one of the attributes displayed by resilient children. She further stated that "Social competence includes qualities such as responsiveness - especially the ability to elicit positive responses from others - flexibility, empathy, caring, communication skills, and a sense of humor" (p. 44).

Elements of social competence were examined in an effort to answer the following research question: Do the elements of social competence (empathy, a sense of humor, communication skills, relationship skills, and social assertiveness) serve as protective factors for violence resiliency among at-risk adolescent males? Information about social competence was obtained through student interviews, teacher interviews and the Interpersonal Reactivity Index (IRI). This investigation revealed that Alex displays more characteristics of a socially competent person than Zach, with Alex demonstrating particular strengths noted in empathy, a sense of humor, and relationship skills 
(especially those outside the family). The elements of social competence are examined below.

\section{Communication Skills}

Good communication skills are a vital element of social competence. This investigation revealed that Alex and Zach were both able to communicate effectively during the interviews. Both were talkative and friendly; however, Alex was more reserved and thoughtful while Zach came across as more outgoing. Interviews with teachers revealed that Alex communicates well in school and is willing to ask questions. One teacher described him as intelligent and articulate. Zach, however, has not displayed effective communication skills with his teachers.

\section{Relationship Skills and Social Assertiveness}

The ability to develop positive relationships is another component of social competence (Benard, 1993; Christiansen, Christiansen \& Howard, 1997; Davis, 1999; Meisels, Atkins-Burnett, \& Nicholson, 1996). According to Benard (1993), "From early childhood on, resilient children tend to establish positive relationships with both adults and peers that help bond them to their family, school, and community" (p. 44). Both Alex and Zach developed close relationships with one or more family members. Alex forged positive connections with his grandparents and especially with his uncle. These relationships helped remove him from an abusive situation and provided a loving and caring environment throughout his life. Zach has a strong connection to his mother and spoke of her often and with high regard. Research has indicated that children with positive and secure parental relationships tend to display higher degrees of social competence and that "adolescents have interpersonal connections in a variety of social 
contexts, all of which also may be instrumental in shaping levels and types of social competence" (Barber \& Erickson, 2001, p. 328).

In addition to family relationships, research points to the notion that aggression is correlated with peer rejection (Meisels, Atkins-Burnett, \& Nicholson, 1996), which emphasizes the importance of positive peer relationships (Davis, 1999). The overarching issue is not popularity, but the ability to choose friendships that will stand the test of time (Davis, 1999). In this respect, Zach has not demonstrated the ability to develop positive peer relationships. He speaks frequently about how many friends he has, that he knows a lot of older students, and that the whole school knows him. However, when asked about his two closest friends he had difficulty coming up with two names. In trying to describe one of them he commented 'I don't really hang out with him that much, but we're like good friends". In contrast, Alex stated that he would talk to just about anyone, but that he only had a few close friends. He spoke easily about his close friends and indicated that they really care about each other and frequently help each other out.

Research also indicated that resilient individuals tend to be good-natured and are able to gain "positive attention from others. They are easy to be around and usually have a close bond with a caregiver or significant adult" (Christiansen, Christiansen \& Howard, 1997, Resilient Children, para. 1). According to one teacher interview, Zach "can really get on kids nerves. I mean, he tries to push buttons". He gains attention in negative ways and while he does assert himself socially, it is not in appropriate ways. Alex is less socially assertive, but he is described by teachers as polite, easy going, friendly, and an all-around good kid who gets along well with others. 


\section{Sense of Humor}

Another characteristic of socially competent individuals is the presence of a sense of humor (Benard, 1993; Christiansen, Christiansen \& Howard, 1997; Davis, 1999). A sense of humor is an important aspect of effectively coping with life stressors (Christiansen, Christiansen \& Howard, 1997; Davis, 1999). According to Davis, (1999) "Good-natured humor allows people to laugh with each other and not take themselves so seriously" (p. 34). Based on interactions with Alex and subsequent interviews with his teachers, he has a good sense of humor. One teacher stated "I think he has a great sense of humor" and continued "He jokes, kind of casual and relaxed. Pretty socially skilled". Zach believed that he had a good sense of humor and described himself stating "I'm pretty funny". Teachers agreed that he liked to joke around, but indicated it was usually at someone else's expense. Additionally, one teacher stated "He thinks he can pick on people and make fun of people, but when it turns around on him he gets very defensive".

Empathy

Empathy is an important component of social competence and is defined as “sharing another's emotional state or context" (Bush, Mullis, \& Mullis, 2000, p. 467). According to Goldstein (1996), "It appears to be the case that the greater the empathy we feel for another person, the more we perceive his or her world and humanness, the less able we are to hurt him or her" (p. 32). According to Kehret (2001), it is important for children to

learn to imagine themselves in someone else's skin. They need to see how painful it is to lose personal belongings to a thief or to be bullied, and they also need to 
learn how satisfying it is to help someone who needs assistance. They need to experience empathy. (para. 4)

Hazler (2000) also argued that "Young people need exposure to the hurt that degrading human dignity causes and the benefits of gaining empathic understanding of others" (Dehumanization, para. 2). Research indicates there is an inverse relationship between empathy and inappropriate behaviors (Bush, C., Mullis, R. \& Mullis, A, 2000; Sneed, 2002). This investigation utilized the Interpersonal Reactivity Index to measure four dimensions of empathy.

Interpersonal Reactivity Index. Davis (1983) developed the Interpersonal Reactivity Index (IRI) to measure four separate dimensions of empathy that include Empathic Concern, Perspective Taking, Personal Distress and the Fantasy Scale. The IRI is a 28 -item self-report questionnaire that includes 7 questions for each of the four subscales of empathy. Each item consists of a five point Likert scale response ranging from 0 (does not describe me well) to 4 (describes me very well). Overall scores for each of the subscales ranges from 0 to 28 . Higher scores are indicative of higher personal levels of that component of empathy.

Perspective Taking and the Fantasy Scale represent cognitive aspects of empathy while Empathic Concern and Personal Distress are emotional (Davis, 1983). Davis described the four scales as follows:

The Perspective-Taking (PT) scale assesses the tendency to spontaneously adopt the psychological point of view of others; the Fantasy (FS) scale taps respondents' tendencies to transpose themselves imaginatively into the feelings and actions of fictitious characters in books, movies, and plays. The other two subscales measure 
typical emotional reactions of the respondents: The Empathic Concern (EC) scale assess "other-oriented" feelings of sympathy and concern for unfortunate others, and the Personal Distress (PD) scale measures "self-oriented" feelings of personal anxiety and unease in tense interpersonal settings. (p. 113-14)

Alex and Zach both had high scores on Empathic Concern and Perspective Taking. According to Davis (1983), neither of these subscales appears to be related to intelligence. Empathic Concern "was related to measures of emotionality and to a nonselfish concern for other people" (p. 121) while Perspective Taking was "consistently associated with better social functioning and higher self-esteem" (p. 119). Of more importance is that noticeable differences in Personal Distress and the Fantasy Scale were observed.

Personal Distress. Research indicates that high scores on Personal Distress were consistently "associated with higher levels of social dysfunction and lower levels of social competence" (Davis, 1983, p. 121) and have been associated with higher levels of aggression (Beven, O’Brien-Malone \& Hall, 2004; Lindsey, Carlozzi \& Eells, 2001). However, results of this study produced contrary results. Alex, the more socially competent and less violent individual, scored a 10 on Personal Distress while Zach scored a 2 .

In an effort to assign meaning to the Personal Distress scores, a search of the literature revealed three studies that utilized the IRI on male subjects. The first study by Lindsey, Carlozzi and Eells (2001) revealed juvenile sex offenders and juvenile delinquent nonsexual offenders scored higher $(11.15,11.85)$ than non-delinquent juveniles (8.0) on Personal Distress. The study included 21 males in each category, 
ranging in age from 13 to 18 . Personal Distress was the only subscale to produce statistically significant differences. Although the study supports the literature that high Personal Distress scores are associated with higher levels of aggression and antisocial behavior, the high scores were less than the midpoint for the possible range of scores. The second study conducted by Sperber (2003) of 85 child molesters in treatment programs revealed an average score of 10.72 on Personal Distress. This study included individuals aged 18 to 61 and over. The outcome was lower than expected and the same group recorded an average score of 20.00 on Empathic Concern, higher than expected. In response to this, Sperber stated

It is likely, however, that Empathic Concern is a measure of general empathy or concern for others, while Personal Distress is a measure of specific empathy directed toward a specific individual's distress. If this is the case, this study's findings offer support for the hypothesis proposed by Hayashino et al. (1995) that child molesters do not lack general empathy but instead lack empathy specific to their victims. (p. 59)

The Personal Distress scores for the child molesters (10.72) in this study were not noticeably different from the juvenile delinquents $(11.15,11.85)$ in the study by Sperber.

The third study by Beven, O'Brien-Malone and Hall (2004) examined " 88 violent offenders incarcerated in maximum-security prisons in Western Australia for non-sexual violent index offenses (homicide, armed robbery, arson, aggravated assault)" (p. 35). Participants ranged in age form 21 to 64 and were compared with male factory workers in a previous study conducted by M. H. Davis in 1980 . The results revealed that the violent offenders scored much lower (10.14) than the factory workers (18.35). Researchers 
concluded "Personal Distress subscale results were in the contrary direction to that expected. Additionally, Personal Distress produced an internal consistency that was far below acceptable and failed to demonstrate any relationships with any of the other measures" (p. 40). The study determined that the IRI was unable to differentiate between offender and non-offender populations on this scale and advised that the "Personal Distress subscale not be used to assess offenders". However, it is interesting to note that the scores for the incarcerated violent offenders (10.14) were highly consistent with the scores reported for the child molesters (10.72) in the Sperber (2003) study, and with the juvenile sex offenders (11.15) and juvenile delinquent nonsexual offenders (11.85) in the study by Lindsey, Carlozzi and Eells (2001).

The assumption that the IRI cannot differentiate between offender and nonoffender populations may not be wholly accurate. In the study by Beven, O'BrienMalone and Hall, offender status is a legal description indicative of an individual being caught, prosecuted and incarcerated for a violent crime. This sample was compared with 24 year-old data collected from a sample of factory workers who represent the nonoffenders in the study. It is possible that many of these male factory workers may have had violent or aggressive tendencies which, at the time, had not escalated to the point of incarceration. There is no discussion about the background or history of the factory workers to support that they did not have violent or aggressive tendencies or that they had not been convicted, incarcerated and released for a prior offense. Coupled with the fact that not all acts of violence and aggression result in legal intervention, it is not possible to accurately assume that the factory workers represent non-violent well-adjusted individuals. 
The relevant question for this study becomes how it is possible that the more aggressive and less socially competent individual scored a 2 on the Personal Distress scale. Building on the theory that "child molesters do not lack general empathy but instead lack empathy specific to their victims", it could be argued that other populations may also lack empathy in specific circumstances. It should not go unnoticed that Zach was accused of molesting four young girls although he indicated he was never formally charged, an experience that is likely not common to most adolescent males. Accordingly, Lindsey, Carlozzi and Eells (2001) reported that "Offenders may consider themselves quite empathetic when thinking about family members, close friends, or fellow gang members, but because they do not perceive their victims as similar to themselves, empathy is not extended to the same degree" (p. 512). Such situational empathy has important implications. The ability to remain personally unaffected by another's plight may have multiple consequences. For law enforcement officers and emergency responders it may serve to facilitate the ability to handle emergency situations productively and professionally. This trait in a violent individual my serve in the reverse and allow them to inflict pain and suffering without the consequence of guilt.

The Personal Distress scale may not be about only one side of the spectrum. As a means of comparison, consider the importance of oxygen in our daily lives. Too little oxygen results in conditions that may lead to suffocation and death; however, too much oxygen creates dangerous conditions conducive to fire and explosions. Just as there is an ideal range of oxygen, perhaps there is some middle ideal range of Personal Distress. Determining this middle range is not simple, especially since the range may change based on specific personality traits and exposure to risk factors. Making an accurate assessment 
requires a more in-depth qualitative component that cannot be easily replicated on a survey. Only through the interviews with Zach did the researcher realize that he had been arrested several times, had skipped school extensively, enjoyed watching other people fight, was being drug tested by his parents, had been accused of molesting four young girls, and had a family member who killed three people and then committed suicide.

Fantasy Scale. The Fantasy Scale is a measure of an individual's tendency to imagine themselves as a character in a book or movie. According to Davis (1983), high scores on the Fantasy Scale "were modestly associated with measures of verbal intelligence and with a tendency toward emotional reactivity" (p. 120). Alex scored a 6 on the Fantasy Scales and Zach scored significantly higher with a 17. Alex was described as quite intelligent by his teachers, a fact not reflected by his academic performance. It is possible that being Hispanic may present cultural issues for Alex that impact his propensity for imagining himself as a book or movie character because he does not relate to them personally.

In comparison, the study by Lindsey, Carlozzi and Eells (2001) revealed juvenile sex offenders posted the highest average score on the Fantasy Scale with 14.96, followed by non-delinquent juveniles (12.63) and the juvenile delinquent nonsexual offenders (11.67). The authors stated "This is interesting because some suggest that sex offenders use fantasy as a means of passively planning offending behavior" (Lane, 1991, p. 518519). This becomes more meaningful when you consider that the child molesters who participated in the study by Sperber (2003) received an average score of 14.16, nearly indiscernible from the scores of the juvenile sex offenders (14.96). The incarcerated violent offenders in the study by Beven, O'Brien-Malone and Hall scored a much lower 
average 9.28. It appears that there are distinct differences between sexual offenders and other types of offenders. Again, of interest is the fact that Zach also received a high score on the Fantasy Scale and was accused of molesting four young girls.

\section{Individual Social Competence and Violence Resiliency}

Alex and Zach vary in their levels of social competence and violence resiliency. Given the presence of multiple risk factors in both of their lives, Alex has shown the capacity to rebound and demonstrates resiliency from violent behaviors while Zach does not. Additionally, Alex displays more of the characteristics of a socially competent person than Zach.

Alex

Despite the presence of numerous risk factors that contribute to the development of violent and aggressive behaviors, Alex has demonstrated an amazing resiliency from violence. Although he does not seem to be socially assertive, he was described as sweet, kind and polite. Teachers also commented on his good character and one described him as "pretty socially skilled". He has a good sense of humor, communicates well with teachers, and appears to have established positive relationships with family, friends and teachers. Interviews and the results of the IRI indicate high levels of Empathic Concern and Perspective Taking. Alex comes across as a socially competent individual.

Zach

Zach has been faced with a number of significant risk factors in his lifetime. In terms of social competence, he is a socially assertive individual, although he tends to assert himself in inappropriate ways. According to interviews with teachers, his sense of humor is typically at the expense of someone else. He has not established positive 
relationships with teachers but does appear to have a close connection with his mother. Interviews did not suggest high levels of Perspective Taking or Empathic Concern, but results of the IRI showed very high levels of perspective taking and high levels of empathic concern. Additionally, the IRI revealed extremely low levels of Personal Distress. He has been in several fights, including one that resulted in his arrest at his former middle school. He does not appear to be as socially competent as Alex and has demonstrated a propensity towards violent and aggressive behaviors both at and away from school.

\section{Other Themes That Emerged}

Several themes emerged during the interview sessions. Themes common to both students were family and school connectedness. Additionally, interviews with Alex revealed strong themes revolving around a sense of future and helping behaviors.

\section{Family Connectedness}

Family connectedness was a recurring theme in interviews with both Alex and Zach. Family connectedness has been cited as a potential protective factor. Both Alex and Zach have strong connections to at least one adult in their immediate family.

Alex. Despite the abuse he suffered at the hands of his father as a child, Alex developed strong family ties with several family members. He expressed gratitude and love for the grandparents he lived with for several years and indicated that they were like his mom and dad. He is particularly close to his uncle, who helped remove him from the abusive situation, and also stated that his uncle was like a father to him. He said his mother worked extensively and was not around often when he was younger. He did not appear to harbor resentment towards her, and asserted that he loves her. He also indicated 
that he does not see his father very often but that "I love him cause, you know, he's my dad. But that's about as far as it goes". He has several brothers and sisters, but is closer to the one he lives with at his mother's house.

Alex indicated that family is important to him and compares other significant people in his life to family. In describing one of his coaches, he stated "Yeah, he's been good to me. I mean he's, he's been like a father figure to me too. Cause I mean I really haven't had no father in my life. But he's been there". He also described his fellow teammates on the football team as "like a family".

Zach. During interviews, Zach identified his mom and dad as the most important people in his life. He spoke frequently about his mother and stated he would rather be grounded than have her express disappointment in him. He exuded a significant sense of pride in her accomplishments and bragged about her recent graduation with a 4.0 grade point average and her intentions to attend law school. He said that he does not fight at school because his mother told him not to and commented that "Well, I'll get arrested. Cause they'll find out and just get kicked out of school. My mom then will be mad at me. So I don't fight at school”. He also described a good day at school as when his mom wakes up in a good mood and tells him to "have a good day at school".

When asked if he had open lines of communication with his mom and dad he responded "My mom it is, but my dad - I don't really see him that much, but I can talk to him about anything too. But I never really see him”. He often compared his parents and indicated that his mom listens to him more often, gives him a later curfew, and trusts him much more than his dad. He even stated "I don't really listen to my dad that much". His 
comments during the interviews clearly communicated the strong connection he has with his mother as well as his admiration for her.

\section{School Connectedness}

There was a significant difference in levels of school connectedness between Alex and Zach. Not only was there a difference in the degree of connectedness to the specific school itself, but there was a substantial disparity on a more fundamental level about the overall value of school in general. School connectedness serves as a potential protective factor for Alex while it presents as a risk factor for Zach.

Alex. During interviews, Alex stated numerous times that he liked school. When asked to describe a bad day at school he responded

Bad day at school. Getting caught skipping. No, but a really bad day. I don't know. I don't have bad days. I just, I try coming to school - the day, it's a good thing. Try to enjoy it, try to have fun.

He has a sense that he belongs in the school and when asked if it would bother him to have to switch schools he responded "Yeah. Cause I really fit here, so I mean it's kind of hard. I'll be a senior next year so it'd be hard to adjust to that kind of environment'. He believes he is treated fairly at school, that the teachers are generally nice and that teachers and administrators care about the students. When asked if he thought the teachers wanted him to be successful in school he responded "Yeah. I think they do. They're always stressing about coming to class and stuff, so that's a pretty good sign".

Despite his academic struggles, Alex understands and appreciates the value of a good education. He mentioned several times that he is trying to break his habit of skipping classes and that he wanted to improve his grades. He wants to attend college and 
recognizes that he must improve his academic performance in high school. When asked if he thought he was gaining anything in school that would be valuable to him in the future he responded

A free education. Cause I mean when you go to college and stuff you got to pay for your education, so. So, the most valuable thing around here. You got people like me that are skipping school and missing a good opportunity, and I kind of feel dumb for doing it. So, I hope to get better.

He appears to truly appreciate the potential benefits associated with completing school.

Zach. During interviews, Zach made it clear that his did not like school and that the only reason he liked to come to school was to see his friends. Asked to describe a bad day at school, he replied "Every day". When asked if he had a sense of belonging at his school he stated "Somewhat. I mean, I know like a lot of older people and everybody's really pretty cool to me". He also said that it would not bother him to have to switch schools because "I can make friends if I needed to. And I have a lot of friends at different schools". He believes that the school is safe, that teachers and other school personnel listen to students. However, he believes that he is treated unfairly by his teachers and stated "a lot of my teachers, I don't think they like me. But if they do, I don't care". Along with his lack of school connectedness, he does not believe that school is a worthwhile endeavor. When asked if he thought he was gaining anything academically in school that would be valuable to him in the future he responded

Not really. I mean they teach me a lot of stuff, but I usually don't listen to them cause I think I know everything, but I don't really. But, like I've made a lot of friends coming to (school) so. 
Overall, Zach views school as a social setting and does not see any value in completing the required work. He was promoted to the ninth grade after repeating seventh grade twice, despite not meeting the requirements provided to him. His academic behaviors remained unchanged and he flunked at least three required courses this academic year.

The notion that he has a lot of friends was a recurring theme in is his discussions of school and he commented "I have just a bunch of friends. Like everybody at the school pretty much knows me". However, when asked to describe his two closest friends he responded "Let me think of two. I have a lot of friends, so. (pause). Well one of them, he plays basketball a lot and he doesn't, well I don't really - cause I don't really hang out with him that much, but we're like good friends". He appears to believe that he has a lot of friends who like him, but this is not supported by statements from interviews with teachers. One teacher stated "I think he just wants to be liked and I don't think he knows how to do that".

An analysis by Blum, Ireland and Blum (2003) indicated that family connectedness was associated with a reduced likelihood for engagement in aggressive behaviors for girls but was not a significant factor for boys, and also found that school connectedness was a protective factor for boys but not for girls. This investigation supports these findings since both students developed family connectedness, but only Alex displayed a strong connection to school. It appears that school connectedness may be an important factor in helping male students overcome risks in their lives to avoid violent and aggressive behavior. However, it may go beyond developing connections to the school environment and may be linked with a deeper belief in the overall value of 
school in general and a connection with the concepts of learning and education as positive and worthwhile.

In terms of school connectedness, it was also found that skipping school correlates with increased levels of overall violence for boys but not for girls (Blum, Ireland \& Blum; 2003). Both Alex and Zach skipped school numerous times during the academic year. The difference may lie in the reasons a student skips school. Zach does not like school, does not believe he is learning anything that will benefit him later in life, and thinks most of his teachers do not like him. For him, the only drawbacks to skipping school are that he will not see his friends and he risks making his mother upset.

Conversely, Alex likes school, believes he is getting a good education that will benefit him in the future, and feels "kind of dumb" for "skipping school and missing a good opportunity". Alex never indicated why he skipped school but said that it somehow became addictive. When he does skip, he often stays in the building and spends time playing basketball in the gymnasium. For Alex, skipping school appears to be more about needing a short recess and does not seem to be associated with any ill feelings towards school or the teachers.

Sense of Future

Throughout the interviews, Alex displayed a real sense of looking to the future both positively and realistically. He has ideas about what he might like to do and has a plan to get there. During interviews, Alex mentioned several times that he wanted to go to college so he could begin a good career. When questioned about his top goals for the next ten years he responded 
First, I want to get a college education. I want to get to college and do good there. I want to get me a nice stable, livable home. And I just want to get a good career started for me and stuff.

When asked what makes a person successful in life he responded 'I don't know. That's, I guess just the way they prevailed. I guess you finish high school and get a good job and you know, modern day life and stuff. Being pretty successful”. He believes he can be successful in the future in terms of getting a job to support himself comfortably and stated "Yeah, I can do that. I'm getting a good education to do that". He mentioned a possible career in public services such as a paramedic. He displayed a real sense of looking to the future both positively and realistically. The notion that a sense of future is important is supported by Benard (1993), who indicated that "Resilient children usually have four attributes; social competence, problem-solving skills, autonomy, and a sense of purpose and future" (p. 44). This study revealed that Alex possesses at least two of these qualities: social competence and a sense of future.

Additionally, research indicates that resilient individuals are intelligent (Davis, 1999), good-natured and display a sense of humor (Benard, 1993; Christiansen, Christiansen \& Howard, 1997), capable of adapting and coping with life's challenges (Christiansen, Christiansen \& Howard, 1997; D’Imperio, Dubow, \& Ippolito, 2000; McWhirter \& McWhirter, 1994), and demonstrate problem solving skills (Benard, 1993; Christiansen, Christiansen \& Howard, 1997).Of importance is that resilience does not come without personal struggles and serious contemplation of difficult decisions. Without risk, resilience doesn't exist (Davis, 1999). Alex has faced significant risks and shown an amazing resilience from violence. 
During interviews, Zach did not reveal a real sense of future. Asked about college he responded "I don't really like, I don't want to go to college. But I mean, if I go into the military or something and they pay for it, I'll probably go to college". He indicated he is not interested in the military as a career but said he would "Just go and serve and see if they'll pay for my college and if they do then I'll go to college and probably get a degree in something. But I have no clue". In describing his top goals for the next ten years he stated “Join the military, graduate, and - I don't really have very many goals, but get a job probably. Well, while I'm in high school get a job. But then, if I graduate, when I graduate, join the military". Despite his lack of goals and vision for the future, he believes he will be successful and make a lot of money because his dad makes a lot of money and his mom has the potential to make a lot of money after she goes to law school. When asked what he might want to do as a career in the future, he evaded the question and responded that his mom had just finished her degree and was going to attend law school next. Zach is a freshman and still has a minimum of three years of high school left, which may lend to his lack of direction and sense of future.

\section{Helping Behaviors}

The theme of helping behaviors was evident throughout interviews with Alex and was supported by interviews with teachers. He described himself as someone who could be both shy and outgoing and said "I like to help people if they're in need or something like that. I mean I'll help some guy on the street if he needs some money or something like that." He continued "Yeah. I like doing that. It's fun. To me it is anyway". He also recounted that when he worked at a local fast food restaurant he would frequently work extra shifts to help out his co-workers. He stated "I got asked to and I always worked for 
people. I thought they'd work for me sometime, but that really didn't happen all the time". Despite their failure to reciprocate his gesture he indicated "It didn't bother me any though".

He expressed an interest in finding a career as a paramedic or some other area of public service. When question about why he was interested in those fields, he responded “To help people.” In describing his two closest friends he said "They're pretty nice people. I mean we care for each other, we help each other out all the time". Interviews with teachers supported that Alex frequently displays helping behaviors at school. Both teachers commented that he would stay after class to help put up chairs, described him as "sweet" and commented about his good character.

Alex's helping behaviors are consistent with Kehret's (2001) assertion that it is important for children to

learn to imagine themselves in someone else's skin. They need to see how painful it is to lose personal belongings to a thief or to be bullied, and they also need to learn how satisfying it is to help someone who needs assistance. They need to experience empathy. (para. 4)

Hazler (2000) also argued that "Young people need exposure to the hurt that degrading human dignity causes and the benefits of gaining empathic understanding of others" (Dehumanization, para. 2). Alex reflected on his experiences as a child and has developed a determination to break the cycle of violence by choosing to behave in a way that he perceives as beneficial. He gains a sense of self-satisfaction and gratification by helping people. As Alex put it, "it's good to help somebody. Makes you feel good about yourself". 
Of all of the students included in the study from the initial survey through the interview process, Alex is the only one who asked any questions about the study and even wished the researcher good luck at the close of the final interview. The theme of helping behaviors did not emerge during interviews with Zach.

\section{Limitations of the Study}

This study utilized an exploratory case design to compare levels of social competence between subjects exposed to similar levels of risk related to engagement in violent behavior. While case studies offer analytical generalization where "the investigator is striving to generalize a particular set of results to some broader theory" (Yin, 2003, p. 37), case studies cannot produce statistical generalization to a larger population (Yin). However, multiple-case designs are considered preferable to singlecase designs in terms of analytic benefits (Yin). Although the literature indicates some fundamental differences between males and females in the areas of violent behaviors and social interactions (Blum, Ireland \& Blum, 2003; Daane, 2003; Hanish, 2000; US DHHS, 2001; Valois, MacDonald, Bretous, Fischer \& Drane, 2002), this study examined only male students. Additionally, this study is limited by reliance on self-reported behaviors on the surveys and participant honesty during the interviews. Due to confidentiality issues, there was no opportunity to observe the subjects in the classroom environment.

$$
\text { Implications for Practice }
$$

Findings of this investigation have generated several implications for schools. They include the following:

1. School connectedness is an important component of promoting violence resiliency for males. Schools should focus on methods of creating school- 
oriented opportunities for all students. The concept of school connectedness should move beyond the walls of the building and help promote the belief that learning and education are worthwhile endeavors.

2. Schools in the Midwest should explore ways to help increase the academic performance of Hispanic males.

3. Schools should strive to encourage students to participate in school and community activities that reinforce the value of helping behaviors.

4. Schools should continue to promote and teach elements of social competence such as communication skills and empathy.

\section{Recommendations for Future Research}

Recommendations for future research include the following:

1. Future research on violence resiliency should focus on gender differences related to risk and protective factors.

2. The academic disparity of Hispanic males versus white males in the Midwest warrants further research. A comprehensive quantitative study of academic performance should focus on regional differences in performance. In addition to grades, the research should evaluate the presence of potential contributing/mitigating factors such as the presence of Hispanic teachers and administrator in the school systems, cultural opportunities in the surrounding communities, and primary languages other than English spoken in the home.

3. Further qualitative study about the significance of extremely low levels of Personal Distress is strongly recommended. Research in this area should continue to focus on individuals who have displayed violent and aggressive 
behaviors; however, comparison groups should include individuals who are known to be non-violent and well-adjusted. The non-violent individuals should be categorized as those with significant risk factors in their lives, and those without significant risk factors. Qualitative research must be conducted to determine the presence or absence of violent and aggressive tendencies and to confirm exposure to risk factors.

4. Additional research should focus on best practices for schools to facilitate an increase in school connectedness on two levels: attachment to the school environment and an overall appreciation for the value of school in general.

\section{Summary Statements}

Youth violence at school is a serious and complex issue that has gained a considerable amount of public attention. While current research has identified risk factors that predispose individuals toward the development of violent tendencies, less information is available about potential protective factors. Through the examination of the elements found in social competence and other potential protective factors, this investigation sought to discover what allows some male students to rebound from toxic situations and experiences and avoid involvement in violence and aggressive behaviors while others do not.

Throughout this investigation, several themes emerged about the impact of the elements of social competence, overall individual social competence, and the presence of other protective factors for violence resiliency. Each subject in this investigation was exposed to several of the following risk factors: poverty, abuse as a child, poor academic achievement, skipping school, drug and alcohol use, a history of arrest, association with 
delinquent peers, and a history of a family member who has committed suicide. One of the subjects had engaged in violent and aggressive behaviors while the other had not. The difference appears to be related to higher levels of social competence, school connectedness and the presence of helping behaviors. Of importance is that young males who have accumulated significant risk factors related to the development of violent and aggressive tendencies can rebound and demonstrate violence resiliency

Several individual elements of social competence were associated with violence resiliency, including the following: (a) a sense of humor; (b) development of positive relationships with parents, school personnel and friends; and (c) empathy. These attributes serve as potential protective factors for violence resiliency by reducing or offsetting the impact of accumulated risk factors. While there were differences noted on communication skills and social assertiveness, other elements of social competence, these were less pronounced. Overall individual social competence was found to be positively associated with violence resiliency.

Other factors also emerged as important in promoting violence resiliency. School connectedness proved to be positively associated with violence resiliency. This went beyond genuine connections to the actual school environment and included a more fundamental belief in the overall value of school in general and a connection with the concepts of learning and education as both beneficial and worthwhile. Along with this, a positive and realistic sense of looking to the future was associated with violence resiliency. The final theme that emerged as important is the presence of helping behaviors, which were also positively related to violence resiliency. 
In conclusion, it is possible for young students to face adversities such as poverty, abuse, academic failure, and a history of drug use and still rebound successfully in terms of violence resiliency. Seemingly insurmountable situations can be overcome through accumulated protective factors. 


\section{REFERENCES}

Acosta, O. M., Albus, K. E., Reynolds, M. W., Spriggs, D., \& Weist, M. D. (2001). Assessing the status of research on violence-related problems among youth [Electronic version]. Journal of Clinical Child Psychology 30(1), 152-160.

Addington, L. A., Ruddy, S. A., Miller, A. K., and DeVoe, J. F. [Project Officer:

Chandler, K. A.]. (2002). Are America's Schools Safe? Student Speak Out: 1999

School Crime Supplement, (NCES 2002-331). Washington, D.C.: U.S.

Department of Education, National Center for Education Statistics

American Justice (Producer). (1999). The Jonesboro schoolyard ambush [Video of television broadcast]. (Available from New Video Group, 126 Fifth Avenue, New York, NY 10011).

Anarchist Cookbook. (2004). Web page retrieved June 27, 2004 from http://www. anarchist-cookbook.com.

Barber, B. K., \& Erickson, L. D. (2001). Adolescent social initiative: Antecedents in the ecology of social connections [Electronic version]. Journal of Adolescent Research, 16(4), 326-354.

Benard, B. (1993). Fostering resiliency in kids. Educational Leadership, 51(3), 44-48.

Beven, J. P., O’Brien-Malone, A., \& Hall, G. (2004). Using the interpersonal reactivity index to assess empathy in violent offenders. International Journal of Forensic Psychology, 1(2), 33-41. 
Bickel, B. (2001). Making light of a tragedy (from the zero tolerance follies files).

Retrieved January 18, 2004, from http://crime.about.com/library/blfiles/blzeroWTC.htm.

Blum, J., Ireland, M., \& Blum, R. W. (2003). Gender differences in juvenile violence: A report from Add Health [Electronic version]. Journal of Adolescent Health, 32, 234-240.

Bogdan, R. C., \& Biklen, S. K. (1998). Qualitative research in education: An introduction to theory and methods. Boston: Allyn and Bacon.

Bowman, D. H. (2001). At school, a cruel culture. Education Week, 20(27), 1+. Retrieved February 17, 2004, from Academic Search Elite database.

Bowman, D. H. (2002). Interpretations of 'zero tolerance' vary. Education Week, 21(30), 1+. Retrieved February 17, 2004, from Academic Search Elite database.

Brendtro, L., \& Long, N. (1995). Breaking the cycle of conflict [Electronic version]. Educational Leadership, 52(5), 52-56.

Breunlin, D. C., Cimmarusti, R. A., Bryant-Edwards, T. L., \& Hetherington, J. S. (2002). Conflict resolution training as an alternative to suspension for violent behavior [Electronic version]. The Journal of Educational Research, 95(6), 349-357.

Bush, C. A., Mullis, R. L. \& Mullis, A. K. (2000). Differences in empathy between offender and nonoffender youth. Journal of Youth and Adolescence, 29(4), 467478.

Centers for Disease Control. (2001). Web-based Injury Statistics Query and Reporting System Fatal (WISQARS Fatal) [Data file]. Available from Centers for Disease Control Web site, http://www.cdc.gov/ncipc/wisqars/default.htm. 
Chen, X., Liu, M., Rubin, K. H., Cen, G., Gao, X., \& Li, D. (2002). Sociability and prosocial orientation as predictors of youth adjustment: A seven-year longitudinal study in a Chinese sample [Electronic version]. International Journal of Behavioral Development, 26(2), 128-136.

Christiansen, J., Christiansen, J. L., \& Howard, M. (1997). Using protective factors to enhance resilience and school success for at-risk students. Intervention in School and Clinic, 33, 86-89. Retrieved July 22, 2003, from Wilson Web database.

Christle, C. A., Jolivette, K., \& Nelson, C. M. (2000). Youth aggression and violence: Risk, resilience, and prevention. (Report No. EDO-ED-00-11). Arlington, VA: ERIC Clearinghouse on Disabilities and Gifted Education No E602.

Cloud, J., Monroe, S., \& Murphy, T. (1999, December 6). The Columbine effect. Time, 154(23), 51+. Retrieved February 17, 2004, from Academic Search Elite database.

Cohen, W. (1999, November 22). Zero-tolerance brawl. U.S. News and World Report, 127(20), 34+. Retrieved February 17, 2004, from Academic Search Elite database.

Curwin, R. L., \& Mendler, A. N. (1999). Zero tolerance for zero tolerance. Phi Delta Kappan, 81(2), 119+. Retrieved February 17, 2004, from Academic Search Elite database.

Daane, D. M. (2003). Child and adolescent violence. Orthopaedic Nursing, 22(1), $23+$. Retrieved June 12, 2004, from Academic Search Premier database.

Daiute, C. \& Fine, M. (2003). Youth perspectives on violence and injustice [Electronic version]. Journal of Social Issues, 59(1), 1-14. 
Davis, M. H. (1983). Measuring individual differences in empathy: Evidence for a multidimensional approach. Journal of Personality and Social Psychology, 44(1), $113-126$.

Davis, N. J. (1999, May). Resilience: Status of the research and research-based programs. Substance Abuse and Mental Health Services Administration.

Dedman, B. (2000). Deadly lessons: School shooters tell why. Chicago Sun-Times, SunTimes Exclusive Report, October 15-16.

The Denver Channel.com. (2002). Boys get in trouble for playing with finger guns. Web page retrieved June 12, 2004 from http://www.thedenverchannel.com/print/ $\underline{1458180 / \text { detail.html? use }=\text { print }}$.

Derbyshire, J. (2001, May 28). The problem with 'zero'. National Review, 53(10), 46+. Retrieved February 17, 2004, from Academic Search Elite database.

DeVoe, J. F., Peter, K., Kaufman, P., Ruddy, S. A., Miller, A. K., Planty, M., et al. (2002). Indicators of school crime and safety: 2002. U. S. Departments of Education and Justice. NCES 2003-009/NCJ 196753. Washington, D. C.

DiIulio, J. J. (1995, November 27). The coming of the super-predators. The Weekly Standard. Retreived March 25, 2004, from LexisNexis Academic database.

D’Imperio, R. L., Dubow, E. F., \& Ippolitio, M. F. (2000). Resilient and stress-affected adolescents in an urban setting [Electronic version]. Journal of Clinical Child Psychology, 29(1), 129-142.

Ehlenberger, K. R. (2001-02). The right to search students [Electronic version]. Educational Leadership, 59(4), 31-35. 
Farrell, A. D., \& Meyer, A. L. (1997). The effectiveness of a school-based curriculum for reducing violence among urban sixth-grade students [Electronic version]. American Journal of Public Health, 87(6), 979-984.

Farrell, A. D., Meyer, A. L., Kung, E. M., \& Sullivan, T. N. (2001). Development and evaluation of school-based violence prevention programs [Electronic version]. Journal of Clinical Child Psychology, 30(1), 207-220.

Foster, K. (Ed.). (2000). School safety using metal detectors. Garland, TX: Garrett Academy of Metal Detection.

Fryxell, D. (2000). Personal, social, and family characteristics of angry students. Professional School Counseling, 4(2), 86-94. Retrieved August 28, 2002, from Academic Search Elite database.

Gagnon, J. C., \& Leone, P. E. (2001). Alternative strategies for school violence prevention. New Directions for Youth Development, 92, 101-125. Retrieved June 10, 2004, from Academic Search Premier database.

Galambos, N. L., \& Leadbeater, B. J. (2000). Trends in adolescent research for the new millennium [Electronic version]. International Journal of Behavioral Development, 24(3), 289-294.

George, R., \& Thomas, G. (2000). Victimization among middle and high school students: A multilevel analysis. The High School Journal 84(1), 48-57. Retrieved February 26, 2002, from WebSPIRS database.

Gluck, S. (1997). Wayward youth, super predator. Corrections Today 59(3), 62+. Retrieved March 10, 2004, from Academic Search Premier database. 
Goals 2000: Educate America Act of 1994. H. R. 1804. Retrieved February 17, 2004, from http://www.ed.gov/legislation/GOALS2000/TheAct/index.html.

Goldstein, A. P. (1996). Violence in America: Lessons on understanding the aggression in our lives. Palo Alto, Ca: Davies-Black Pub.

Gordon Rouse, K. A., Longo, M., \& Trickett, M. (1999). Fostering resilience in children. Bulletin 875-99, retrieved February 17, 2004, from the Ohio State University Web site: http://ohioline.osu.edu/lines/ bulls.html.

Hanish, L. D. (2000). Children who get victimized at school: What is known? What can be done? Professional School Counseling 4(2), 113-119. Retrieved August 28, 2002, from Academic Search Elite database.

Hawkins, J. D., Herrenkohl, T. I., Farrington, D. P., Brewer, D., Catsalano, R. F., Harachi, T. W., et al (2000). Predictors of youth violence (OJJDP Publication No. NCJ 179065). Washington, DC: U. S. Department of Justice, Office of Juvenile Justice and Delinquency Prevention.

Hazler, R. J. (2000). When victims turn aggressors: Factors in the development of deadly school violence. Professional School Counseling 4(2), 105-112. Retrieved August 28, 2002, from Academic Search Elite database.

Henderson, N., \& Milstein, M. M. (2003). Resiliency in schools: Making it happen for students and educators (Revised ed.). Thousand Oaks, CA: Corwin Press.

Henry, D. B., Tolan, P. H., Gorman-Smith, D. (2001). Longitudinal family and peer group effects on violence and nonviolent delinquency [Electronic version]. Journal of Clinical Child Psychology 30(1), 172-186. 
The History Channel (Producer). (1996). 20 $0^{\text {th }}$ century with Mike Wallace: Slaughter at schools [Video of television broadcast]. (Available from New Video, 126 Fifth Avenue, New York, NY 10011).

Holloway, J. H. (2001-2002). The dilemma of zero tolerance [Electronic version]. Educational Leadership, 59(4), 84-85.

Howard, N. (2002). Law asks state to define 'persistently dangerous schools'. The Safety Zone, 4(2), 1-2.

John, K. (2001). Measuring children's social functioning [Electronic version]. Child Psychology \& Psychiatry Review, 6(4), 181-188.

Johnson, D. W., \& Johnson, R. T. (1995). Why violence prevention programs don’t work - and what does. Educational Leadership, 52(5), 63-68.

Kehret, P. (2001). Encouraging empathy. School Library Journal 47(8), 44-45. Retrieved August 28, 2002, from Academic Search Elite database.

Kip Kinkel Organization. (2000). Web page retrieved June 27, 2004 from http://www. geocities.com/kipkinkelfanclub/.

Kline, B. E., \& Short, E. B. (1991). Changes in emotional resilience: Gifted adolescent boys. Roeper Review, 13(4), 184-187. Retrieved July 21, 2003, from Academic Search Premier database.

LeBoeuf, D., \& Delany-Shabazz, R. V. (1997). Conflict resolution. Office of Juvenile Justice and Delinquency Prevention, Fact Sheet \#55. U. S. Department of Justice.

Lindsey, R. E., Carlozzi, A. F., \& Eells, G. T. (2001). Differences in the dispositional empathy of juvenile sex offenders, non-sex-offending delinquent juveniles, and nondelinquent juveniles. Journal of Interpersonal Violence, 16(6), 510-522. 
Litvak-Miller, W. \& McDougall, D. (1997). The structure of empathy during middle childhood and its relationship to prosocial behavior. Genetic, Social \& General Psychology Monographs, 123(3), 303+. Retrieved August 28, 2002 from Academic Search Elite database.

Luthar, S. S. (1991). Vulnerability and resilience: A study of high-risk adolescents [Electronic version]. Child Development, 62, 600-616.

Mandleco, B. L., \& Peery, J. C. (2000). An organizational framework for conceptualizing resilience in children. Journal of Child \& Adolescent Psychiatric Nursing, 13(3), 99-112. Retrieved August 28, 2002, from Academic Search Elite database.

McCarthy, M. M., \& Webb, L. D. (2000). Legal principles in preventing and responding to school violence. NASSP Bulletin, 84(614), 32-45. Retrieved November 14, 2001, from Wilson Web database.

McWhirter, J. J., McWhirter, B. T. (1994). High- and low-risk characteristics of youth: The five Cs of competency. Elementary School Guidance \& Counseling, 28(3), 188-196. Retrieved August 28, 2002, from Academic Search Elite database.

Medina, J. (2002, November 6). Metal detectors making students late, if not safer [Electronic version]. New York Times, p. A25.

Meisels, S. J., Atkins-Burnett, S., \& Nicholson, J. [Project officer: West, J.] (1996). Assessment of social competence, adaptive behaviors, and approaches to learning with young children (Working Paper No. 96-18). Washington, D.C.: U. S. Department of Education, National Center for Education Statistics. 
Menard, S. (2002). Short- and long-term consequences of adolescent victimization (OJJDP Publication No. NCJ 191210). Retrieved March 5, 2002 from http://www.ncjrs.org/pdffiles1/ojjdp/191210.pdf.

Moseley, S. (1999). Antisocial behavior in youth: Causes, consequences and interventions. Retrieved April 5, 2002, from University of Oregon, College of Education ERIC Clearinghouse on Educational Management Web site: http://eric.uoregon.edu/trends_issues/safety/moseley.html.

National Center for Injury Prevention and Control. CDC Injury Research Agenda. Atlanta (GA): Centers for Disease Control and Prevention; 2002.

National School Safety Center. (2003). School Associated Violent Deaths Report, 2004 [Data File]. Available from http://www.nssc1.org.

No Child Left Behind (2001), PL 107-110. Retrieved February 17, 2004, from http://www.ed.gov/policy/elsec/leg/esea02/index.html.

O’Toole, M. E. (n.d.). The school shooter: A threat assessment perspective. Federal Bureau of Investigation, Department of Justice; Quantico, VA. Available from http://www.fbi.gov/publications.htm.

Pelliccioni (2003). Is intent required? Zero tolerance, scienter, and the substantive due process rights of students [Electronic version]. Case Western Reserve Law Review 53(977), 977-1007.

Petersen, G. J. (2005). Student misbehavior and violence: A reexamination of the enemy within. In F. English \& L. Frase (Eds.). Sage Handbook of Educational Leadership: New Dimensions and Realities. (p. 463-482) Thousand Oaks, CA: Sage Publications. 
Petersen, G. J., Pietrzak, D., and Speaker K. M. (1998). The enemy within: A national study on school violence and prevention [Electronic version]. Urban education, $33,331-359$.

Petersen, G. J., Thompson, R., Gawerecki, J., \& Cauldwell, N. (2003, November) Seeing the same school through different eyes: A study of stakeholders' perceptions of school violence. Paper presented at the annual conference of the University Council for Educational Administration, Portland, OR.

Peterson, R. L., \& Skiba, R. (2000). Creating school climates that prevent school violence. Preventing School Failure, 44(3), 122-130. Retrieved March 10, 2004, from Academic Search Premier database.

Reddy, M., Borum, R., Berglund, J., Vossekuil, B., Fein, R., \& Modzeleski, W. (2001). Evaluating risk for targeted violence in schools: Comparing risk assessment, threat assessment, and other approaches [Electronic version]. Psychology in the Schools, 38(2), 157-172.

Robelen, E. W. (2003, September 24). States report few schools as dangerous. Education Week, 23(4), 1+. Retrieved February 17, 2002 from Academic Search Elite database.

Robelen, E. W. (2003, October 22). Persistent analysis. Education Week, 23(8), 25. Retrieved February 17, 2002 from Academic Search Elite database.

Rutter, M. (2000). Resilience in the face of adversity. Speech given at Medicine Meets Millennium:World Congress on Medicine and Health 21 July - 31 August 2000. Retreived July 23, 2003, from http://www.mh-hannover.de/aktuelles/projeckt/ $\underline{\mathrm{mmm} / \text { englishversion/fs_programme/speech/Rutter_V.html. }}$ 
Schiraldi, V. (2001, February 5). Will the real John DiIulio please stand up. Washington Post. Retrieved March 16, 2004, from http://www.crimelynx.com/duilio.html.

Schreck, C. J., Miller, J. M., \& Gibson, C. L. (2003). Trouble in the school yard: A study of the risk factors of victimization at school [Electronic version]. Crime \& Delinquency, 49(3), 460-484.

Skiba, R., \& Peterson, R. (1999). Zap zero tolerance. Education Digest, 64(8), 24+. Retrieved February 17, 2004 from Academic Search Elite database.

Sneed, C. D. (2002). Correlates and implication for agreeableness in children [Electronic version]. The Journal of Psychology, 136(1), 59-67.

Speaker, K. M., \& Petersen, G. J. (2000). School violence and adolescent suicide: Strategies for effective intervention [Electronic version]. Educational Review, $52(1), 65-74$.

Sperber, K. G. (2003). Potential applications of an existing offender typology to child molesting behaviors (Doctoral dissertation, University of Cincinnati, 2003). Retrieved from http://www.uc.edu/criminaljustice/graduate/Dissertations.html

Stader, D. L. (2002). Student searches. Clearing House, 76(2), 66-70. Retrieved March 10, 2004, from Academic Search Premier database.

Strauss, A. \& Corbin, J. (1998). Basics of qualitative research: Techniques and procedures for developing grounded theory. Thousand Oaks, CA: SAGE Publications.

Study: D.A.R.E. shows no impact at 10-year follow-up. (1999, August 9). Alcoholism and Drug Abuse Weekly, 11(31), 6+. 
Thornton, T. M., Craft, C. A., Dahlberg, L. L., Lynch, B. S., \& Baer, K. (2002). Best practices of youth violence prevention: A sourcebook for community action (Rev.). Atlanta: Centers for Disease Control and Prevention, National Center for Injury Prevention and Control.

Trump, K. S. (2000). Classroom killers? Hallway hostages?: How schools can prevent and manage crises. Thousand Oaks, CA: Corwin Press.

U.S. Department of Education Website. Web page retrieved February 17, 2004 from http://www.ed.gov.

U.S. Department of Health and Human Services. (2001). Youth Violence: A Report of the Surgeon General. Rockville, MD: U.S. Department of Health and Human Services, Centers for Disease Control and Prevention, National Center for Injury Prevention and Control; Substance Abuse and Mental Health Services Administration, Center for Mental Health Services; and National Institutes of Health, National Institute of Mental Health.

Valois, R. F., MacDonald, J. M., Bretous, L., Fischer, M. A., \& Drane, J. W. (2002). Risk factors and behaviors associated with adolescent violence and aggression [Electronic version]. American Journal of Health Behavior, 26(6), 454-464.

Vorrasi, J. A., \& Garbarino, J. (2000). Poverty and youth violence: Not all risk factors are created equal. In V. Polakow (Ed.). The public assault on America's children: Poverty, violence and juvenile injustice. (pp. 59-77). New York, NY: Teachers College Press.

Vosssekuil, B., Fein, R., Reddy, M., Borum, R., \& Modzeleski, W. (2002). The final report and findings of the safe school initiative: Implications for the prevention of 
school attacks in the United States. U.S. Department of Education, Office of Elementary and Secondary Education, Safe and Drug-Free Schools Program and U.S. Secret Service, National Threat Assessment Center, Washington, D.C.

Walker, H. M. (1999, May 26). Key questions about school safety. Testimony presented to the Oregon Senate Education Committee; Senator Tom Hartung, Chair. Retrieved June 27, 2004, from http://eric.uoregon.edu/trends_issues/safety/ testimony.html.

Walker, H. M., \& Sprague, J. R. (1999). The path to school failure, delinquency, and violence: Causal factors and some potential solutions. Intervention in School and Clinic, 35(2), 67-73.

Walsh, M. (2001, March 21). Schools get the sales pitch: Better safe than sorry. Education Week, 20(27), 8. Retrieved June 10, 2004 from Academic Search Premier database.

Werner, E. E. \& Smith, R. S. (2001). Journeys form childhood to midlife: Risk, resilience, and recovery. Ithaca, N.Y.: Cornell University Press.

Wilson, J. J. (2000). Safe from the start: Taking action on children exposed to violence (OJJDP Publication No. NCJ 182789). Washington, DC: U.S. Department of Justice, Office of Juvenile Justice and Delinquency Prevention.

Yell, M. L., \& Rozalski, M. E. (2000). Searching for safe schools: Legal issues in the prevention of school violence. Journal of Emotional \& Behavioral Disorders, 8(3), 187-196. Retrieved February 29, 2004, from Academic Search Premier database. 
Yin, R. K. (2003). Case study research: Design and methods ( $3^{\text {rd }}$ ed.). Thousand Oaks, CA: Sage Publications.

Youth Risk Behavior Surveillance System, 2003 [Data file]. Available from the Centers for Disease Control, National Center for Chronic Disease Prevention and Health Promotion Web site, http://www.cdc.gov/HealthyYouth/yrbs/index.htm. 
Appendix A

Student Survey Questionnaire

DO NOT write your name on this survey. The answers you give will be kept private. Your answers will not be shared with anyone. Answer the questions based on what you really do.

Completing the survey is voluntary. Whether or not you answer the questions will not affect your grade in any classes you are taking. If you are not comfortable answering a question, just leave it blank.

The questions that ask about your background will be used only to describe the types of students completing this survey. The information will not be used to find out your name. No names will ever be reported.

Make sure to read every question. Fill in the ovals completely. When you are finished, follow the instructions of the person giving you the survey.

\section{Thank you very much for your help.}

1. How old are you?
A. 14 years old or younger
B. 15 years old
C. 16 years old
D. 17 years old
E. 18 years old or older

2. In what grade are you?
A. 9 th grade
B. 10th grade
C. 11 th grade
D. 12th grade

3. How do you describe yourself? (Select one or more responses.)
A. American Indian or Alaska Native
B. Asian
C. Black or African American
D. Hispanic or Latino
E. Native Hawaiian or Other Pacific Islander
F. White

4. Are you eligible for the free and reduced lunch program at school?
A. Yes
B. No
C. I'm not sure 
5. During the past 12 months, how many times have you skipped school?
A. 0 times
B. 1 time
C. 2 or 3 times
D. 4 or 5 times
E. 6 or more times

6. During the past 12 months, how would you describe your grades in school?
A. Mostly A's
B. Mostly B's
C. Mostly C's
D. Mostly D's
E. Mostly F's
F. None of these grades
G. Not sure

7. How often do you wear a seat belt when riding in a car driven by someone else?
A. Never
B. Rarely
C. Sometimes
D. Most of the time
E. Always

8. During the past 30 days, how many times did you ride in a car or other vehicle driven by someone who had been drinking alcohol?
A. 0 times
B. 1 time
C. 2 or 3 times
D. 4 or 5 times
E. 6 or more times

9. During the past 30 days, how many times did you drive a car or other vehicle when you had been drinking alcohol?
A. 0 times
B. 1 time
C. 2 or 3 times
D. 4 or 5 times
E. 6 or more times 


\section{The next 11 questions ask about violence-related behaviors.}

10. During the past 30 days, on how many days did you carry a weapon such as a gun, knife, or club?
A. 0 days
B. 1 day
C. 2 or 3 days
D. 4 or 5 days
E. 6 or more days

11. During the past 30 days, on how many days did you carry a gun?
A. 0 days
B. 1 day
C. 2 or 3 days
D. 4 or 5 days
E. 6 or more days

12. During the past 30 days, on how many days did you carry a weapon such as a gun, knife, or club on school property?
A. 0 days
B. 1 day
C. 2 or 3 days
D. 4 or 5 days
E. 6 or more days

13. During the past 30 days, on how many days did you not go to school because you felt you would be unsafe at school or on your way to or from school?
A. 0 days
B. 1 day
C. 2 or 3 days
D. 4 or 5 days
E. 6 or more days

14. During the past 12 months, how many times has someone threatened or injured you with a weapon such as a gun, knife, or club on school property?
A. 0 times
B. 1 time
C. 2 or 3 times
D. 4 or 5 times
E. 6 or 7 times
F. 8 or 9 times
G. 10 or 11 times
H. 12 or more times 
15. During the past 12 months, how many times has someone stolen or deliberately damaged your property such as your car, clothing, or books on school property?
A. 0 times
B. 1 time
C. 2 or 3 times
D. 4 or 5 times
E. 6 or 7 times
F. 8 or 9 times
G. 10 or 11 times
H. 12 or more times

16. During the past 12 months, how many times were you in a physical fight?
A. 0 times
B. 1 time
C. 2 or 3 times
D. 4 or 5 times
E. 6 or 7 times
F. 8 or 9 times
G. 10 or 11 times
H. 12 or more times

17. During the past 12 months, how many times were you in a physical fight in which you were injured and had to be treated by a doctor or nurse?
A. 0 times
B. 1 time
C. 2 or 3 times
D. 4 or 5 times
E. 6 or more times

18. During the past 12 months, how many times were you in a physical fight on school property?
A. 0 times
B. 1 time
C. 2 or 3 times
D. 4 or 5 times
E. 6 or 7 times
F. 8 or 9 times
G. 10 or 11 times
H. 12 or more times

19. During the past 12 months, did your girlfriend ever hit, slap, or physically hurt you on purpose?
A. Yes
B. No 
20. Have you ever had a friend who committed suicide?
A. Yes
B. No
C. I'm not sure

21. During the past 12 months, how many times have you been teased or picked on at school?
A. 0 times
B. a few times, but not very often
C. at least 2 or 3 times every month
D. at least 2 or 3 times every week
D. every day

22. During the past 12 months, have you teased or picked on someone else at school?
A. yes
B. no

23. During the past 12 months, how many different people have you teased or picked on at school?
A. 0 people
B. 1 or 2 people
C. 3 or 4 people
D. 5 or 6 people
E. more than 6 people

The next 5 questions ask about drinking alcohol. This includes drinking beer, wine, wine coolers, and liquor such as rum, gin, vodka, or whiskey. For these questions, drinking alcohol does not include drinking a few sips of wine for religious purposes.

24. During your life, on how many days have you had at least one drink of alcohol?
A. 0 days
B. 1 or 2 days
C. 3 to 9 days
D. 10 to 19 days
E. 20 to 39 days
F. 40 to 99 days
G. 100 or more days

25. How old were you when you had your first drink of alcohol other than a few sips?
A. I have never had a drink of alcohol other than a few sips
B. 8 years old or younger
C. 9 or 10 years old
D. 11 or 12 years old
E. 13 or 14 years old
F. 15 or 16 years old
G. 17 years old or older 
26. During the past 30 days, on how many days did you have at least one drink of alcohol?
A. 0 days
B. 1 or 2 days
C. 3 to 5 days
D. 6 to 9 days
E. 10 to 19 days
F. 20 to 29 days
G. All 30 days

27. During the past 30 days, on how many days did you have 5 or more drinks of alcohol in a row, that is, within a couple of hours?
A. 0 days
B. 1 day
C. 2 days
D. 3 to 5 days
E. 6 to 9 days
F. 10 to 19 days
G. 20 or more days

28. During the past 30 days, on how many days did you have at least one drink of alcohol on school property?
A. 0 days
B. 1 or 2 days
C. 3 to 5 days
D. 6 to 9 days
E. 10 to 19 days
F. 20 to 29 days
G. All 30 days

The next 4 questions ask about marijuana use. Marijuana also is called grass or pot.

29. During your life, how many times have you used marijuana?
A. 0 times
B. 1 or 2 times
C. 3 to 9 times
D. 10 to 19 times
E. 20 to 39 times
F. 40 to 99 times
G. 100 or more times 
30. How old were you when you tried marijuana for the first time?
A. I have never tried marijuana
B. 8 years old or younger
C. 9 or 10 years old
D. 11 or 12 years old
E. 13 or 14 years old
F. 15 or 16 years old
G. 17 years old or older

31. During the past 30 days, how many times did you use marijuana?
A. 0 times
B. 1 or 2 times
C. 3 to 9 times
D. 10 to 19 times
E. 20 to 39 times
F. 40 or more times

32. During the past 30 days, how many times did you use marijuana on school property?
A. 0 times
B. 1 or 2 times
C. 3 to 9 times
D. 10 to 19 times
E. 20 to 39 times
F. 40 or more times

The next 10 questions ask about other drugs.

33. During your life, how many times have you used any form of cocaine, including powder, crack, or freebase?
A. 0 times
B. 1 or 2 times
C. 3 to 9 times
D. 10 to 19 times
E. 20 to 39 times
F. 40 or more times

34. During the past 30 days, how many times did you use any form of cocaine, including powder, crack, or freebase?
A. 0 times
B. 1 or 2 times
C. 3 to 9 times
D. 10 to 19 times
E. 20 to 39 times
F. 40 or more times 
35. During your life, how many times have you sniffed glue, breathed the contents of aerosol spray cans, or inhaled any paints or sprays to get high?
A. 0 times
B. 1 or 2 times
C. 3 to 9 times
D. 10 to 19 times
E. 20 to 39 times
F. 40 or more times

36. During the past 30 days, how many times have you sniffed glue, breathed the contents of aerosol spray cans, or inhaled any paints or sprays to get high?
A. 0 times
B. 1 or 2 times
C. 3 to 9 times
D. 10 to 19 times
E. 20 to 39 times
F. 40 or more times

37. During your life, how many times have you used heroin (also called smack, junk, or China White)?
A. 0 times
B. 1 or 2 times
C. 3 to 9 times
D. 10 to 19 times
E. 20 to 39 times
F. 40 or more times

38. During your life, how many times have you used methamphetamines (also called speed, crystal, crank, or ice)?
A. 0 times
B. 1 or 2 times
C. 3 to 9 times
D. 10 to 19 times
E. 20 to 39 times
F. 40 or more times

39. During your life, how many times have you used ecstasy (also called MDMA)?
A. 0 times
B. 1 or 2 times
C. 3 to 9 times
D. 10 to 19 times
E. 20 to 39 times
F. 40 or more times 
40. During your life, how many times have you taken steroid pills or shots without a doctor's prescription?
A. 0 times
B. 1 or 2 times
C. 3 to 9 times
D. 10 to 19 times
E. 20 to 39 times
F. 40 or more times

41. During your life, how many times have you used a needle to inject any illegal drug into your body?
A. 0 times
B. 1 time
C. 2 or more times

42. During the past 12 months, has anyone offered, sold, or given you an illegal drug on school property?
A. Yes
B. No

Note: Questions were utilized from the 2003 Youth Risk Behavior Surveillance System to develop this survey. 
Appendix B

\title{
District Consent Form
}

\author{
Dr. $x x x$, Superintendent of $x x x$ School District \\ Administration Building \\ $x x x$ \\ $x x x$
}

Dear Dr. $x x x$,

I am requesting the participation of the $x x x$ School District with a research project I am conducting for my doctoral dissertation. I am a doctoral candidate in the Educational Leadership cooperative state program at the University of Missouri-Columbia. This research looks at risk factors that have been shown to increase the likelihood of the development of aggressive or violent behaviors in youth. The overall purpose of this research is to discover what types of risks high school boys are exposed to and how they respond to and overcome these risks.

This study would be limited in scope to one of the high schools in your district. The diverse composition of $x x x$ would make it an ideal location. I appreciate the importance of limiting disruptions to the normal school day. The study would entail the following:

- Recommendations for up to 20 student participants from the school principal and/or counselor based on the perceived risks those students are exposed to.

- A brief questionnaire administered to the recommended students. This should take approximately 15-20 minutes and would be given by me in an empty room. Parental consent and student assent forms would be required for participation, and sample copies have been provided for you.

- A series of 3-5 interviews with 2-4 of the student participants interviews to gain a better understanding of their thoughts and perceptions about stressors in their lives and how they cope with negative situations. These would be 30-45 minutes in length and take place over a period of 3-6 weeks to minimize disruption to the school day.

- Interviews with district personnel (teachers, counselors and the principal). Each person would participate in one interview that would be 30-45 minutes in length. These interviews would be scheduled before school, after school, or during planning periods to minimize disruption to the school day.

- Several observations during the period of a month (lunch, pep rally, after school events) that would be unobtrusive and not interfere with normal events.

\section{Risks and Benefits}

- Students: There are certain risks and discomforts that may be associated with this research. For students these include possible boredom, a small time commitment during the school day, and possible embarrassment at answering personal questions. 
The benefits to students include the knowledge that the data collected during this study are contributing to furthering research on youth behaviors, and a $\$ 5$ gift card to Wal-Mart for completing the questionnaire. Additionally, if a student is selected to participate in the interview process, he will receive an additional $\$ 50$ gift card to WalMart for his time and effort

- District Employees at Participating Location: Risks and discomforts include possible boredom and a small time commitment during a planning period or at a time outside the regular school day. Benefits include the knowledge that the data collected during this study are contributing to furthering research on youth behaviors.

- $x x x$ School District: The risks and discomforts to the district include the use of school time to assist in the process of gathering information from students and other school personnel. Beyond the benefits of helping contribute to a growing body of knowledge on youth behaviors, I can offer your district a series of three professional development workshops/presentations at no cost. Qualified professionals at CMSU from the Safety Sciences Department, the Criminal Justice Department and the Education Department have agreed to offer presentations on a variety of topics including school safety, laboratory safety, legal issues related to schools, and information on the relationship between schools and the juvenile justice system. I would be happy to discuss your district's needs to customize the workshops as necessary.

I have included copies of the informed consent documents for your review and records. If you have any questions or concerns regarding this study, or if any problems arise, you may contact me at (660) 543-4963 or you may contact the Project Advisor, Dr. James Machell, at (660) 543-8823. You may also ask questions or state concerns to Michele Reznicek, Compliance Officer for the MU Campus IRB, at (573) 882-9585.

If at this point you are still interested in participating, please complete the consent form and keep this letter for future reference. Thank you for your time and consideration.

Sincerely,

Leigh Ann Blunt 


\section{Consent Form}

I agree to allow the $x x x$ School District to participate in the research study being conducted by Leigh Ann Blunt. I understand that:

- Individual participation is completely voluntary, and consent may be withdrawn at any point in the study.

- The identity of all participants and the School District will be protected in the reporting of the findings.

- All collected data will be secured until this project is completed, and at completion of the project, all collected data will be destroyed after three years.

Signed:

Date: 
Appendix C

\section{Parental Consent Form}

Your son has been invited to participate in a research study conducted by Leigh Ann Blunt. She is a doctoral student at the University of Missouri-Columbia. This research looks at risk factors that sometimes lead to the development of aggressive behaviors in youth. The overall purpose of this research is to discover what types of risks high school boys are exposed to and how they respond to and overcome these risks. Your son's name was randomly generated by computer.

Your son's participation involves:

1. Filling out a short survey that will take approximately 15 to 20 minutes. This survey asks questions about things like:

* the use of alcohol and/or drugs,

* cigarette smoking,

* driving,

* family income level,

$*$ being teased \& bullied,

* school grades,

* attendance,

* weapons carrying,

* fighting

2. Possible selection for a series of interviews to better understand his opinions about stressors in his life and how he copes with negative situations. There will be 3-5 interviews that last 30-45 minutes each. The interviews will be spaced out over several weeks. These will take place at school and will not require any time before or after school. Your son's grades and attendance record will not be affected. Questions will focus on things like:

* how he spends his free time,

* plans after graduation,

* his opinions about the school,

* involvement in after-school clubs and athletics,

$*$ being teased or threatened at school,

* fights at school,

* skipping school,

* his opinions about the availability of weapons, alcohol and drugs to teenagers.

\section{His participation includes risks and benefits.}

\section{Risks:}

* possible boredom,

* a small time commitment during the school day,

* possible embarrassment at answering personal questions. 


\section{Benefits:}

* helping with important research,

* a small token of appreciation for filling out the survey

* and, if your son is selected to participate in the interview process, he will get a \$50 gift card to Wal-Mart as thanks for his help.

Your son's participation is voluntary. He may choose not to participate in this research study. He may also withdraw at any time. Your son will NOT be penalized in any way if he chooses not to participate or to withdraw. Your son may also choose not to answer any questions that he doesn't want to.

His identity will never be shared. Your son's name will not be used in the study or in any other reports or presentations about this study. The name of the school and the school district will not be used in the study. All records will be kept confidential as required by State and Federal laws. All records related to the study will be maintained in a secure and confidential location for three years and will then be destroyed. No information provided by your son will be shared with anyone (including other participants and school district personnel) except in the case of mandatory reporting of suspected child abuse, which must be reported by law. Only four individual stories will be published as part of the study. It is possible that someone who knows your son may be able to identify him by his life story.

Some district personnel will also participate in separate interviews and share their opinions about the safety of the school and how they think students handle stressful situations. The researcher will also make several general observations of the school environment during classes, lunch, passing periods, and at activities like pep rallies.

If you have any questions about this study, or if any problems come up, please contact one of the following people:

* Leigh Ann Blunt can be reached by phone at (660) 543-4963. She can also be reached by e-mail at blunt@cmsu1.cmsu.edu.

* Project Advisor, Dr. James Machell, can be reached at (660) 543-8823.

* You may also ask questions or state concerns to Michele Reznicek, Compliance Officer for the MU Campus Institutional Review Board, at (573) 882-9585.

\section{Please keep this letter for your records and return the enclosed consent form.}




\section{Parental Consent Form}

Please fill in the information below and mail this page in the enclosed pre-addressed and stamped envelope by (insert date that is three weeks from the mailing date of the consent form). Please retain the first page of this letter for your records.

Please Check all that apply:

My son may participate in this study

My son may fill out the survey, but may not participate in the interview process

My son may not participate in any portion of this study

Please mail me confirmation that this consent form has been received.

Please e-mail me confirmation that this consent form has been received. My email address is:

If you request and do not receive confirmation that your consent form has been received, please contact Leigh Ann Blunt at the number located on the second page of this letter. If a consent form is not received, your son will not be allowed to participate in any portion of this study.

Date:

Your son's name:

Signature of parent or legal guardian: 
Appendix D

Student Consent Form

You have been invited to participate in a research study conducted by Leigh Ann Blunt. She is a doctoral student at the University of Missouri-Columbia. This research looks at risk factors that sometimes lead to the development of aggressive behaviors in youth. The overall purpose of this research is to discover what types of risks high school boys are exposed to and how they respond to and overcome these risks. Your parents recently received information about this study and have allowed you to participate if you want to.

\section{Your participation involves:}

1. Filling out a short survey that will take about 15 to 20 minutes. This survey asks questions about things like:

* the use of alcohol and/or drugs,

* cigarette smoking,

* driving,

* family income level,

* being teased \& bullied,

* school grades,

* attendance,

* weapons carrying,

* fighting

2. You might be selected for interviews to share your opinions about stressors in your life and how you deal with them. There will be 3-5 interviews that last 30-45 minutes each. The interviews will be spaced out over several weeks. These will take place at school and will not require any time before or after school. Your grades and attendance will not be affected. Questions will focus on things like:

* how you spend your free time,

* your plans after graduation,

* your opinions about your school,

* involvement in after-school clubs and athletics,

* being teased or threatened at school,

* fights at school,

* skipping school,

* your opinions about the availability of weapons, alcohol and drugs to teenagers.

\section{Your participation includes risks and benefits.}

\section{Risks:}

* possible boredom,

* a small time commitment during the school day,

* possible embarrassment at answering personal questions. 


\section{Benefits:}

* helping with important research,

* a small token of appreciation for filling out the survey

* and, if you are selected to participate in the interview process, you will get a \$50 gift card to Wal-Mart as thanks for your help.

Your participation is voluntary. You may choose not to answer any questions you don't want to. If you don't want to be in this study or you decide you don't want to continue after you have started, just tell me. No one will know that you decided to stop and you will still receive the token of appreciation. If you were interviewed, you will still receive the gift card for your help.

Your identity will never be shared. Your name will not be used in the study or in any other reports or presentations about this study. All my notes and records will be kept confidential as required by State and Federal laws. All records will be kept in a secure and confidential location for three years and will then be destroyed. Nothing you say will be shared with anyone (including your parents, other participants, school district personnel, or the police) except in the case of mandatory reporting of suspected child abuse, which I am required by law to report. Only four individual stories will be included in the study. It is possible that someone who knows you may be able to identify you by your life story.

Some teachers will also participate in separate interviews and share their opinions about the safety of the school and how they think students handle stressful situations. You may see me around school observing the general school environment during classes, lunch, passing periods, or at activities like pep rallies. I will not stop to speak with you during any of these observations.

If you have any questions about this study, or if any problems come up, you should speak with your parents and have them contact me. I can be reached by phone at (660) 5434963. I can also be reached by e-mail at blunt@,cmsu1.cmsu.edu. I will try to answer any questions you have. This letter is yours to keep. 


\section{$\underline{\text { Assent Form }}$}

Name:

I understand that:

- My participation is completely voluntary, and I may withdraw at any point in the study.

- My identity will be protected in the reporting of the findings.

- All collected data will be secured until this project is completed, and at completion of the project, all collected data will be destroyed after three years.

Please mark all that you agree with:

I have read this assent form and been given the opportunity to ask questions.

I agree to complete the questionnaire only

I agree to complete the questionnaire and, if selected, participate in the interview process

I do not want to participate in any part of this study

Signed:

Date: 


\section{Appendix E}

\section{Teacher Consent Form}

You are being asked to participate in an interview for a research study conducted by Leigh Ann Blunt, a doctoral student at the University of Missouri-Columbia. This research looks at risk factors that have been shown to increase the likelihood of the development of aggressive or violent behaviors in youth. The overall purpose of this research is to discover what types of risks high school boys are exposed to and how they respond to and overcome these risks.

This interview should take 30-45 minutes of your time. We can schedule the interview before or after school or during your planning period. Participation in this study is completely voluntary. You may choose not to answer any of the questions you do not want to answer. You may withdraw from participation at any time you wish, including in the middle of the interview or after it is completed. If you decide at a later time that you do not want me to use your interview or parts of your interview in my study, I will respect that decision. Please do not hesitate to contact me with any concerns or questions about your participation. I can be reached at (660) 543-4963.

All reasonable measures to protect the confidentiality of your identity will be taken. Your identity will not be revealed in any publication or presentation that may result from this study. The confidentiality of all study related records will be maintained in accordance with State and Federal laws. No information provided by you will be shared with anyone (including other participants and school district personnel).

If you have any questions or concerns regarding this study, or if any problems arise, you may contact me at (660) 543-4963 or you may contact the Project Advisor, Dr. James Machell, at (660) 543-8823. You may also ask questions or state concerns to Michele Reznicek, Compliance Officer for the MU Campus IRB, at (573) 882-9585.

If at this point you are still interested in participating, please complete the consent form and keep this letter for future reference. Thank you for your time and consideration.

Sincerely,

Leigh Ann Blunt 


\section{Consent Form}

I being conducted by Leigh Ann Blunt. I understand that:

, agree to participate in the research study

- My participation is completely voluntary, and I may withdraw at any point in the study.

- My identity will be protected in the reporting of the findings.

- All collected data will be secured until this project is completed, and at completion of the project, all collected data will be destroyed.

Signed:

Date: 


\section{Appendix F}

\section{Student Interview Protocol}

Before each interview, remind participants that all answers are confidential and will not be shared with anyone, including parents, teachers, principals, other participants, or any other organization (the only exception to this is law requiring mandatory reporting of child abuse). Participants may choose not to answer any questions they are not comfortable with or simply do not want to answer.

For student interviews - more informal in nature. Let them know that I am very interested in what they think, and that there are no right or wrong answers. I am here to listen to them, not to judge them. I am not making any assessments about whether or not they are a "good person".

Do you live at home? With whom? Any brothers or sisters? How long have you lived there? Tell me a little about your house/apt - do you have your own room. Do you have a computer? Internet access? Your own phone?

Do you have a cell phone? A pager? A car? (Who pays for it)?

Do you have a job? Tell me about it. Why do you choose to work? Do you help pay the bills at home?

Describe your neighborhood.

Tell me about your school.

Are you in any school clubs or on any athletic teams?

If no, why not? Are any of your friends in clubs or on teams?

If yes, why did you choose that club/team? How long have you been doing it?

What do you like most about it? How much of your time does it take up? Are your friends in it with you?

What school activities do you like to go to (dances, games, etc). How often do you go? Have you ever skipped school? Why? What did you do? Did you get caught? (If not, how did you get away with it?)

Do you think the teachers at your school care about students? Explain - give examples

Tell me about your favorite teacher at this school? Why? Were you (or are you now) in his/her class?

Tell me about the worst teacher in this school? Why? Were you (or are you now) in his/her class?

What do you think of your assigned teachers this year? Do you think your teachers want you to be successful in their courses?

Do you think the teachers at this school listen to students? Explain - give examples

What to you think about the principal?

Do you think students are treated fairly (equally) at this school? Explain 
Is there a teacher you feel comfortable talking to when something is bothering you? A counselor? An administrator? A coach? Anyone else - custodian, cook, secretary?

How would you rate the overall safety of the school?

Have you ever had anything stolen from you? At school? How did that make you feel?

Did you report it? (Why/why not) Do you know who was responsible?

Have you ever stolen anything from someone at school? What? Why?

Have you ever been verbally threatened (teased) at school? By whom? Why? How did you handle it? (Did you report it - why/why not?)

Have you ever threatened someone at school? Who? Why? Did they report you?

Have you ever been physically threatened at school? By whom? Was there a weapon involved? How did you handle it? (Did you report it - why/why not?)

Have you ever been in a fight? At school? Did you get hurt and how badly? Who started it?

Have you ever carried a weapon on you? At school? Why? Where did you get it?

How hard is it for someone your age to get access to a weapon?

What types of security measures does your school utilize? Do you believe they are effective? Do you think a student in this school get a knife into the building? A gun? How hard would it be? Do you know of anyone who has brought a weapon into the building? Did you report it?

What about drugs/alcohol at school - how hard would it be for someone to bring drugs/alcohol into the building? To use drugs/alcohol during school?

Have you ever tried drugs/alcohol? Which ones? Why? What about your friends? How did the drugs/alcohol make you feel? Would you do it again? Do you think they are harmful to you? What do you think your parents would say?

What do you like to do after school and on weekends?

Do you tell your parents where you go? Why/Why not?

Where do you think you'll be after graduation? Where would you like to be? 


\section{Appendix G}

\section{Teacher Interview Protocol}

Before each interview, remind participants that all answers are confidential and will not be shared with anyone, including parents, teachers, principals, other participants, or any other organization (the only exception to this is law requiring mandatory reporting of child abuse). Participants may choose not to answer any questions they are not comfortable with or simply do not want to answer.

Tell me about your school.

How would you rate the overall safety of the school?

How do you think the students would rate the overall safety of the school?

What types of physical security measures does your school utilize? Do you believe they are effective? (access control, metal detectors, SRO, self-locking doors, visitor sign-in, emergency intercom/phone system, locker searches, drug dogs)

Beyond physical security measures, what types of policies and programs are in place to help ensure a safe school environment? (zero tolerance policy, peer mediation, violence prevention programs, dress codes). Do you believe they are effective?

Is there a way for students to report concerns anonymously if they wanted to? Explain.

How long have you known the student?

Do you know anything about his background?

How does he interact with other students? Provide examples.

How do you think other students respond to him? Provide examples.

Does he get victimized at school? (teased, bullied, etc) How often? Why do you think this is?

Can you tell me anything about his friends?

Do you think he has a good sense of humor? Explain. Does he laugh a lot, make jokes, kid around with other students?

Do you know if he participates in any school-sponsored activities? Which ones.

Do you know if he attends school extra-curricular activities (games, dances, etc)

How does he interact with his teachers? How does he respond to you?

How often to you interact with him at school? In what capacity?

Have you ever interacted with him outside of school? Explain.

If the student became aware of someone who brought a weapon to school, do you think he would report it? Why?

Tell me a little about his behaviors in your class?

Do you think these behaviors are consistent in his other classes? Explain.

What do you think of him as a student? As a person?

What kinds of grades does he get in your class?

Does he complete his homework and other assignments?

Does he talk to you in the time immediately before or after class on a regular basis? If so, what does he like to talk about?

Have you ever had to send him to the office? Explain. How often? 
Has he ever skipped your class that you were aware of?

If he asked you for a letter of reference, would you provide one? Why/Why not? If so, what would you say?

Tell me about his behaviors in situations outside your classroom? (lunch, passing period, before or after school)

How does he interact with authority figures in school (principal, vice-principal, counselor)? 


\section{Appendix $\mathrm{H}$}

\section{Interpersonal Reactivity Index Questionnaire}

The following statements inquire about your thoughts and feelings in a variety of situations. For each item, indicate how well it describes you by choosing the appropriate letter on the scale at the top of the page: A, $\mathrm{B}, \mathrm{C}, \mathrm{D}$, or E. When you have decided on your answer, fill in the letter next to the item number. READ EACH ITEM CAREFULLY BEFORE RESPONDING. Answer as honestly as you can. Thank you.

\section{ANSWER SCALE:}

A

DOES NOT

DESCRIBE

ME WELL
B $\quad$ C

$\mathrm{D}$

$\mathrm{D}$

\section{DESCRIBES}

ME VERY

WELL

1. I daydream and fantasize, with some regularity, about things that might happen to me.

2. I often have tender, concerned feelings for people less fortunate than me.

3. I sometimes find it difficult to see things from the "other guy's" point of view.

4. Sometimes I don't feel very sorry for other people when they are having problems.

5. I really get involved with the feelings of the characters in a novel.

6. In emergency situations, I feel apprehensive and ill-at-ease.

7. I am usually objective when I watch a movie or play, and I don't often get completely caught up in it.

8. I try to look at everybody's side of a disagreement before I make a decision.

9. When I see someone being taken advantage of, I feel kind of protective towards them.

10. I sometimes feel helpless when I am in the middle of a very emotional situation.

11. I sometimes try to understand my friends better by imagining how things look from their perspective.

12. Becoming extremely involved in a good book or movie is somewhat rare for me.

13. When I see someone get hurt, I tend to remain calm.

14. Other people's misfortunes do not usually disturb me a great deal.

15. If I'm sure I'm right about something, I don't waste much time listening to other people's arguments.

16. After seeing a play or movie, I have felt as though I were one of the characters. 


\section{ANSWER SCALE:}

A

DOES NOT

DESCRIBE

ME WELL
B

C

D DESCRIBES

ME VERY

WELL

17. Being in a tense emotional situation scares me.

18. When I see someone being treated unfairly, I sometimes don't feel very much pity for them.

19. I am usually pretty effective in dealing with emergencies.

20. I am often quite touched by things that I see happen.

21. I believe that there are two sides to every question and try to look at them both.

22. I would describe myself as a pretty soft-hearted person.

23. When I watch a good movie, I can very easily put myself in the place of a leading character.

24. I tend to lose control during emergencies.

25. When I'm upset at someone, I usually try to "put myself in his shoes" for a while.

26. When I am reading an interesting story or novel, I imagine how I would feel if the events in the story were happening to me.

27. When I see someone who badly needs help in an emergency, I go to pieces.

28. Before criticizing somebody, I try to imagine how $\underline{I}$ would feel if I were in their place. 
Leigh Ann Blunt was born in Kansas City, Missouri on December 28, 1970. She attended elementary and high school in Grandview Missouri, and received a Bachelor of Science in Education with a focus in English in 1993 from Missouri Western State College. After graduation, she taught high school language arts for four years in St. Joseph, Missouri. She then received a Master of Science in Industrial Safety Management from Central Missouri State University in 1999. She completed the requirements for a Doctor of Education with an emphasis in Educational Leadership from the University of Missouri-Columbia in 2005. She currently teaches in the Safety Sciences Department at Central Missouri State University. She is married and has twin daughters, Karyn and Kelly. 